\title{
AN INVESTIGATION INTO THE COLD HEAVY OIL PRODUCTION WITH SAND PROCESS USING SYNTHETIC CORES AND DESIGNED EXPERIMENTS
}

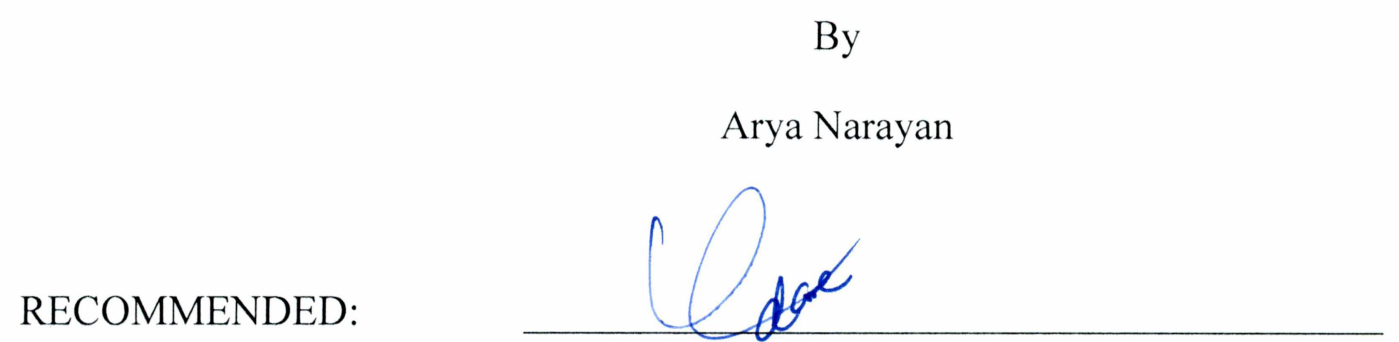

Dr. Obadare Awoleke

Advisory Committee Chair

Mohobbat Ahnad

Dr. Mohabbat Ahmadi

Advisory Committee Member

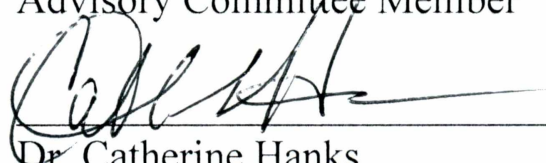

Advisory Committee Member

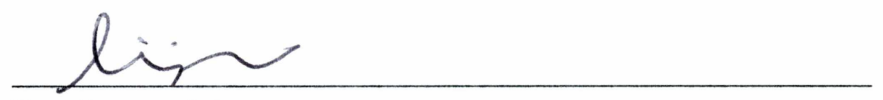

Dr. Jenny Liu

Advisory Committee Member

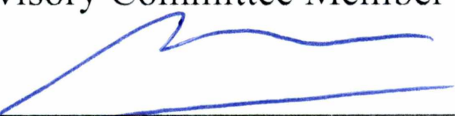

Dr. Abhijit Dandekar,

Chair, Department of Petroleum Engineering

APPROVED:

Dr. Douglas bioering

Dean, College of Engineering and Mines

Dr. John Eichelberger

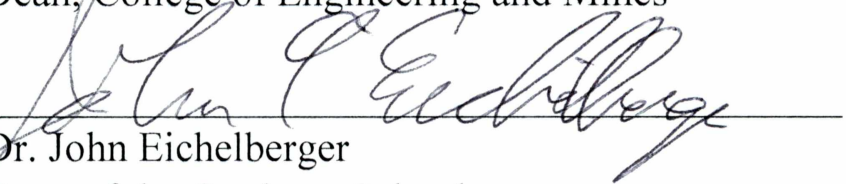

Dean of the Graduate School

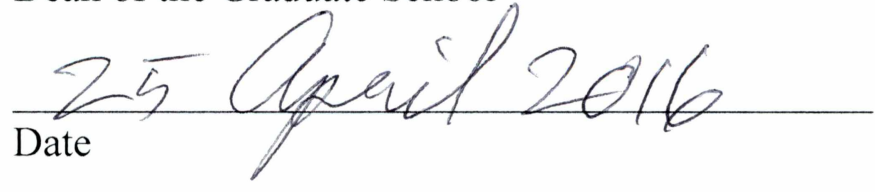





\title{
AN INVESTIGATION INTO THE COLD HEAVY OIL PRODUCTION WITH SAND PROCESS USING SYNTHETIC CORES AND DESIGNED EXPERIMENTS
}

\author{
A \\ THESIS \\ Presented to the Faculty \\ of the University of Alaska Fairbanks \\ in Partial Fulfillment of the Requirements \\ for the Degree of \\ MASTER OF SCIENCE
}

By

Arya Narayan

Fairbanks, AK

May 2016 


\begin{abstract}
This study deals with the development of a methodology for making low compressive strength cores used in an experimental investigation of the Cold Heavy Oil Production with Sand (CHOPS) process. An experimental setup was designed and built to investigate the effect of rock compressive strength as well as flow parameters, such as oil viscosity, net and total confining pressure, and injection rate, on core permeability. The approach was to optimize the value of a response variable by changing the values of the affecting factors.

Sand blends were prepared by varying the ratios of aggregate, cementing material and water to prepare synthetic cores. An experimental unit was built to simulate wormhole propagation during the CHOPS process, where oil, at an ambient temperature, was injected into 2 -inch $\times 4$-inch cores at varying rates of $0.5-10 \mathrm{ml} / \mathrm{min}$ under differential confining pressures of 500 and $1000 \mathrm{psia}$. The pressure drop across the core was monitored and recorded throughout the process.

When non-swelling clay is used as a cementing material compared with actual cement to make synthetic core, the compressive strength of the samples falls dramatically by $64 \%$. Two factors were considered in the coreflood experiments: Oil Viscosity (370 and $690 \mathrm{cp}$ ) and Injection Rates ( 0.5 and $3 \mathrm{ml} / \mathrm{min}$ ) at a net confining pressure of 500 psia, below the compressive strength of the core. It is hypothesized that injecting oil of different viscosities at different rates affects the internal structure of the core in different ways (there is fluid-rock interaction) and thus, at lower pore volumes of injection, the permeability of the core for high viscosity oil is almost $11.2 \%$ greater than for low viscosity oil. Also, design of experiment approach was used and regression model was developed for permeability of core based on values recorded at specific pore volumes injected for different injection rates and oil viscosities. It was found that at a constant confining pressure for all rates and at lower pore volumes injected, $99.8 \%$ of the variance in permeability can be explained by oil viscosity, injection rate and their interaction. At higher pore volumes injected, the variance in permeability that can be explained by oil viscosity, the injection rate and their interaction is only $40.63 \%$.
\end{abstract}




\section{Dedicated to}

Papa and Amma for their endless love, support, and encouragement, and to my princess Avni. 


\section{Table of Contents}

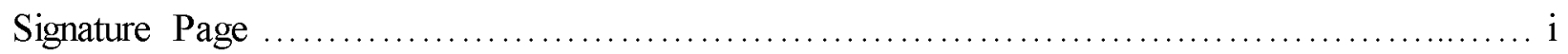

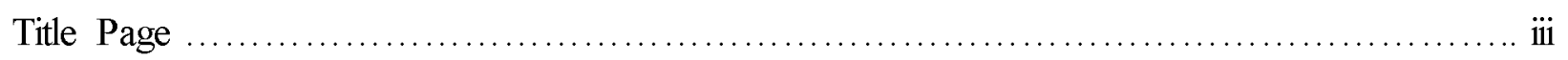

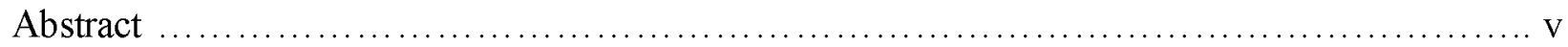

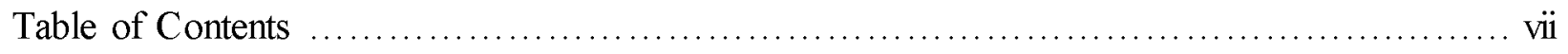

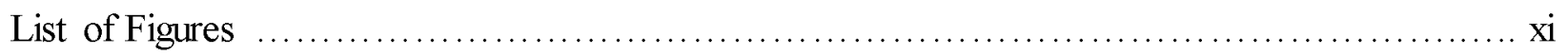

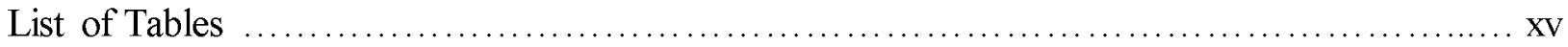

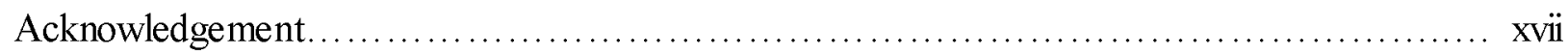

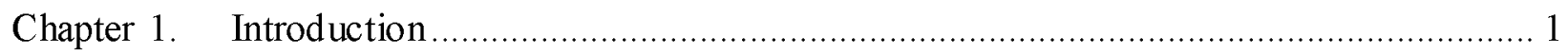

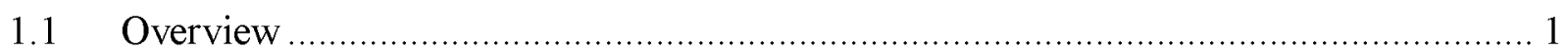

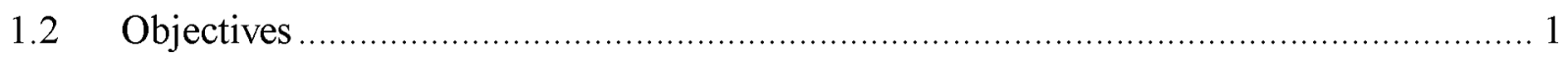

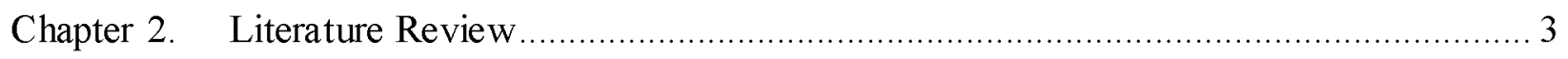

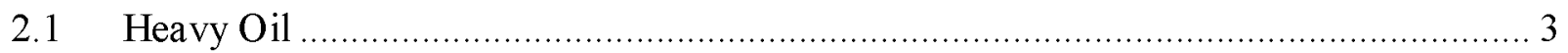

2.1.1 Global Heavy Oil Reserves ...................................................................... 4

2.1.2 Heavy Oil in Alaska ............................................................................... 4

2.2 Cold Heavy Oil Production with Sand ......................................................... 5

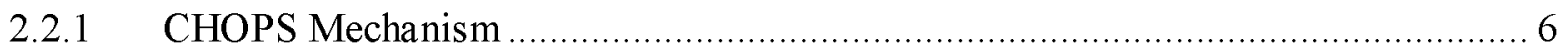

2.2.2 Sand Production ....................................................................................... 7

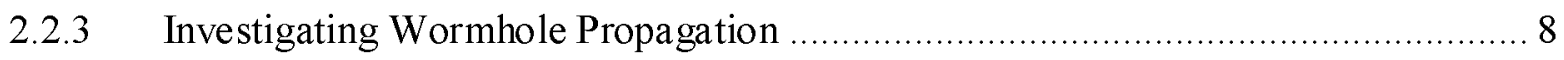

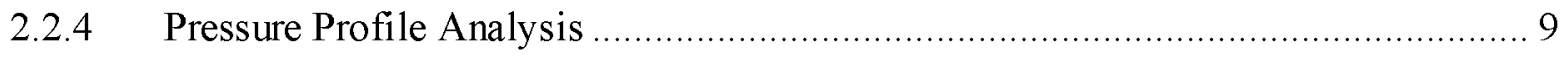

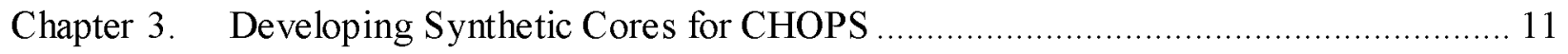

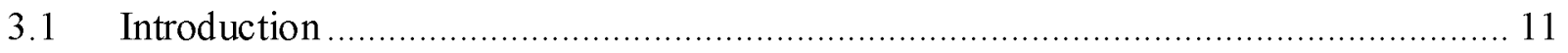

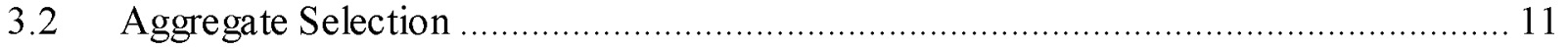

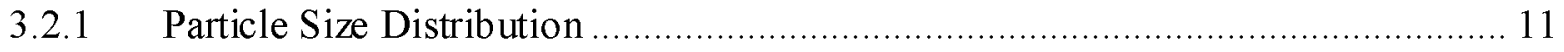

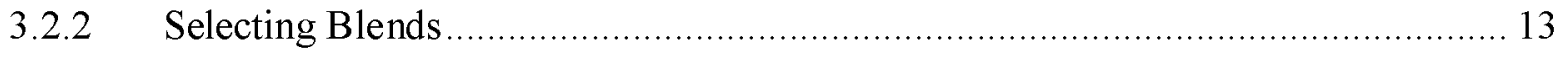




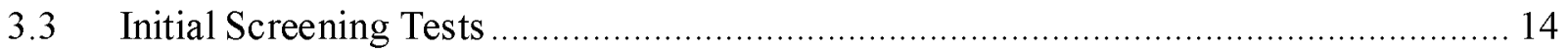

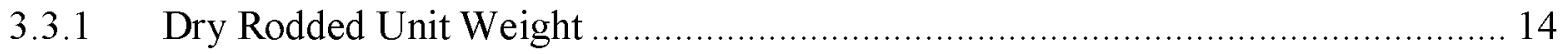

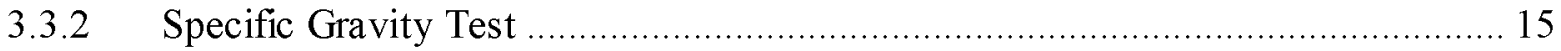

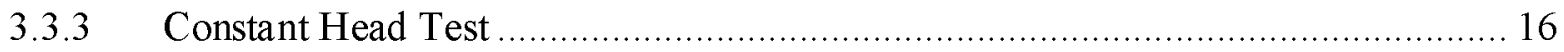

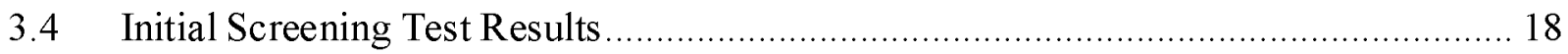

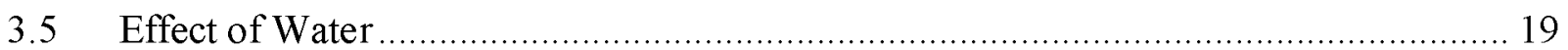

3.6 Mixing Aggregate, Cement, and Water ................................................................ 19

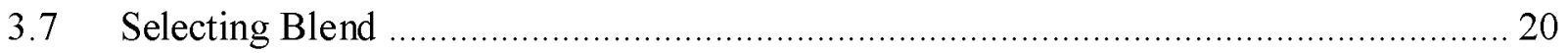

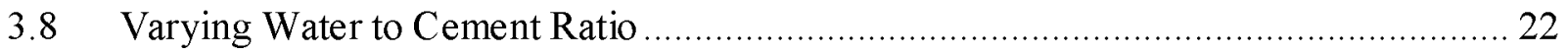

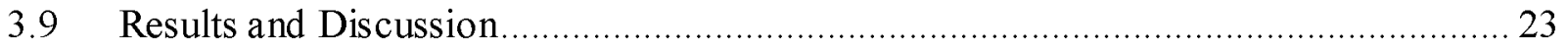

Chapter 4. CHOPS Experimental Setup - System Components and Assembly ..................... 27

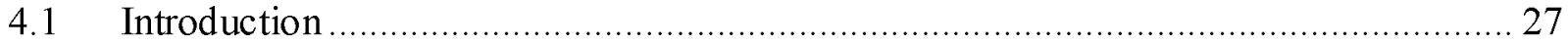

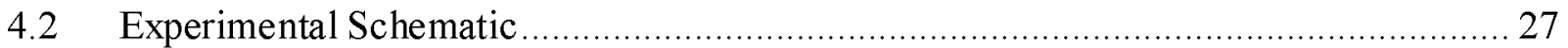

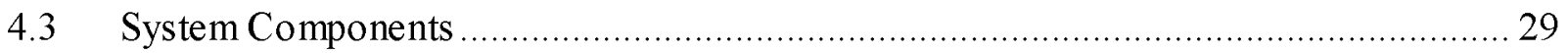

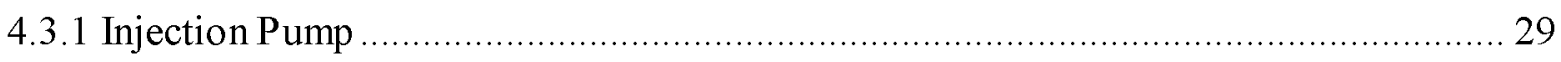

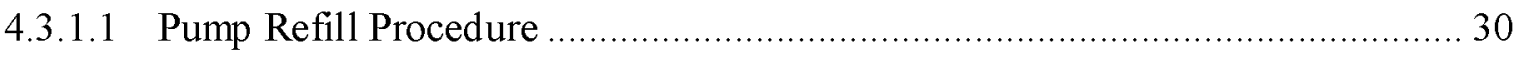

4.3.1.2 Pump Injection Procedure ........................................................................... 30

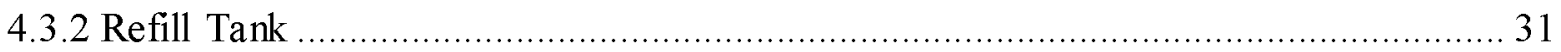

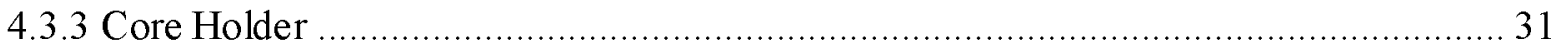

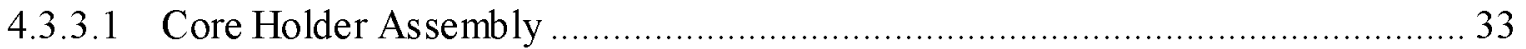

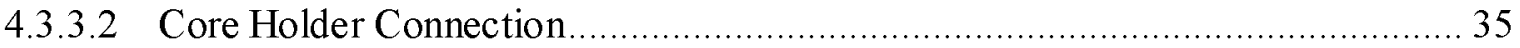

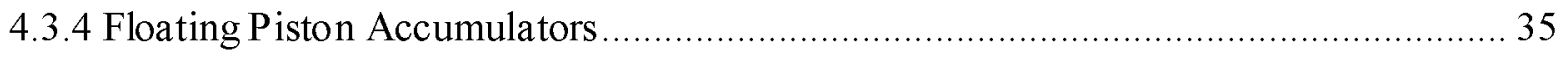

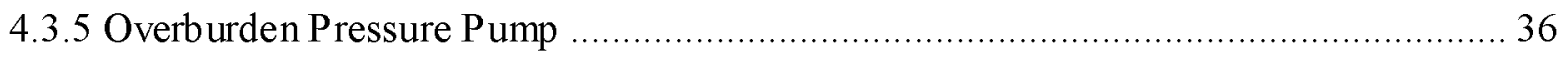

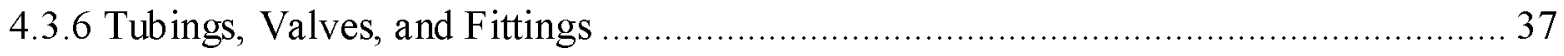

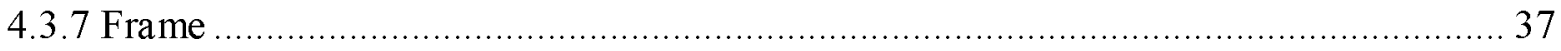




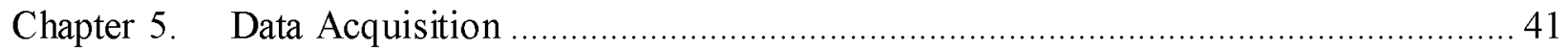

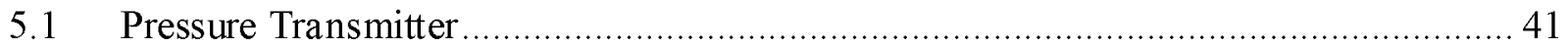

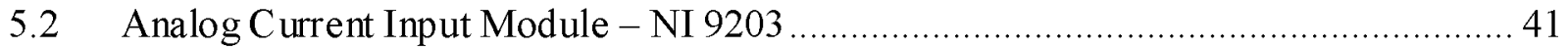

$5.3 \quad$ Wiring Transmitter and Analog Input Module .................................................. 42

5.4 LabVIEW Software ............................................................................. 43

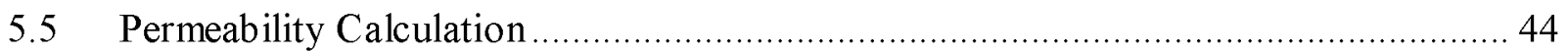

Chapter 6. Experimental Procedure and Troubleshooting ............................................. 45

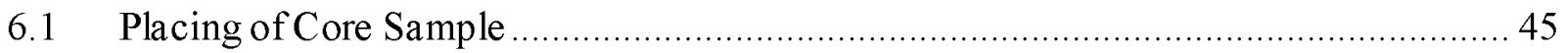

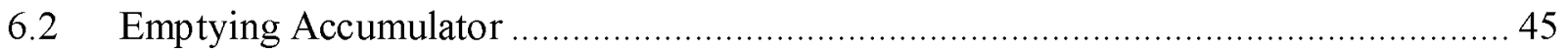

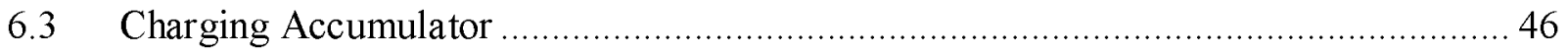

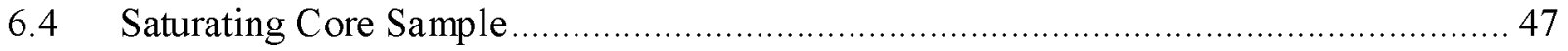

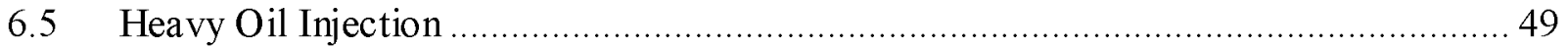

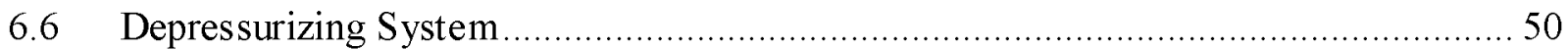

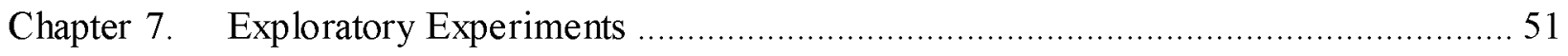

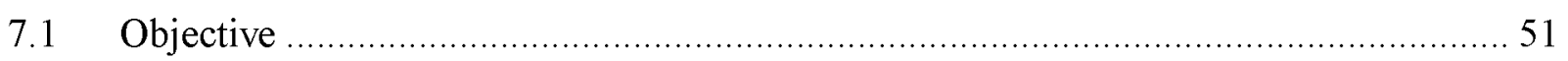

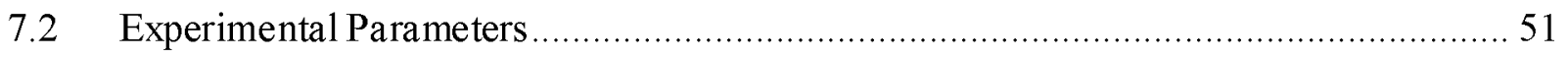

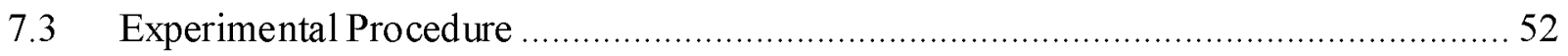

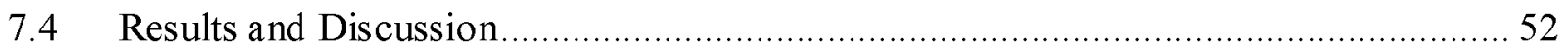

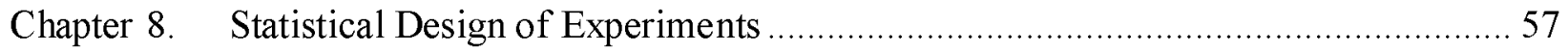

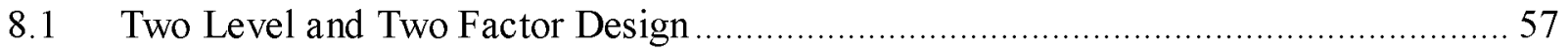

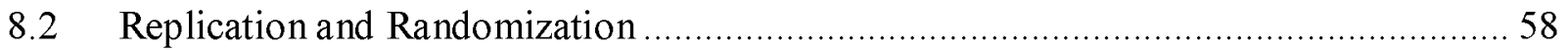

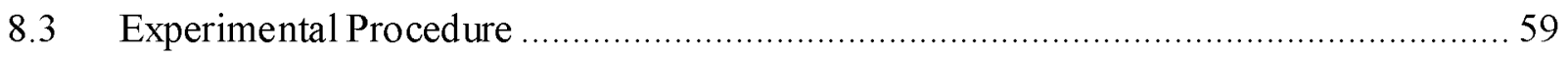

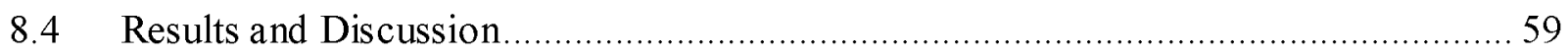

8.5 Qualitative Comparison of Results with Existing Literature .................................. 61

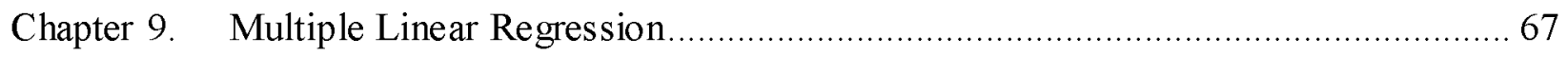




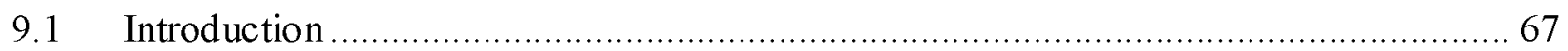

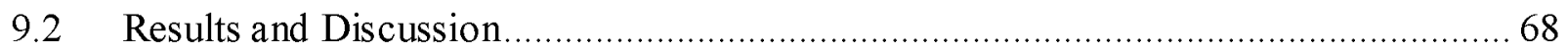

Chapter 10. Conclusions and Recommendation ....................................................... 71

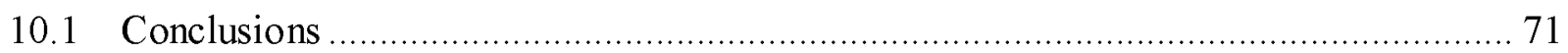

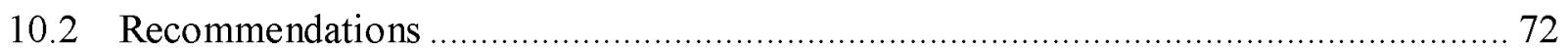

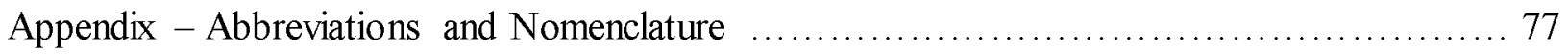




\section{List of Figures}

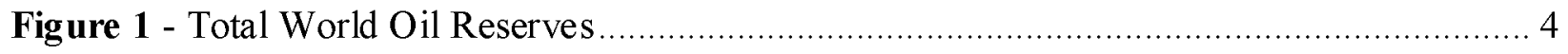

Figure 2 - Global Heavy Oil Reserves ..................................................................... 4

Figure 3 - Heavy Oil in North Slope Alaska ...................................................................... 5

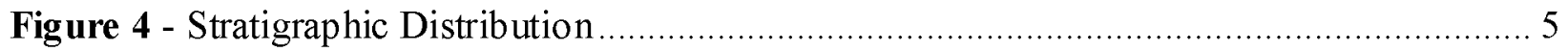

Figure 5 - Wormhole Channel Model - Dendritic and Constant Channels .............................. 6

Figure 6 - The Separation of Two Distinguishable Periods in Cold Production. ...................... 7

Figure 7 - Axisymmetric Core Holder and Sand pack ................................................ 8

Figure 8 - Longitudinal section of wormhole before (initial) and after (final) sand production. .. 8

Figure 9 - Pressure Profile Before and After Sand Production during CHOPS (Tremblay et al., 1996)

Figure 10 - Pressure Gradient as a Function of Time (Meza-Diaz et al., 2010) ..................... 10

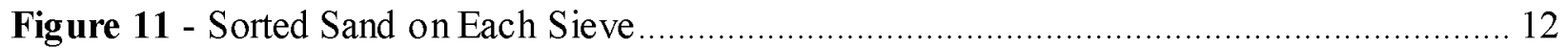

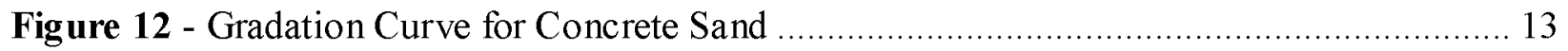

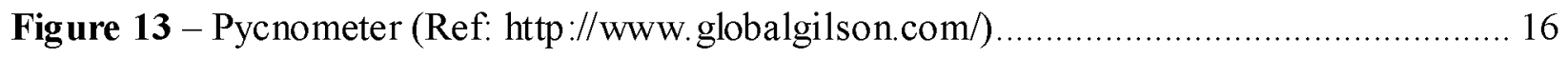

Figure 14 - Constant Head Permeameter Schematic (http://www.uwstout. edu/) ................... 18

Figure 15 - Comparison for Initial Screening Test Results .............................................. 19

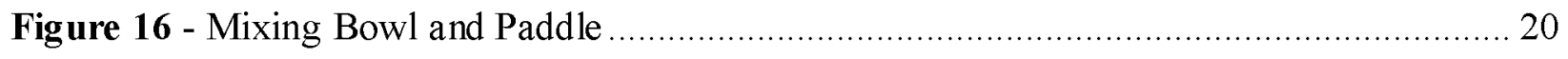

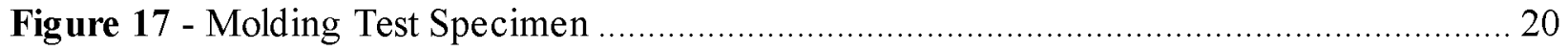

Figure 18 - Compressive Strength Testing Machine .................................................... 21

Figure 19 - Destructive Compressive Strength Testing …............................................ 21

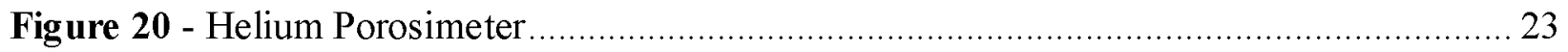

Figure 21 - TinyPerm II Portable Air Permeameter ...................................................... 23

Figure 22 -Specimen Properties as a Function of Water to Cement Ratio .......................... 23

Figure 23 - Specimen Properties as a Function of Water to Clay Ratio ................................ 24

Figure 24 - Cores Setting in 2" x 4" Molds .................................................................. 24

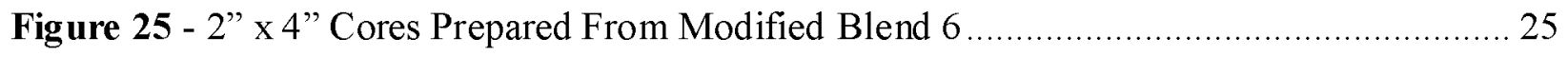

Figure 26 - Flowchart for Core Develop ment Methodology ............................................... 25

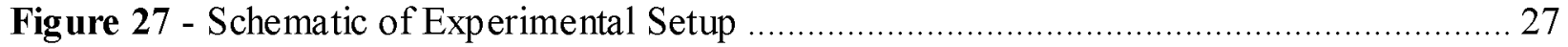

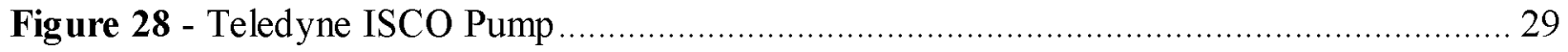

Figure 29 - Pump Controller Front Panel..................................................................... 30 


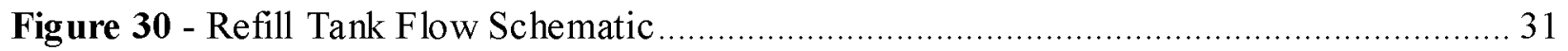

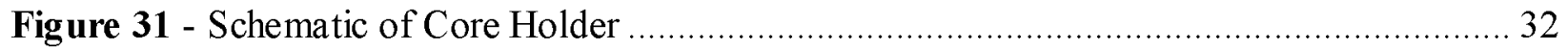

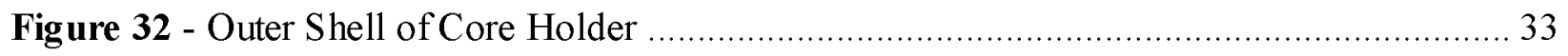

Figure 33 - Pressure Tapping from Top Bushing of Core Holder to Rubber Sleeve ................. 33

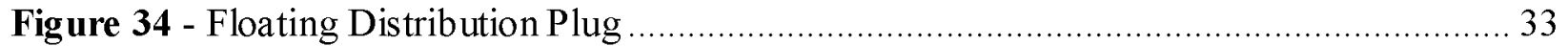

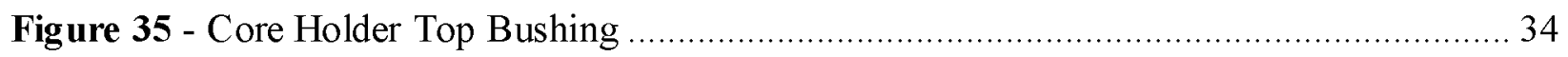

Figure 36 - Core Holder Bottom Bushing ........................................................................... 34

Figure 37 - Schematic of Core Holder Bottom Bushing .................................................... 34

Figure 38 - Floating Distribution Plug and Outlet Assembly ............................................ 35

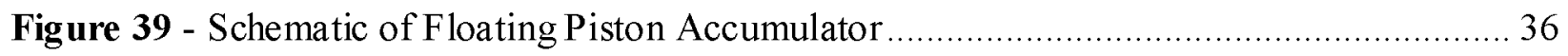

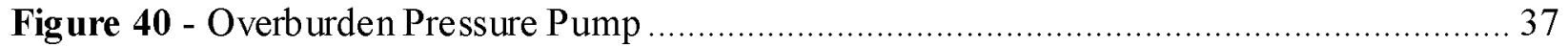

Figure 41 - Frame Designed for Laboratory Setup ...................................................... 38

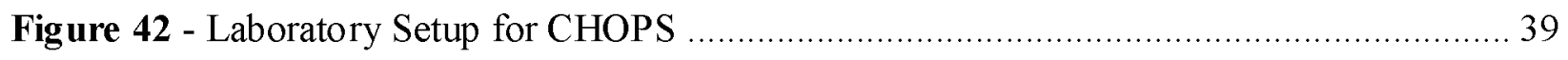

Figure 43 - Foxboro IGP10 Pressure Transmitter .................................................... 41

Figure 44 - NI 9203 Current Analog Input Module ....................................................... 41

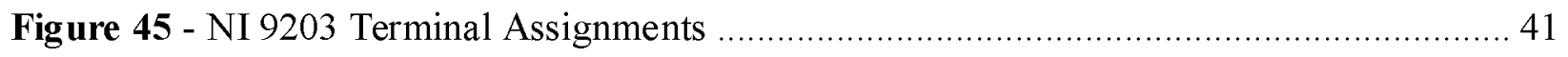

Figure 46 - Wiring Sketch of Data Acquisition System .................................................. 42

Figure 47 - Pressure Transmitter Connections ........................................................... 42

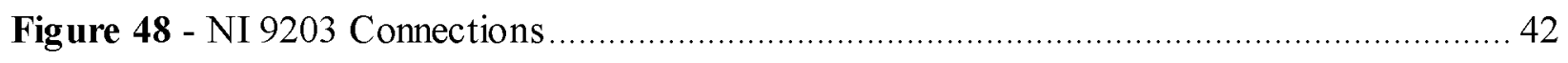

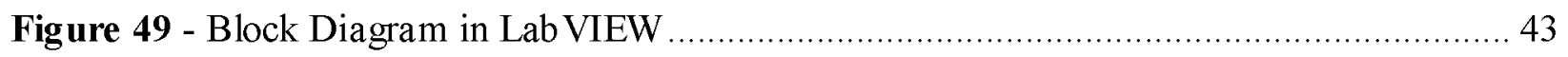

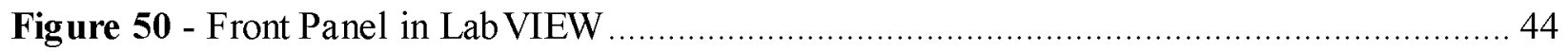

Figure 51 - Flow Diagram for Emptying Accumulator Before Charging ........................... 46

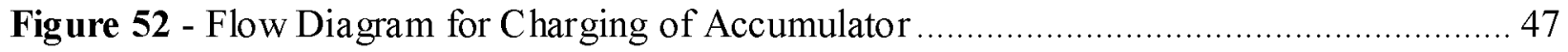

Figure 53 - Flow Diagram for Saturating Core with Water ............................................... 49

Figure 54 - Flow Diagram for Heavy Oil Injection into the Core Holder ..............................50

Figure 55 - Core Permeability versus Pore Volume Injected for Varying Rate of Injection and Constant Differential Confining Pressure of 500 psia ...................................................... 53

Figure 56 - Core Permeability versus Pore Volume Injected for Varying Rate of Injection and Constant Differential Confining Pressure of 1000 psia .

Figure 57 - Permeability versus Pore Volume for Five Basic Experimental Runs using Design of Experiments at DCP 500 psi. 
Figure 58 - Core Samples Post Experiment.

Figure 59 - Sample Collected at the Outlet of Core Holder.....

Figure 60 - Comparison of Pressure Profile of Experiments Conducted with Tremblay et al., 1996.

Figure 61 - Digitized Plot for Pressure Gradient as a Function of Time, Meza-Diaz et al, 2010.64

Figure 62 - Pressure Profile as a Function of Time for Exploratory Experiment - 1 65

Figure 63 - Effect of Model Coefficients vs. Pore Volumes Injected 69

Figure 64 - P-Values at Variable Pore Volumes . 70 


\section{List of Tables}

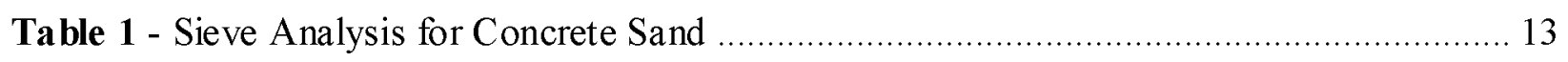

Table 2 - Six Blends with Varying Weight Percentage of Different Aggregates ...................... 14

Table 3 - Dry Rodded Unit Weights of Six Blends ............................................................ 15

Table 4 - Specific Gravity of Six Blends ................................................................. 16

Table 5 - Hydraulic Conductivity of Blend ................................................................. 18

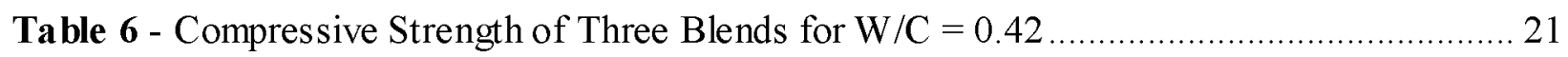

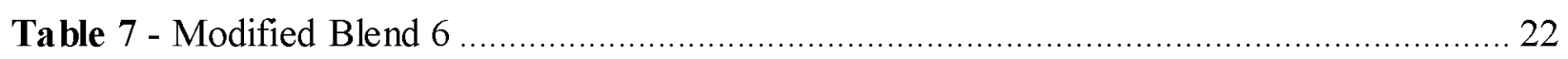

Table 8 - Varying W/C for Modified Blend 6 ................................................................ 22

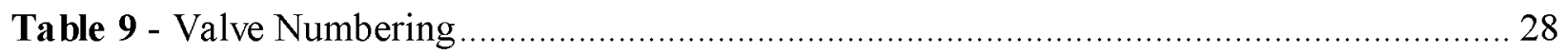

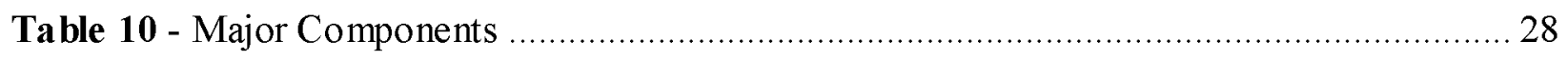

Table 11 - Technical Specification of Teledyne ISCO Pump ................................................ 29

Table 12 - Core Holder Part List (Refer Figure 31) ........................................................ 32

Table 13 - Physical Properties of Synthetic Heavy Oil used for Exploratory Experiment ......... 51

Table 14 - Physical Properties of Core .................................................................. 51

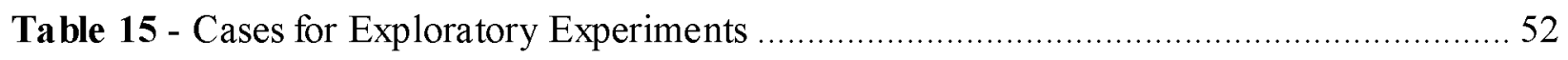

Table 16 - Rate of Injection and Time Taken to Inject 2.5 Pore Volumes ............................. 52

Table 17 - Factors, Levels and Response Variable ........................................................ 57

Table 18 - Full Factorial Design for Two Factors and Two Levels ...................................... 58

Table 19 - Sequence of Randomly Assigned Experimental Runs ...................................... 59

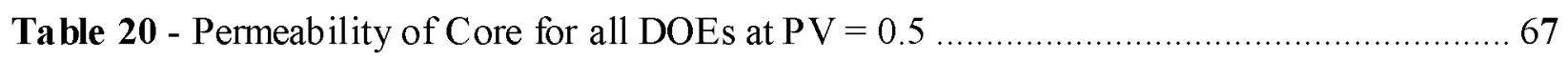

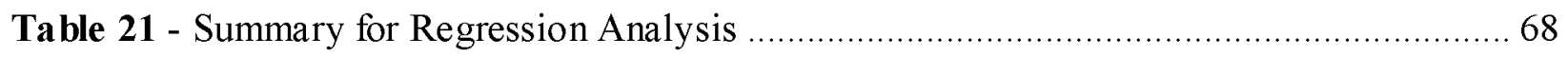




\section{Acknowledgements}

I would like to express my sincere gratitude to my advisor, Dr. Obadare Awoleke, who has supported me throughout my thesis with his patience and knowledge. I attribute the level of my Master's degree to his encouragement and effort.

I would like to thank my committee members, Dr. Mohabbat Ahmadi, Dr. Catherine Hanks, and Dr. Jenny Liu, for their insightful comments and encouragement.

I am grateful to the Petroleum Engineering Department Chair Dr. Abhijit Dandekar for partially funding my graduate studies and I take this opportunity to express gratitude to all of the Petroleum Department faculty members for their help and support.

I would also like to thank my parents, Mr. K. Narayana Pillai and Mrs. Geetha Narayan, my sister, Aparna Narayan, and brother-in-law, Reagan Bhaskar, for their unconditional love and support.

I am indebted to my friends Mohit Paryani, Bakul Mathur, and Radhakrishnan Balasubramanian for helping me stay sane through difficult times. Their support and care helped me overcome setbacks and stay focused on my graduate studies. 
xviii 


\section{Chapter 1. Introduction}

\subsection{Overview}

Cold Heavy Oil Production with Sand (CHOPS) began in the late 1980s in Canada, and in the 1990s, it was recognized as the first production option for heavy oil exploitation in unconsolidated heavy oil reservoirs (Dusseault, 2002). CHOPS is defined as primary heavy oil production that involves deliberate initiation of sand influx into an oil well. It is postulated that high permeability paths, called wormholes, are initiated mainly in the near-wellbore region. The wormholes are filled with sand suspended in foamy oil, with their tips propagating away from the wellbore into the formation.

Most CHOPS reservoirs are unconsolidated sands of $\sim 29-31 \%$ porosity. The thinnest producing reservoirs are $\sim 4 \mathrm{~m}$ and the thickest are just in excess of $30 \mathrm{~m}(8-15 \mathrm{~m}$ is most common). Mean grain size varies from 80 to $250 \mathrm{~mm}$, ranging from well sorted to poorly sorted. Clay content can be as high as $5 \%$ but usually it is $1-2 \%$. In typical CHOPS reservoirs, saturations are $\mathrm{S}_{\mathrm{o}}=0.85-$ $0.88, \mathrm{~S}_{\mathrm{w}}=0.12-0.15$ and $\mathrm{S}_{\mathrm{g}}=0$ (Dusseault and El-Sayed, 2000).

In the past, sand packs were used to investigate wormhole propagation. The sands used were not sieved and cleaned before packing in the cell. The sand pack was imaged using a Computerized Tomography (CT) scanner. The CT images revealed that wormholes were formed in the pack while sand was produced. The wormhole initiated and propagated in regions within the pack where the porosity was higher, i.e., where the unconfined compressive strength of the sand was lower. The porosity in the region outside the wormhole did not change when the wormhole developed (Tremblay et al., 1996a, 1996b and Jian-Yang et al., 1999).

\subsection{Objectives}

The objective of the first part of this experiment was to synthesize low compressive strength cores with properties in the range found in unconsolidated heavy oil formations. In previous experiments sand packs were used to investigate the wormhole propagation process during CHOPS. Synthetic cores are made from aggregate, cement/clay and water. Porosity and permeability are affected by aggregate size to different degrees. Increasing aggregate size will increase the permeability. Porosity depends less on particle size; rather, it is affected more by factors such as particle shape, sorting, packing and cementation. Increasing the proportion of cement/clay in the mixture fills the void spaces and also reduced both the porosity and permeability of a specimen. Therefore, various 
mixes were selected, tested and screened to attain the desired core properties. The synthetic cores made using this new methodology are more representative of the unconsolidated formation.

The objective of the second part of this experiment was to design and build an experimental set up to simulate wormhole development and propagation during the CHOPS process. A syringe pump was used to inject water into an oil accumulator, which in turn pushed the oil ahead of the floating piston into the water-saturated core in the core holder. Samples of produced water, oil and solids from the outlet of the core holder were collected at each rate. The differential pressure across the core was recorded throughout the flooding process to calculate the permeability of core.

Exploratory experiments were conducted by varying the net confining pressure on the core and injection rate to know the limitations of the built setup when heavy oil is introduced to the system. Those experiments helped to explore how varying the oil injection rate affects the permeability of the core for two cases, namely, differential confining pressure less than the compressive strength of core and differential confining pressure greater than the compressive strength of core. Design of experiment was used and regression models were developed to understand the effect of oil viscosity, injection rate and their interaction on core permeability at constant net confining pressure occurring due to core structure deformation. 


\section{Chapter 2. Literature Review}

The continuous increase in energy demand due to the economic development in recent years has resulted in reduced availability of petroleum resources. These resources were mainly composed of conventional oil reserves with high market value that can be produced and processed with simple and technically well-established methods. The increasing demand has led to the consideration of unconventional resources as an alternate supply for energy resource. The International Energy Agency (IEA) does not recognize any standard definition for unconventional resources. As the use of newer technologies increases, unconventional becomes conventional. Therefore, the definition of unconventional is time-dependent. At present, heavy oil is considered as unconventional resource due to technical difficulties involved in its production. The section below discusses the properties of heavy oil that make it difficult to flow and the methods used to produce heavy oil. This literature review focuses mainly on Cold Heavy Oil Production with Sand (CHOPS), one of the methods to produce heavy oil.

\section{1 Heavy Oil}

Heavy crude oil is defined as any liquid petroleum with an API gravity less than $20^{\circ}$ (Dusseault, 2001). The U.S. Geological Survey (USGS) defines heavy oil as oil with viscosity greater than $100 \mathrm{cp}$ and API gravity lower than $22.3^{\circ}$ API. The American Petroleum Institute's API gravity is a standard to express the specific weight of oils and is evaluated using the formula given:

API gravity $=\frac{141.5}{\gamma_{0}}-131.5$

Heavy oil is mostly thought to be expelled from source rocks as light or medium oil and subsequently migrate into a trap. If the trap is exposed to an oxidizing zone, processes like water washing, bacterial degradation, and evaporation can convert the oil to heavy oil. It is also proposed that heavy oil can be formed due to biodegradation occurring at depth in subsurface reservoirs, in which lighter ends are preferentially consumed by bacterial activity in the reservoir, leaving heavier hydrocarbons behind. This explanation permits biodegradation to occur in any reservoir that has a water leg and has not been heated to more than $176^{\circ} \mathrm{F}$ (Head et al., 2003; Larter et al., 2003; Larter et al., 2006).

Heavy oil pools and tar sand deposits are formed at shallow depths near the ground surface (generally within $1000 \mathrm{~m}$ depth, few within $2000 \mathrm{~m}$ ) and are distributed mainly in younger strata. 
More than $90 \%$ of heavy oil is distributed in Cretaceous and Tertiary reservoirs (Chilingarian and Ean, 1978; Hu, 1988).

\subsubsection{Global Heavy Oil Reserves}

According to the World Resources Institute, huge reserves of heavy oil and oil sands are found in Canada and Venezuela (Dusseault, 2001). Heavy Oil, Extra Heavy Oil, and Bitumen make up about $70 \%$ of world's total oil resources of 9 to 13 trillion barrels, Figure 1 (IEA, 2011). Fourfifths of these deposits are in the Western Hemisphere, Figure 2. The largest reserves of heavy crude oil in the world are located north of the Orinoco River in the 270 -mile long by 40 -mile wide Orinoco Belt in eastern Venezuela (EIA, 2011). In the United States, heavy hydrocarbon deposits are estimated to be more than eight times the nation's remaining reserves of conventional crude oil.

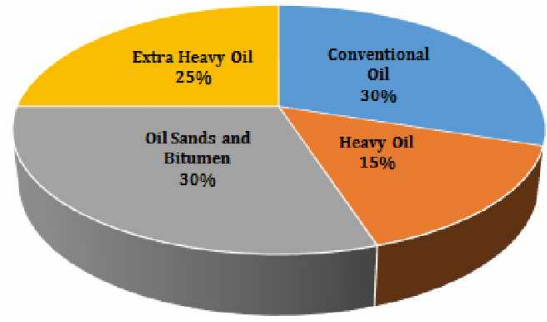

Figure 1 - Total World Oil Reserves

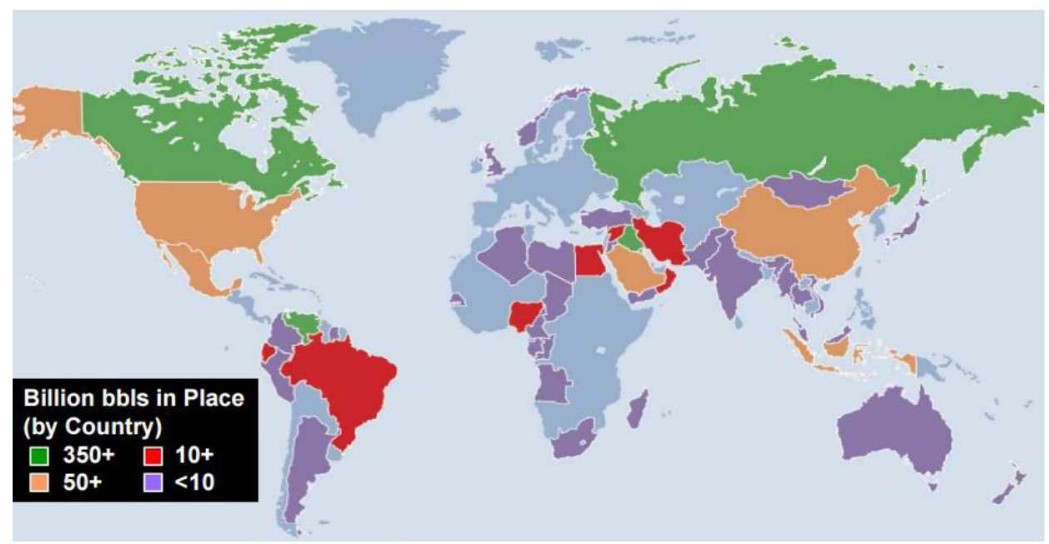

Figure 2 - Global Heavy Oil Reserves

\subsubsection{Heavy Oil in Alaska}

Alaska is known for its petroleum resources in the North Slope, with two of the largest producing fields in North America, Prudhoe Bay and the Kuparuk River unit. Heavy Oil in the North Slope 
is found in multiple zones and oil in place ranges from 18 to 27 billion barrels (Bbbl), which remain untapped because of the complexity of producing heavy oil in an Arctic environment. Initial appraisal in the North Slope is focused on the 12 to $18 \mathrm{Bbbl}$ within the Lower Ugnu (M-sand), Figure 3 (Young et al., 2010).

The Ugnu formation is quite cold, with temperatures of 45 to $65^{\circ} \mathrm{F}$. The Ugnu structure is characterized by a normal-faulted monoclinal dip toward the northeast and the pool varies from a depth of 4,500 ft in the east to $3,000 \mathrm{ft}$ in the west with heavy oil $14-22{ }^{\circ} \mathrm{API}$. The lower Ugnu is separated from the underlying West Sak sands by a regionally extensive mudstone that ranges from 100 to $150 \mathrm{ft}$ thickness. West Sak and Schrader Bluff have viscous oil deposits of 8-14 ${ }^{\circ}$ API, Figure 4 (Alaska Oil and Gas Association).

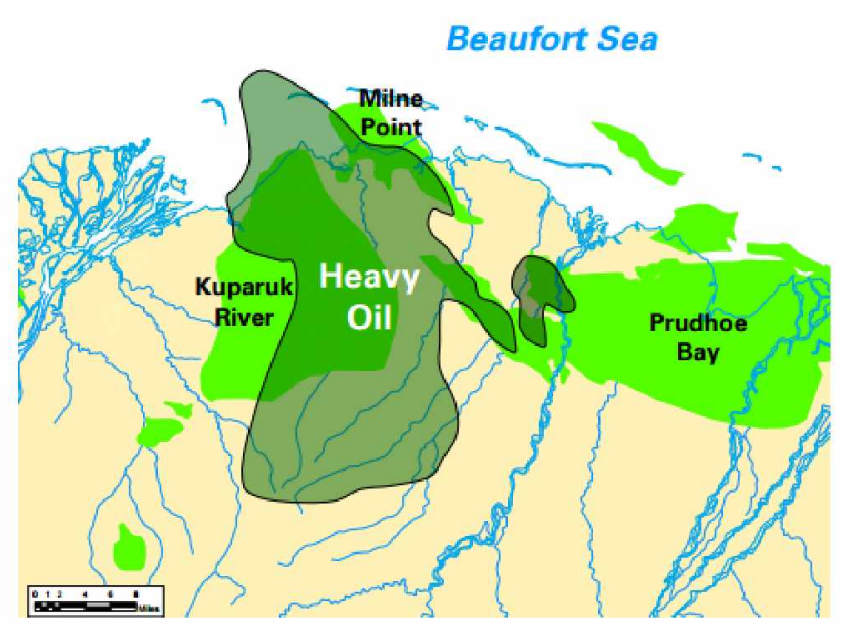

Figure 3 - Heavy Oil in North Slope Alaska

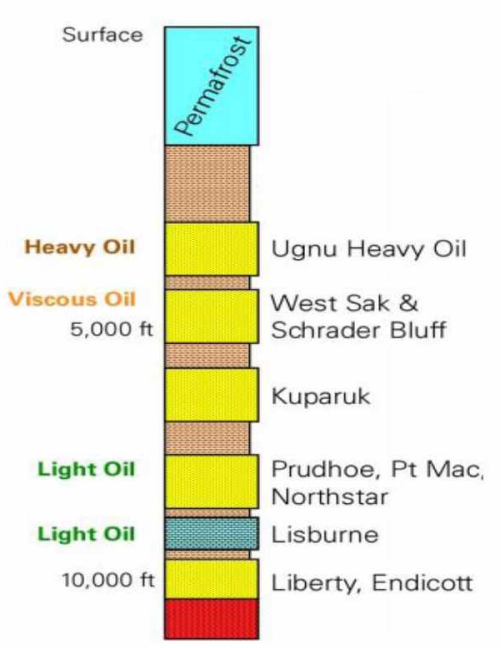

Figure 4 - Stratigraphic Distribution

\subsection{Cold Heavy Oil Production with Sand}

CHOPS is a primary oil recovery technique that involves deliberate initiation of sand production, which in turn results in high oil production due to increased porosity and permeability. CHOPS technology began in the late 1980s in Canada and in the 1990s it was recognized as the first production option for heavy oil exploitation in unconsolidated reservoirs (Dusseault \& El-Sayed, 2000). All CHOPS reservoirs are unconsolidated sands of $\sim 29-31 \%$ porosity. The thinnest producing reservoirs are $\sim 4 \mathrm{~m}$ and the thickest are just in excess of $30 \mathrm{~m}$ ( $8-15 \mathrm{~m}$ is most common). The heavy oil recovery factor of CHOPS can reach $15-20 \%$ with an oil production rate of 3.2-47.7 $\mathrm{m}^{3} /$ day (Han et al., 2007). 


\subsubsection{CHOPS Mechanism}

Heavy oil flows more efficiently if sand enters the wellbore for four major reasons:

1) Enhanced Drainage Radius

2) Grain Movement

3) Gas Bubble Expansion

4) Continuous Pore Deblocking

During the initial phase of cold production, thousands of cubic meters of sand are produced and the drainage area is enhanced as high permeability channels called wormholes from the wellbore propagating into the reservoir. The main cause of wormhole formation is believed to be the flux of the fluids through unconsolidated sand. This flux exerts a drag force strong enough to overcome the forces that hold sand grains together. The sand grains are transported along the wormhole. Heavy oils are at its bubble point in reservoir. As the production starts and pressure drops, gas is evolved but the capillary forces is stronger than the continuous phase coalescence thereby the bubbles are separated from each other. Usually these bubbles block the pores reducing the flow rates but as the sand is produced continuously with the oil, the bubbles also flow and through expansion it provides an internal drive force thereby deblocking the pores.

There are two models proposed for the wormhole growth: Constant and Dendritic Channel, Figure 5. In the former, the channels develop by branching repeatedly and a three-dimensional geometry is created where volume density remains constant, and in the latter, a number of channels develop outwards and the number remains constant with distance (Tremblay et al., 1999).

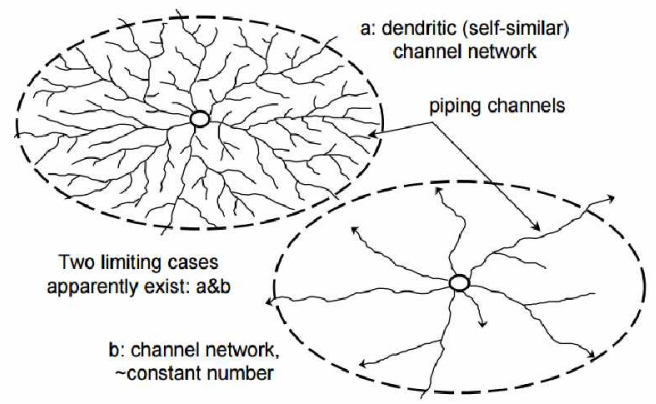

Figure 5 - Wormhole Channel Model - Dendritic and Constant Channels 
Apart from permeability enhancement effects, grain mobility facilitates liquid movement. Because of drag force, an increased flow rate up a factor of two is expected out of the grain movement. Gas bubble theory also explains the improvement of heavy oil recovery. Heavy oils are at their bubble point in reservoirs. As the production starts and pressure drops, gas is evolved but the capillary forces are stronger than the continuous phase coalescence, thereby separating the bubbles from each other. Normally, the bubbles block the pores, reducing the flow rates, but as the sand is produced along with the oil, the bubbles can flow with it and provide internal drive force through expansion (Dusseault, 1993).

\subsubsection{Sand Production}

There are two periods of sand production: fast and slow growth of wormholes. During fast growth the pressure differences between the wormhole tips and the reservoir are enough to initiate wormhole growth at high rates, resulting in more sand production. The flow of sand and oil is almost plug flow. Considering constant bottom hole pressure (BHP), the pressure at the wormhole tips builds up, thereby decreasing the pressure differences between most of the wormhole tips and the reservoir to cause further growth of wormholes. Hereafter, wormhole stops expanding, although it is possible that some wormholes may still grow. However, oil flow into the wormhole zone continues. An open channel forms at the top of the wormhole and scouring effects within wormholes become dominant. The sand production at this point declines until the scouring effects clean out most of the sand from the wormholes. A sharp decline in sand production rate is observed in sand when a wormhole stopped growing and an open channel formed at the top of the wormhole.

Figure 6 explains the two different periods in sand production (Tremblay et al., 1999).

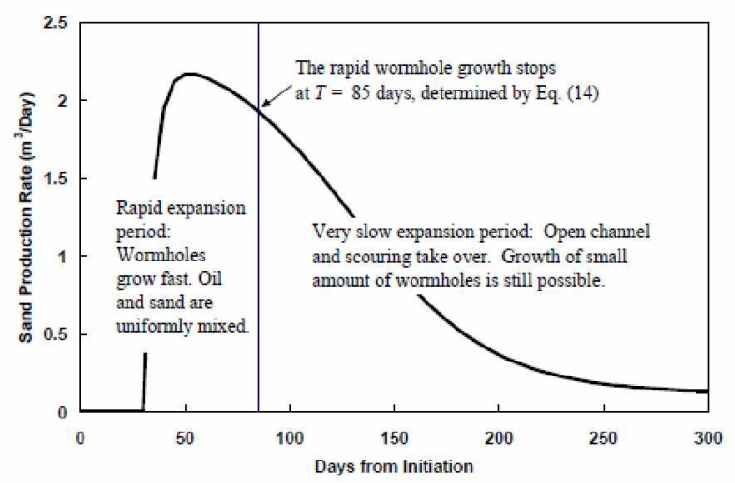

Figure 6 - The Separation of Two Distinguishable Periods in Cold Production. 


\subsubsection{Investigating Wormhole Propagation}

Sand packs were used to investigate the wormhole propagation. The sands used were not sieved and cleaned before packing in the cell. The average sand grains were of the size of $177 \mu \mathrm{m}$. The sand was saturated with oil of viscosity $21.5 \mathrm{~Pa}$.s. The sand was packed in a cylinder which had an orifice located at one of the ends. The sand was packed so as to obtain porosity of $32 \%$, representing the field condition. A positive displacement pump injected water to push the piston, thereby pushing the oil through the porous disk into the sand pack. The pore pressure at the production end was measured, Figure 7.

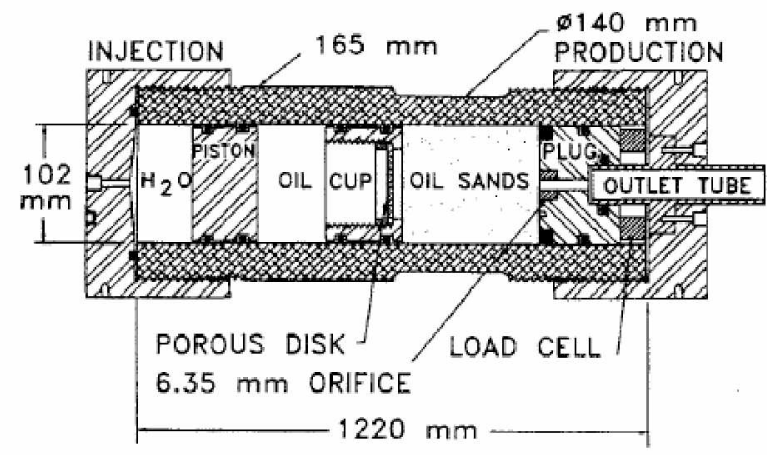

Figure 7 - Axisymmetric Core Holder and Sand pack

The sand pack was imaged using CT scanner. The CT images revealed that a high-porosity channel (wormhole) formed in the pack while sand was produced, Figure 8.

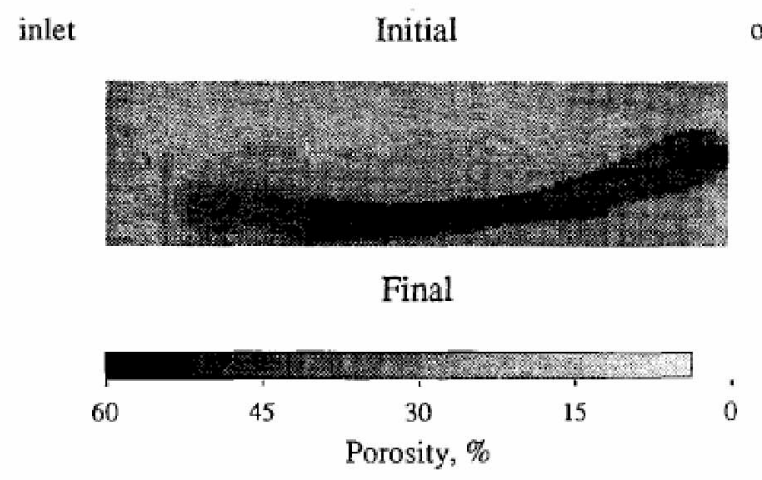

Figure 8 - Longitudinal section of wormhole before (initial) and after (final) sand production.

The wormhole followed regions within the pack where the porosity was higher, i.e., where the unconfined compressive strength of the sand was lower. This experiment suggested that wormholes will form within the weaker sands of a formation. The wormhole converged as the 
orifice was approached. The development of these high-permeability channels increases the drainage of the reservoir, which leads to higher oil recovery (Tremblay et al., 1996).

\subsubsection{Pressure Profile Analysis}

Permeability was measured from flow rate and pressure drop from the experiment conducted in the previous section. Figure 9 shows the pressure profile before and after sand production. A and $\mathrm{A}^{\prime}$ indicate the times at which the injection flow rate is changed. B to $\mathrm{C}$ shows the collapse of sand around the orifice, which led to a sudden increase in pore pressure because the oil did not have time to drain and therefore supported the stress entirely. B' to D' indicate a decrease in injection pressure, which can be explained by an increase in the permeability of the region near the orifice. $\mathrm{D}$ to $\mathrm{E}$ shows a decrease in pore pressure because of buildup of effective stresses around the perforation as oil started to drain. D' to E' indicates that injection pressure declines quickly as the wormhole started to develop Tremblay et al., 1996.

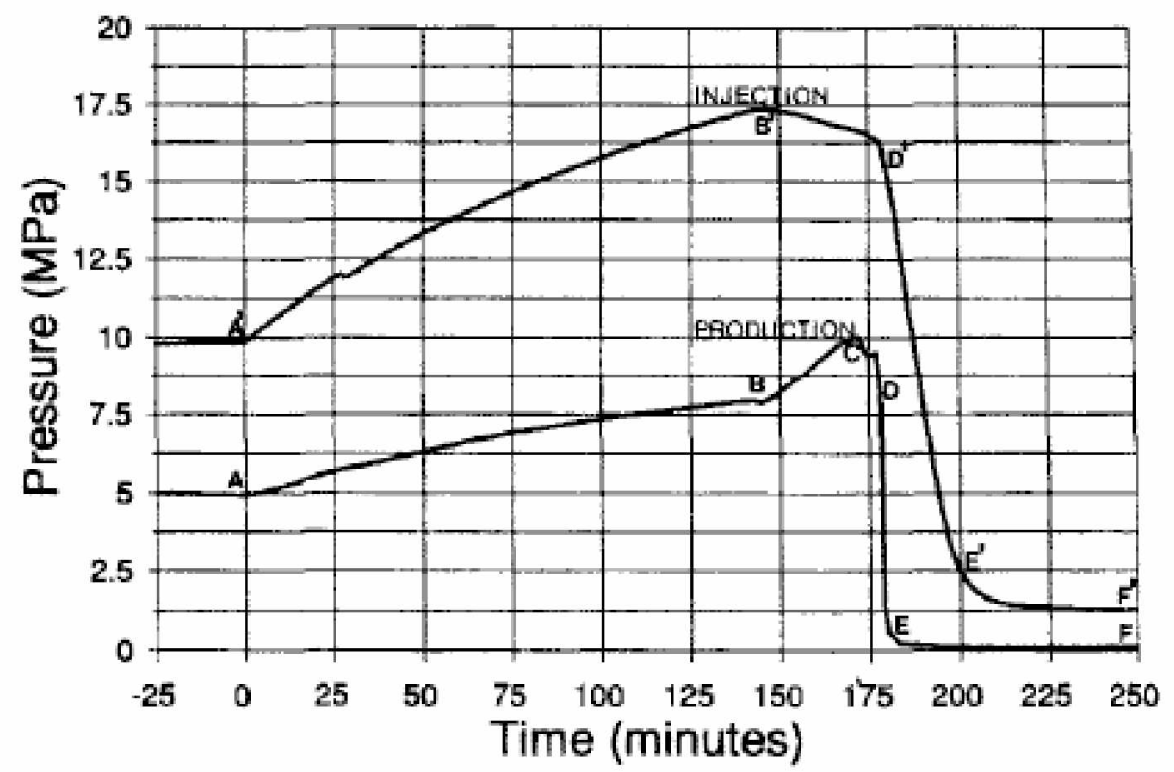

Figure 9 - Pressure Profile Before and After Sand Production during CHOPS (Tremblay et al., 1996) In later experiments, the effect of slot size and rate on sand production was assessed. The results from the experiment indicated that the right slot size combined with drawdown rates could control sand production with significant increases in permeability in horizontal wells, Figure 10 (Meza-Diaz et al., 2010). 


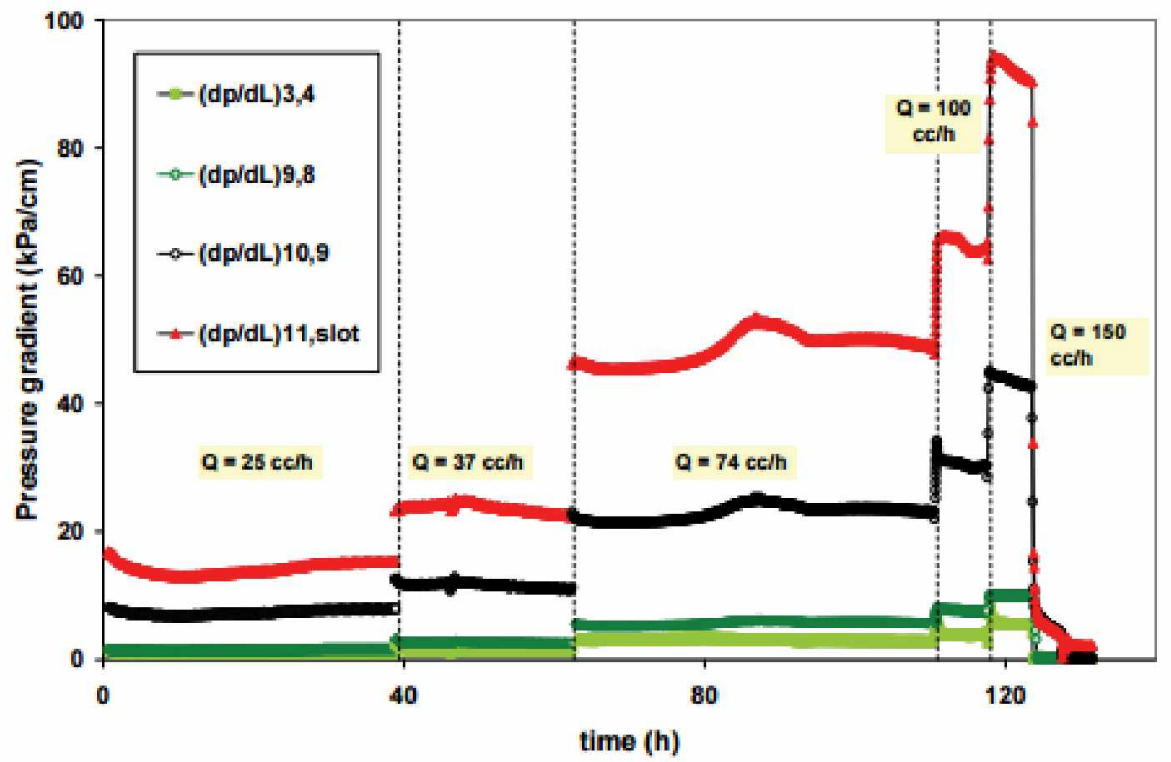

Figure 10 - Pressure Gradient as a Function of Time (Meza-Diaz et al., 2010) 


\section{Chapter 3. Developing Synthetic Cores for CHOPS}

\subsection{Introduction}

This chapter describes the procedure for making cores that represent the CHOPS formation. Cores are made mixing aggregate, cementing material, and water. For preliminary testing, cement was used as the binding material to start the tests with American Society for Testing and Materials (ASTM) standards, and was later replaced by clay.

\subsection{Aggregate Selection}

The efficacy of the CHOPS process depends largely on the rock properties of the reservoir. This section describes the techniques used to ensure proper aggregate selection.

\subsubsection{Particle Size Distribution}

The grading or size distribution of aggregate is important because it determines the paste requirement for workable mixture. Workability is the ease with which the paste can be placed. When the particles have uniform size, the porosity is the greatest, but when a wider range of sizes is used, the void spaces between large particles are filled with smaller ones and the mixture becomes less workable.

Sieve analysis (or gradation test) was done to evaluate the particle size distribution of concrete sand. This was done by sieving the aggregates as per ASTM C136 - Standard Test Method for Sieve Analysis of Fine and Coarse Aggregates. The procedure follows:

1) The concrete sand was heated in the oven until it was completely dry.

2) The sieves were stacked with the pan at the bottom. Sieve sizes used: \#8, \#10,\#16, \#30, $\# 50, \# 80, \# 100$, and \#200.

3) The concrete sand was weighed, poured to the top sieve, and covered with a lid.

4) The stack was placed in mechanical sieve shaker and ran for 10 minutes.

5) On completion of sieving, the material on each sieve was weighed.

6) The mass of aggregate retained on each sieve was obtained by subtracting the weight of the empty sieve from the mass of the sieve and the retained soil. 
7) Percent retained on each sieve was calculated by dividing the weight retained on each sieve by the original sample mass.

8) Percent passing was calculated by starting with $100 \%$ and subtracting the percent retained on each sieve as a cumulative procedure.

9) The sum of these retained masses should approximate the initial mass of the soil sample. A loss of more than two percent is considered unsatisfactory and the experiment needs to be repeated.

10) At the end the aggregate sample on each sieve was placed in its corresponding labelled storage bin.

Figure 11 shows the sieve stack and sands received in various sieves. Table 1 summarizes the results of sieve analysis and Figure $\mathbf{1 2}$ is a semi-logarithmic plot of grain size vs. percent passing.

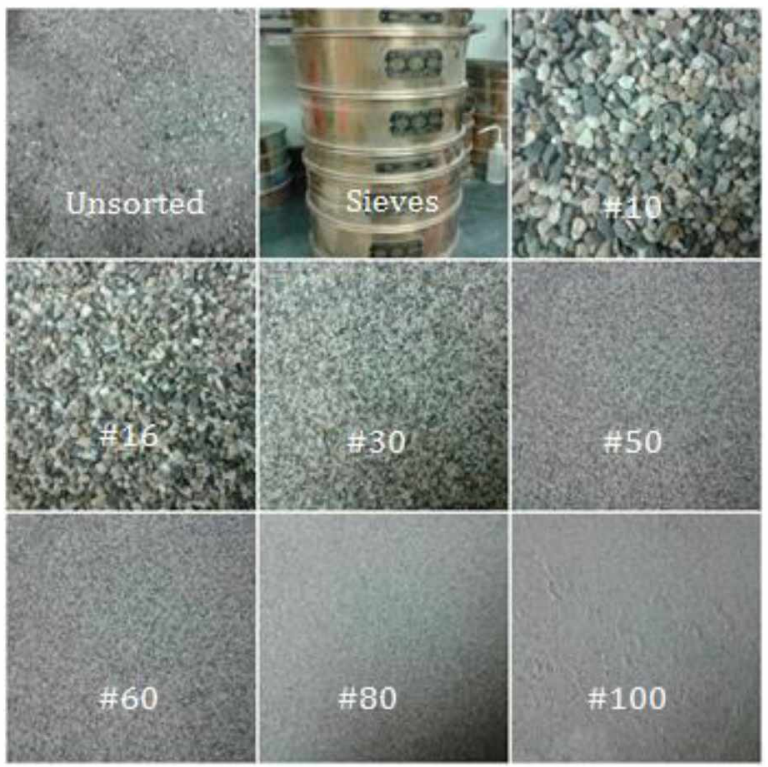

Figure 11 - Sorted Sand on Each Sieve 


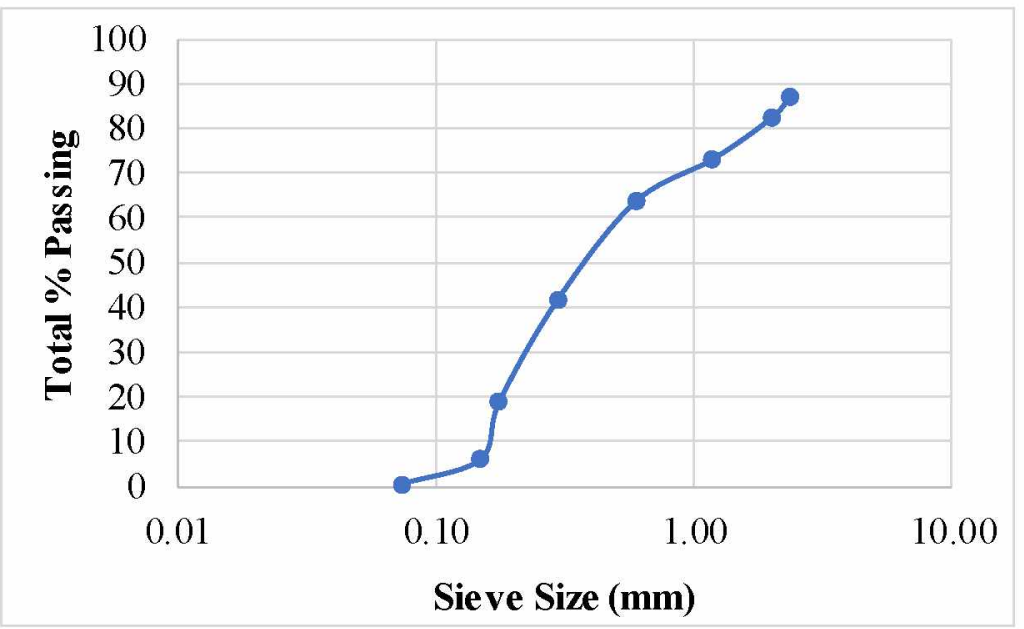

Figure 12 - Gradation Curve for Concrete Sand

Table 1 - Sieve Analysis for Concrete Sand

\begin{tabular}{|c|c|c|c|c|c|c|c|}
\hline $\begin{array}{c}\text { US } \\
\text { Mesh } \\
\text { Size }\end{array}$ & $\begin{array}{l}\text { Sieve } \\
\text { Size } \\
(\mathrm{mm})\end{array}$ & $\begin{array}{c}\text { Mass } \\
\text { Sieve } \\
(\mathrm{g})\end{array}$ & $\begin{array}{c}\text { Mas s } \\
\text { Sieve+Aggregate } \\
\text { (g) }\end{array}$ & $\begin{array}{c}\text { Mas s } \\
\text { Retained } \\
\text { (g) }\end{array}$ & $\begin{array}{c}\% \\
\text { Retained } \\
\text { on Sieve }\end{array}$ & $\begin{array}{c}\text { Total \% } \\
\text { Retained } \\
\text { (\% Larger) }\end{array}$ & $\begin{array}{c}\text { Total \% } \\
\text { Passing } \\
\text { (\% Smaller) }\end{array}$ \\
\hline$\# 8$ & 2.38 & 1008.4 & 1134.40 & 126.00 & 12.80 & 12.80 & 87.20 \\
\hline$\# 10$ & 2.00 & 965.6 & 1014.10 & 48.50 & 4.93 & 17.73 & 82.27 \\
\hline$\# 16$ & 1.19 & 903.5 & 993.10 & 89.60 & 9.10 & 26.83 & 73.17 \\
\hline$\# 30$ & 0.60 & 1100.8 & 1195.10 & 94.30 & 9.58 & 36.41 & 63.59 \\
\hline$\# 50$ & 0.30 & 1024.4 & 1240.20 & 215.80 & 21.92 & 58.33 & 41.67 \\
\hline$\# 80$ & 0.18 & 737.4 & 960.30 & 222.90 & 22.64 & 80.98 & 19.02 \\
\hline$\# 100$ & 0.15 & 972.0 & 1099.90 & 127.90 & 12.99 & 93.97 & 6.03 \\
\hline$\# 200$ & 0.07 & 943.70 & 998.34 & 54.64 & 5.55 & 99.52 & 0.48 \\
\hline Pan & 0.00 & 879.70 & 884.40 & 4.70 & 0.48 & & \\
\hline \multicolumn{4}{|c|}{ Total Mass Retained $(\mathrm{g})=$} & 984.34 & & & \\
\hline \multicolumn{4}{|c|}{ Original Sample Mass $(\mathrm{g})=$} & 1000 & & & \\
\hline \multicolumn{4}{|c|}{ Percentage Loss $(\%)=$} & 1.566 & & & \\
\hline
\end{tabular}

\subsubsection{Selecting Blends}

As per ASTM C33, Standard Specification for Concrete Aggregates, very fine sand increases the water demand of the mixture, while very coarse sand compromises its workability. Too much sand 
on one sieve, i.e., gap-grading, increases the water demand of the mixture. The amount of material passing the \#50 and \#100 sieves affects workability. Smaller aggregates have more surface area, requiring more water for wetting the surface and more paste for lubricating the surface. So for a given water content and paste, a bigger aggregate will give higher workability.

Considering these facts, six blends were developed, as in Table $\mathbf{2}$, using different sizes of aggregates such that the weight of aggregates removed in each blend was added proportionally to the weight of aggregates used in that particular blend.

Table 2 - Six Blends with Varying Weight Percentage of Different Aggregates

\begin{tabular}{|c|c|c|c|c|c|c|c|c|c|c|c|}
\hline \multicolumn{2}{|c|}{ Blend - 1 } & \multicolumn{2}{|c|}{ B lend - 2 } & \multicolumn{2}{c|}{ Blend - 3 } & \multicolumn{2}{c|}{ Blend - 4 } & \multicolumn{2}{c|}{ Blend - 5 } & \multicolumn{2}{c|}{ Blend - 6 } \\
\hline Mesh & \% Wt & Mesh & $\%$ Wt & Mesh & $\%$ Wt & Mesh & $\%$ Wt & Mesh & $\%$ Wt & Mesh & $\%$ Wt \\
\hline$\# 10$ & 8.34 & $\# 16$ & 16.76 & $\# 16$ & 16.98 & $\# 10$ & 9.92 & $\# 30$ & 14.27 & $\# 16$ & 14.39 \\
\hline$\# 30$ & 16.22 & $\# 30$ & 17.64 & $\# 30$ & 17.87 & $\# 16$ & 18.33 & $\# 50$ & 32.65 & $\# 30$ & 15.15 \\
\hline$\# 50$ & 37.11 & $\# 80$ & 41.69 & $\# 50$ & 40.9 & $\# 80$ & 45.59 & $\# 80$ & 33.73 & $\# 50$ & 34.66 \\
\hline$\# 80$ & 38.33 & $\# 100$ & 23.92 & $\# 100$ & 24.24 & $\# 100$ & 26.16 & $\# 100$ & 19.35 & $\# 80$ & 35.8 \\
\hline
\end{tabular}

3.3 Initial Screening Tests

Varying the water to cement ratio for all six blends would have resulted in many experimental combinations. Hence, initial screening tests were performed to curtail the number of combinations.

\subsubsection{Dry Rodded Unit Weight}

The ratio of the weight of the sample of oven-dry aggregate blend to the volume of the container gives the dry rodded unit weight of the aggregate blend. This test was used to compute the Maximum Specific Gravity of the loose blend.

Each blend was prepared by mixing aggregates based on their proportion by weight to get $5000 \mathrm{~g}$ of sample. As per ASTM C29 - Standard Test Method for Bulk Density and Voids in Aggregate, the following procedure was used to calculate DRUW:

1) Weigh the empty bucket and record it as $W_{\text {bucket. }}$

2) Fill the bucket with the blend in three layers and rod each layer 25 times.

3) Level the surface with the tamping rod.

4) Weigh the bucket with aggregate and record it as $W_{\text {bucket+blend. }}$ 
5) Find the inside volume of the bucket and then calculate the DRUW $\left(\mathrm{kg} / \mathrm{m}^{3}\right)$ using the given formula. This is recorded in Table 3 for all six blends.

$$
\text { DRUW } \equiv \rho_{\text {blend }}=\frac{\mathrm{W}_{\text {bucket }+ \text { blend }}-\mathrm{W}_{\text {bucket }}}{\mathrm{V}_{\text {bucket }}}
$$

Table 3 - Dry Rodded Unit Weights of Six Blends

\begin{tabular}{|c|c|c|c|c|c|}
\hline Blend 1 & Blend 2 & Blend 3 & Blend 4 & Blend 5 & Blend 6 \\
\hline $\mathrm{kg} / \mathrm{m} 3$ & $\mathrm{~kg} / \mathrm{m3}$ & $\mathrm{kg} / \mathrm{m} 3$ & $\mathrm{~kg} / \mathrm{m3}$ & $\mathrm{kg} / \mathrm{m} 3$ & $\mathrm{~kg} / \mathrm{m} 3$ \\
\hline 1511 & 1496.66 & 1464.66 & 1523.66 & 1531.66 & 1509.66 \\
\hline
\end{tabular}

\subsubsection{Specific Gravity Test}

A pycnometer was used to determine the specific gravity of each blend, Figure 13. As per ASTM C128 - Standard Test Method for Relative Density (Specific Gravity) and Absorption of Fine Aggregate, the following procedure was used to calculate the specific gravity of blends:

1) The weight of each blend was measured and recorded under (A) in Table 4.

2) The mass of the pycnometer filled with water was designated as (B) in Table 4.

3) Half of the water in the pycnometer was taken out and the sample (blend) is placed inside Entrapped air was removed by subjecting the contents to a partial vacuum $30 \mathrm{~mm} \mathrm{Hg}$ and the mechanical shaker for 15 minutes.

4) Later, the pressure was gradually removed using the bleed valve. Immediately after removing the entrapped air, the pycnometer is again filled with water and weighed. This weight was recorded under (C) in Table 4.

5) Maximum Specific Gravity was calculated using given equation and recorded in Table 4.

$$
\mathrm{G}_{\mathrm{mm}}=\frac{\mathrm{A}}{\mathrm{A}+\mathrm{B}-\mathrm{C}}
$$




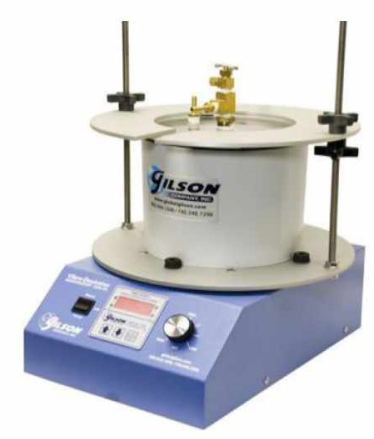

Figure 13 - Pycnometer (Ref: http://www.globalgilson.com/)

Table 4 - Specific Gravity of Six Blends

\begin{tabular}{|c|c|c|c|c|c|}
\hline Sample & $\begin{array}{c}\mathbf{A}=\mathbf{M}_{\text {dry }} \\
(\mathbf{g})\end{array}$ & $\begin{array}{c}\mathbf{B}=\mathbf{M}_{\text {pyc+water }} \\
(\mathbf{g})\end{array}$ & $\begin{array}{c}\mathbf{C}=\mathbf{M}_{\text {pyc+water+sample }} \\
(\mathbf{g})\end{array}$ & $\begin{array}{c}\mathbf{V}_{\mathbf{m m}}=\mathbf{A}+\mathbf{B}-\mathbf{C} \\
(\mathbf{g})\end{array}$ & $\mathbf{G}_{\mathbf{m m}}$ \\
\hline Blend 1 & 500 & 6409 & 6762 & 147 & 3.4014 \\
\hline Blend 2 & 500 & 6409 & 6700 & 209 & 2.3923 \\
\hline Blend 3 & 500 & 6409 & 6642 & 267 & 1.8727 \\
\hline Blend 4 & 500 & 6409 & 6775 & 134 & 3.7313 \\
\hline Blend 5 & 500 & 6409 & 6802 & 107 & 4.6729 \\
\hline Blend 6 & 500 & 6409 & 6730 & 179 & 2.7933 \\
\hline
\end{tabular}

\subsubsection{Constant Head Test}

The purpose of this test is to determine the permeability (hydraulic conductivity, rate/area) of a blend. The constant head permeability test involves flowing water through a column of sample under a constant pressure difference, Figure 14. The test was conducted according to ASTM D2434 - Standard Test Method for Permeability of Granular Soils. The procedure is as follows:

1) Remove the cap and upper chamber of the cylindrical cell (permeameter) and measure the inside diameter to calculate the cross sectional area. Also, measure the sample length of the permeameter.

2) Place one of the porous disks at the base of the chamber, then place a filter paper on top of the porous disk.

3) Mix the blend with water and pour it into the chamber using a circular motion to fill it uniformly to a depth of $1.5 \mathrm{~cm}$. 
4) Use a tamping device to compact the layer of soil and repeat the tamping procedure until the soil is within $2 \mathrm{~cm}$ of the top of the lower chamber section.

5) Place the rubber gasket between the chamber sections and continue filling with blend until the level of the soil is about $2 \mathrm{~cm}$ below the rim of the upper chamber. Place a filter paper on top followed by the porous disk.

6) Place the compression spring on the porous disk. Close the cap tightly using the nuts provided.

7) Fill the permeameter to a few $\mathrm{cm}$ above the top of the soil.

8) Connect the flexible tube from the tail of the funnel to the bottom outlet of the permeameter and keep the valves on the top of the permeameter open.

9) Place tubing from the top outlet to the sink to collect any water that may come out.

10) Open the bottom valve and allow the water to flow into the permeameter.

11) As soon as the water begins to flow out of the top control valve, close the control valve, letting water flow out of the outlet for some time.

12) Close the bottom outlet valve and disconnect the tubing at the bottom.

13) Connect the funnel tubing to the top side port.

14) Open the bottom outlet valve and raise the funnel to a convenient height to get a reasonably steady flow of water.

15) Let the flow stabilize and measure the time it takes to fill a definite volume and measure the temperature of the water. Record time as $\mathrm{t}$, volume as $\mathrm{q}$, and temperature as $\mathrm{T}$.

16) Measure the vertical distance between the funnel head level $\left(\mathrm{H}_{1}\right)$ and the chamber outflow level $\left(\mathrm{H}_{2}\right)$ and record the distance as $\mathrm{h}(\mathrm{H} 2-\mathrm{H} 1)$, Table 5.

17) Calculate the permeability using the following equation:

$$
K=\frac{q l}{A \prime t h}
$$




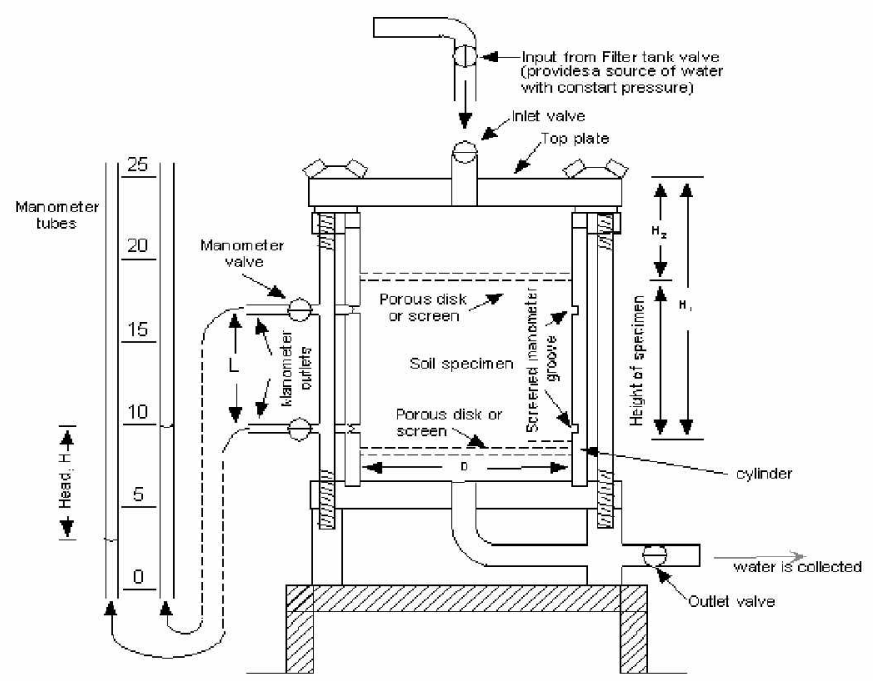

Figure 14 - Constant Head Permeameter Schematic (http://www. uwstout.edu/)

Table 5 - Hydraulic Conductivity of Blend

\begin{tabular}{|c|c|c|c|c|c|c|c|c|c|}
\hline & $\begin{array}{c}\mathbf{H}_{1} \\
(\mathbf{c m})\end{array}$ & $\begin{array}{c}\mathbf{H}_{2} \\
(\mathbf{c m})\end{array}$ & $\begin{array}{c}\mathbf{L} \\
(\mathbf{c m})\end{array}$ & $\begin{array}{c}\mathbf{h} \\
(\mathbf{c m})\end{array}$ & $\begin{array}{c}\mathbf{q} \\
\left(\mathbf{c m}^{3}\right)\end{array}$ & $\begin{array}{c}\mathbf{t} \\
(\mathbf{s})\end{array}$ & $\begin{array}{c}\mathbf{q} / \mathbf{t A} \\
(\mathbf{c m} / \mathbf{s})\end{array}$ & $\mathbf{h} / \mathbf{L}$ & $\begin{array}{c}\mathbf{k} \\
(\mathbf{c m} / \mathbf{s})\end{array}$ \\
\hline Blend - 1 & 36 & 52 & 7.62 & 16 & 700 & 59.04 & 0.260 & 2.100 & 0.124 \\
\hline Blend - 2 & 40 & 53 & 7.62 & 13 & 1000 & 60.04 & 0.365 & 1.706 & 0.214 \\
\hline Blend - 3 & 66 & 81 & 7.62 & 15 & 1000 & 60.07 & 0.365 & 1.969 & 0.185 \\
\hline Blend - 4 & 41 & 58 & 7.62 & 17 & 710 & 62.24 & 0.250 & 2.231 & 0.112 \\
\hline Blend - 5 & 68 & 77 & 7.62 & 9 & 780 & 58.04 & 0.295 & 1.181 & 0.250 \\
\hline Blend - 6 & 65 & 79 & 7.62 & 14 & 830 & 59.02 & 0.308 & 1.837 & 0.168 \\
\hline
\end{tabular}

\subsection{Initial Screening Test Results}

Figure 15 summarizes the results for the screening tests. It was observed that there was not much difference in the densities of Blend $-1,4,5$ and 6.

1) Blend -2 and 3 had low densities with Blend 3 being the lowest, whereas, both had high hydraulic conductivity with Blend -2 being the highest.

2) Blend -6 had intermediate values of hydraulic conductivity and density.

3) Blend -4 had density between Blend - 5 and Blend -1 .

Hence, Blend - 5, 3 and 1 were discarded and Blend -2, 4 and 6 were considered for further studies. 


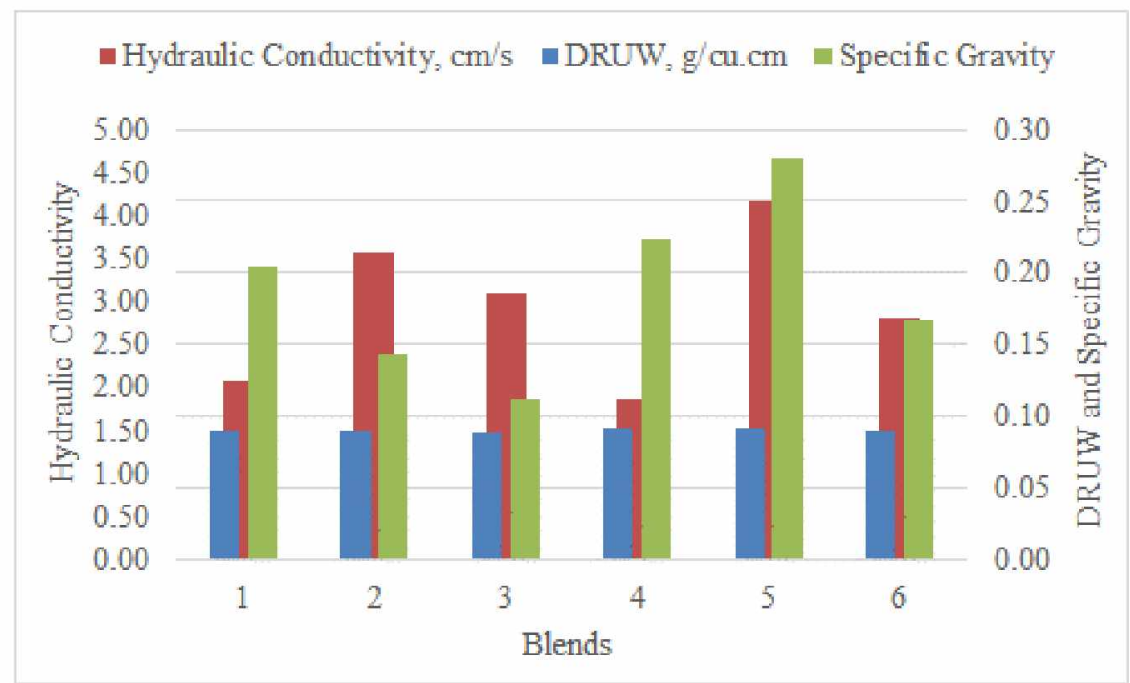

Figure 15 - Comparison for Initial Screening Test Results

\subsection{Effect of Water}

Water is used to hydrate the binding material (cement or clays). The strength of the core depends on porosity and water to cement ratio (W/C). A high $\mathrm{W} / \mathrm{C}$ ratio means the mixture has a high porosity because it is difficult to develop bonds within a sparse particle setting. This leads to weak bonds (low strength mixture). One gram of cement requires 0.22 grams of water in order to fully hydrate. However, the volume of the products of hydration is greater than the volume of cement and water used in the reaction. Producing $1 \mathrm{ml}$ of hydrated cement requires $1.2 \mathrm{ml}$ of water. This equates to a W/C ratio of 0.42 for complete hydration (Aitcin and Neville, 2003).

\subsection{Mixing Aggregate, Cement, and Water}

According to ASTM C109 - Test Method for Compressive Strength of Hydraulic Cement Mortars, mortar consists of 1 part cement and 2.75 parts of sand proportioned by mass. Thus, for the Base case, an aggregate to cement ratio $(\mathrm{A} / \mathrm{C})$ of 2.75 and water to cement ratio (W/C) of 0.42 was used to make a batch of aggregate, cement, and water. Portland cement was used as binding material. As per ASTM C109, the following procedure was used to make the molds for testing compressive strength:

1) The materials for a batch were introduced into a dry bowl with a dry paddle, Figure 16.

2) All the mixing water was placed in a dry bowl, cement was added to the water, and the mixer was started at the slow speed for $30 \mathrm{~s}$. 
3) The aggregate (sand) was slowly and gradually added over a $30 \mathrm{~s}$ period while mixing at slow speed and later for $60 \mathrm{~s}$ while mixing at medium speed.

4) The mixer was stopped for $15 \mathrm{~s}$ to scrape down the batch collected on the sides of the bowl.

5) The fresh batch was poured into 2.5 " cubical molds to test for compressive strength, Figure 17.

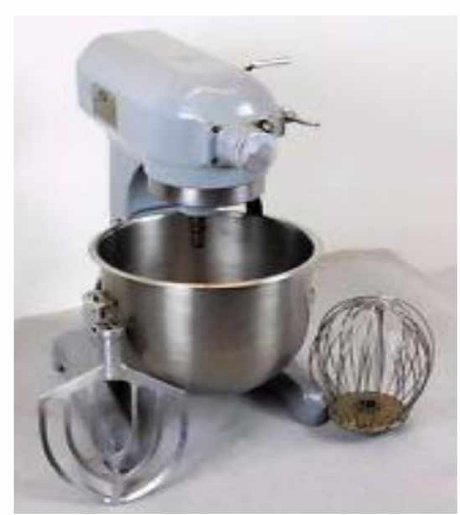

Figure 16 - Mixing Bowl and Paddle

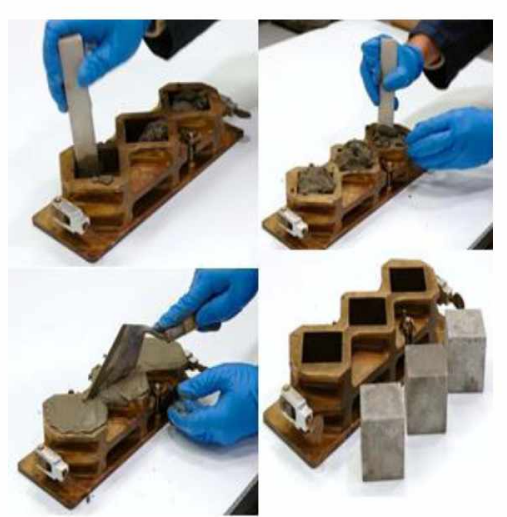

Figure 17 - Molding Test Specimen

Twelve samples for each blend (\#2,\#4,\#6), 36 samples total, were made to be tested for compressive strength.

\subsection{Selecting Blend}

The specimen was taken out of the mold and soaked in water. This process is called curing. It ensures that the crystals within the specimen matrix grow due to the reaction of cement and water, giving strength to the specimen. According to ASTM C109 - Test Method for Compressive Strength of Hydraulic Cement Mortars, the following procedure was used to test the specimen:

1) The specimen were taken out from the water; all its faces were wiped and cleaned.

2) Each cube was placed on the compressive strength testing machine, Figure 18, such that the load to be applied was to the opposite side of the cube as the cast (that is, not the top and bottom).

3) Load was applied to specimen until it broke, Figure 19.

4) From the chart recorded during the testing, the maximum load applied by the testing machine was noted and compressive strength was calculated using equation (5). 


$$
C_{s}=\frac{P}{A^{\prime \prime}}
$$

Table 6 shows the compressive strength of three blends for 7, 14, and 28 days.

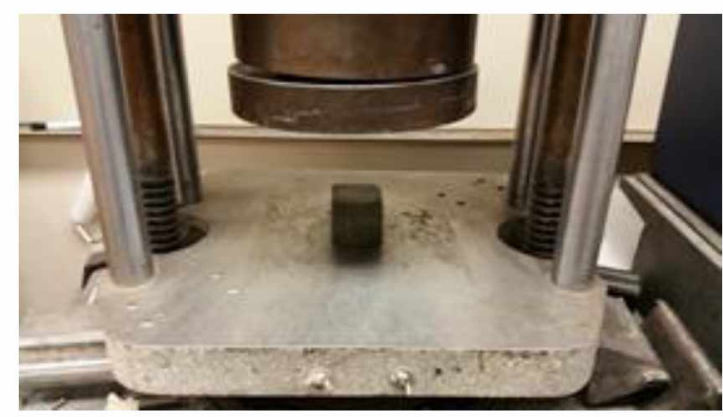

Figure 18 - Compressive Strength Testing Machine

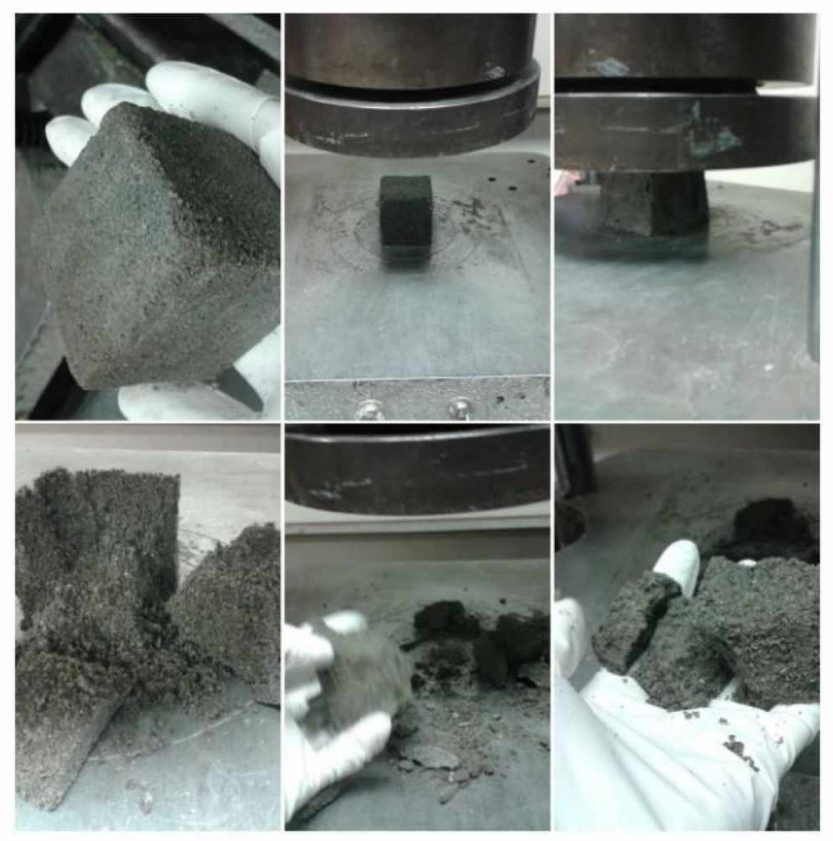

Figure 19 - Destructive Compressive Strength Testing

Table 6 - Compressive Strength of Three Blends for W/C $=0.42$

\begin{tabular}{|c|c|c|c|}
\hline \multirow{2}{*}{ Sample } & \multicolumn{3}{|c|}{ Compressive Strength (psi) } \\
\cline { 2 - 4 } & $\mathbf{7}$ days & $\mathbf{1 4}$ days & $\mathbf{2 8}$ days \\
\hline Blend 2 & 1945 & 2155 & 2304 \\
\hline Blend 4 & 1706 & 2128 & 2245 \\
\hline Blend 6 & 1689 & 2024 & 2217 \\
\hline
\end{tabular}

It was observed that Blend 6 had the least compressive strength. As the desired compressive strength $(500-600$ psi) was less than the compressive strength of Blend 6 , the $\%$ weight of mesh 
size \#16 and \#30 was increased, whereas the $\%$ weight of \#50 and \#80 was decreased, Table 7 , to get Modified Blend 6.

Table 7 - Modified Blend 6

\begin{tabular}{|c|c|}
\hline Sieve Size & \% Weight \\
\hline$\# 16$ & 20 \\
\hline$\# 30$ & 20 \\
\hline$\# 50$ & 30 \\
\hline$\# 80$ & 30 \\
\hline
\end{tabular}

\subsection{Varying Water to Cement Ratio}

The compressive strength of unconsolidated sandstone reservoirs ranges from 500 to 1700 psia (Dusseault, 2002). Therefore, to reduce the compressive strength of the specimen, the $\mathrm{W} / \mathrm{C}$ ratio was increased and proportionally the $\mathrm{A} / \mathrm{C}$ ratio was decreased. The coarser aggregates proportion was increased in order to decrease the compressive strength. The Modified Blend 6 was then used to make batches for varying $\mathrm{W} / \mathrm{C}$ ratio, Table 8 .

Table 8 - Varying W/C for Modified Blend 6

\begin{tabular}{|c|c|c|c|c|c|c|c|}
\hline & \multirow{2}{*}{$\mathbf{A} / \mathbf{C}$} & \multirow{2}{*}{$\mathbf{W} / \mathbf{C}$} & \multirow{2}{*}{$\begin{array}{c}\text { Cement } \\
(\mathbf{g})\end{array}$} & \multirow{2}{*}{$\begin{array}{c}\text { Water } \\
(\mathbf{m l})\end{array}$} & \multicolumn{4}{|c|}{$\begin{array}{c}\text { Modified Blend 6 } \\
(\mathbf{g})\end{array}$} \\
\cline { 5 - 8 } & & & $\begin{array}{c}\# \mathbf{1 6} \\
\mathbf{( 2 0 \% )}\end{array}$ & $\begin{array}{c}\# \mathbf{3 0} \\
\mathbf{( 2 0 \% )}\end{array}$ & $\begin{array}{c}\# \mathbf{5 0} \\
(\mathbf{3 0 \%})\end{array}$ & $\begin{array}{c}\# \mathbf{8 0} \\
(\mathbf{3 0 \%})\end{array}$ \\
\hline 2.75 & 0.48 & 842.55 & 407.80 & 463.40 & 463.40 & 695.11 & 695.11 \\
\hline 4.55 & 0.80 & 556.62 & 445.30 & 506.02 & 506.02 & 759.03 & 759.03 \\
\hline 6.82 & 1.20 & 389.36 & 467.23 & 530.95 & 530.95 & 796.42 & 796.42 \\
\hline 9.09 & 1.60 & 299.40 & 479.03 & 544.36 & 544.36 & 816.54 & 816.54 \\
\hline
\end{tabular}

A 2" cubical mold was used to test for compressive strength and a 1.5" x 2" cylindrical mold was used to test for porosity and air permeability. Porosity was measured using a Helium Porosimeter, which works on the principle of Boyle's law, Figure 20. Permeability was measured using an air permeameter (Figure 21) where air is pulled out from the sample using rubber nozzle. A microcontroller unit monitors the syringe volume and the transient vacuum pulse created at the sample surface and computes a response function. Using the response function, the matrix permeability can be determined from the calibration charts and tables provided with the air permeameter. 

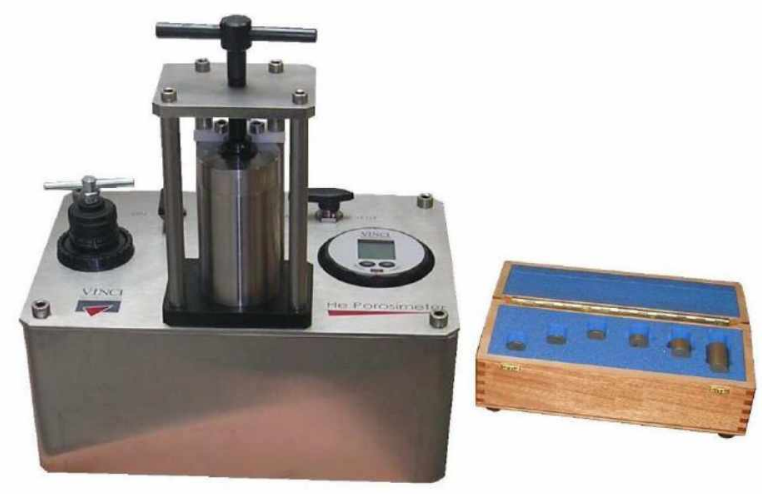

Figure 20 - Helium Porosimeter

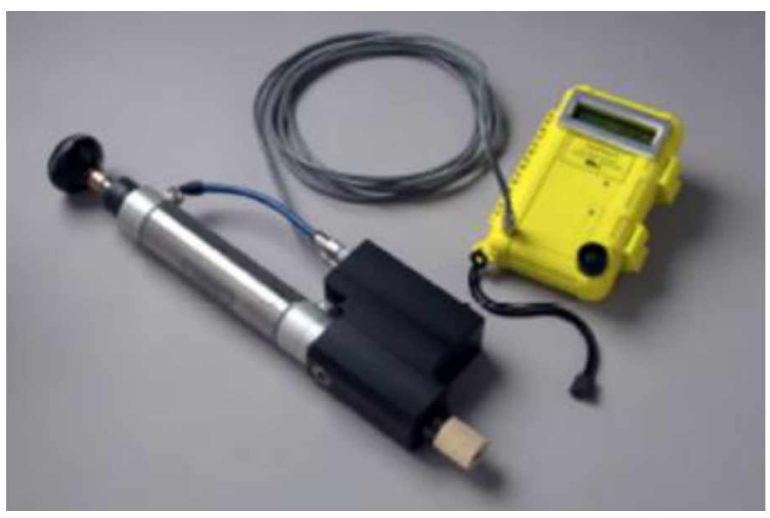

Figure 21 - TinyPerm II Portable Air

Permeameter

\subsection{Results and Discussion}

Figure 22 summarizes the results for compressive strength, porosity, and permeability for varying water to cement ratios. It was observed that increasing water to cement ratio increases the porosity and permeability of the specimen, whereas decreases the compressive strength. This was because with increase in water content, the bond between aggregate to cement becomes weaker.

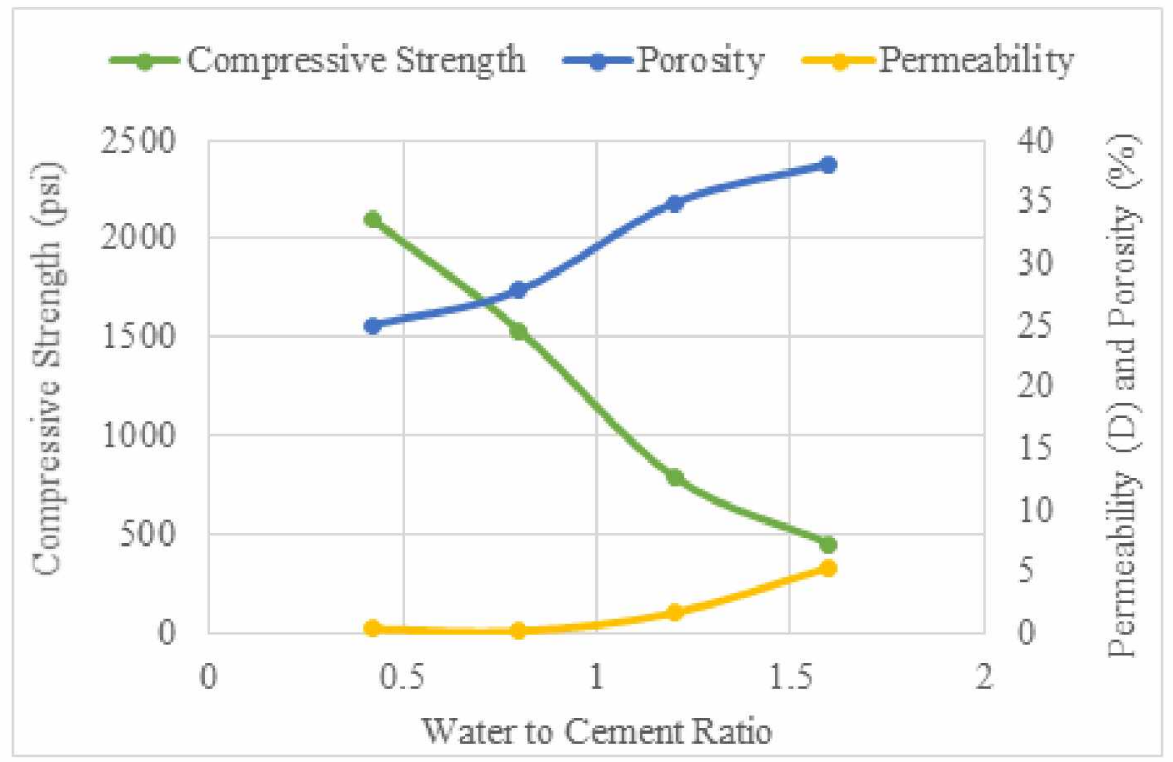

Figure 22 -Specimen Properties as a Function of Water to Cement Ratio

To represent the reservoir rock more accurately, cement was replaced with non-swelling clay, kaolinite, for all the samples. Figure $\mathbf{2 3}$ summarizes the results for all the tests performed with varying water to clay ratios. It was observed the compressive strength of specimen made with clay 
was less than the compressive strength of specimens with cement, because clay needed less water to hydrate when compared to cement.

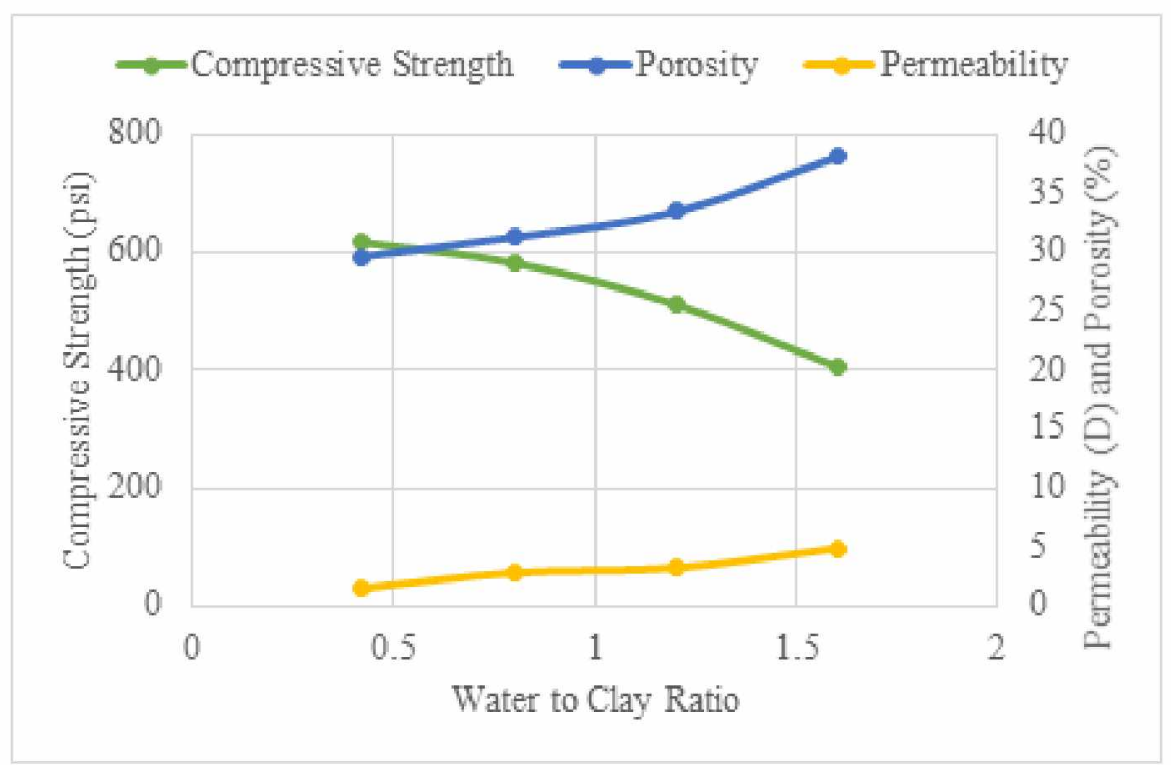

Figure 23 - Specimen Properties as a Function of Water to Clay Ratio

Therefore, Modified Blend 6, with a water to clay ratio of 1.20 and aggregate to clay ratio of 6.82 , was chosen to make synthetic cores for the CHOPS experiment. Figure 24 shows a 2" x 4 " core setting in mold and Figure 25 shows the synthetic cores used for further studies.

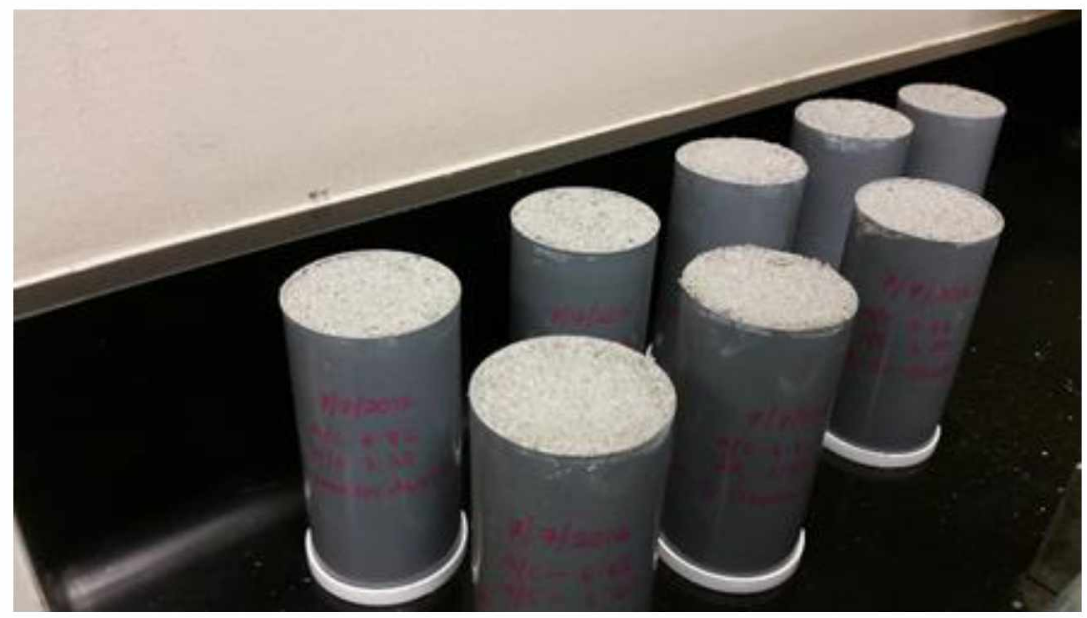

Figure 24 - Cores Setting in 2" x 4" Molds 


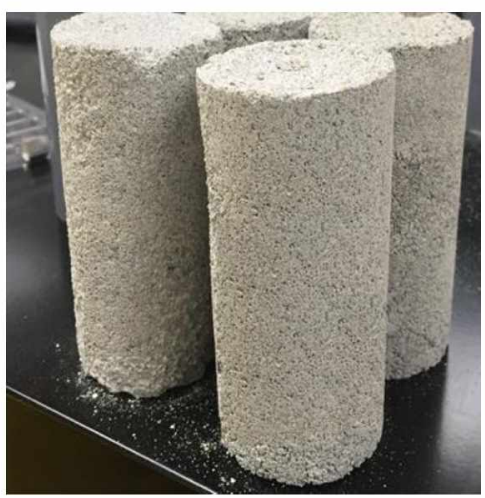

Figure 25 - 2" x 4" Cores Prepared From Modified Blend 6

Figure 26 summarizes the methodology of developing a synthetic core for the CHOPS experiment.

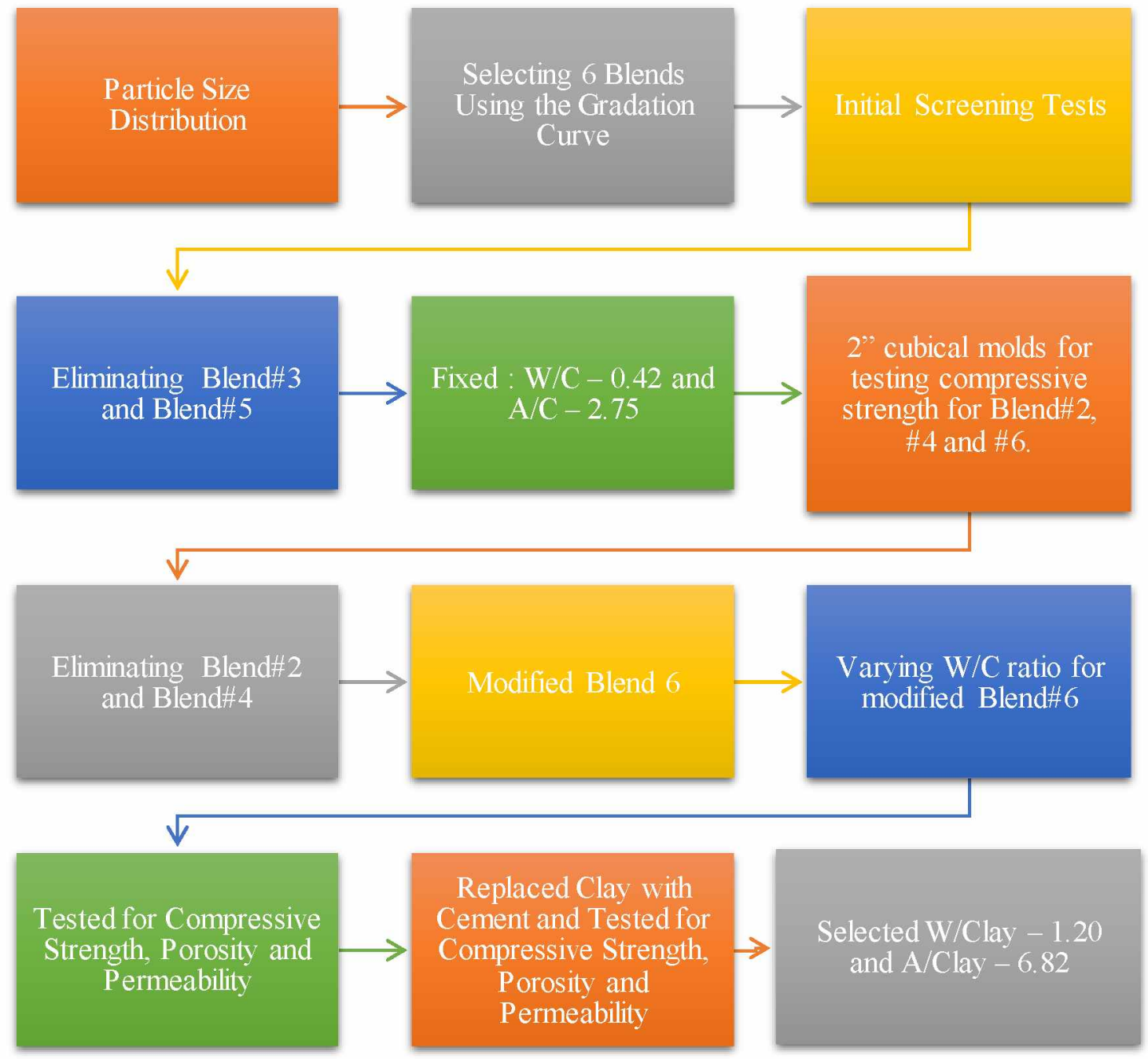

Figure 26 - Flowchart for Core Development Methodology 


\section{Chapter 4. CHOPS Experimental Setup - System Components and Assembly}

\subsection{Introduction}

This chapter describes the components required for setting up a CHOPS experiment. The setup was designed for a pressure rating of 5000 psia. The set up consisted of a core holder, injection pump, overburden pump, accumulator, refill tank, pressure gauges, pressure transducer, and a data acquisition system. These components were either mounted or placed on a frame and were connected using tubing and fittings.

\subsection{Experimental Schematic}

Figure 27 shows the schematic of the experimental setup at the University of Alaska Fairbanks. The apparatus consists of an injection pump, floating piston accumulators, core holder, overburden pump, refill tank, pressure gauges, pressure transducer, and the data acquisition system. The injection pump displaces fluid at a different range of flow rates and the pump also suitable to inject fluid either at constant flow rate or constant pressure. The data acquisition system monitors and logs pressure data generated during the experiment. The flow system serves as a network for the different fluids to be used in the experiment, like oil and brine, and the overburden pressure pump provided the required confining pressure to the core inside the core holder. Table 9 gives the valve numbering and Table $\mathbf{1 0}$ lists the major components and vendors.

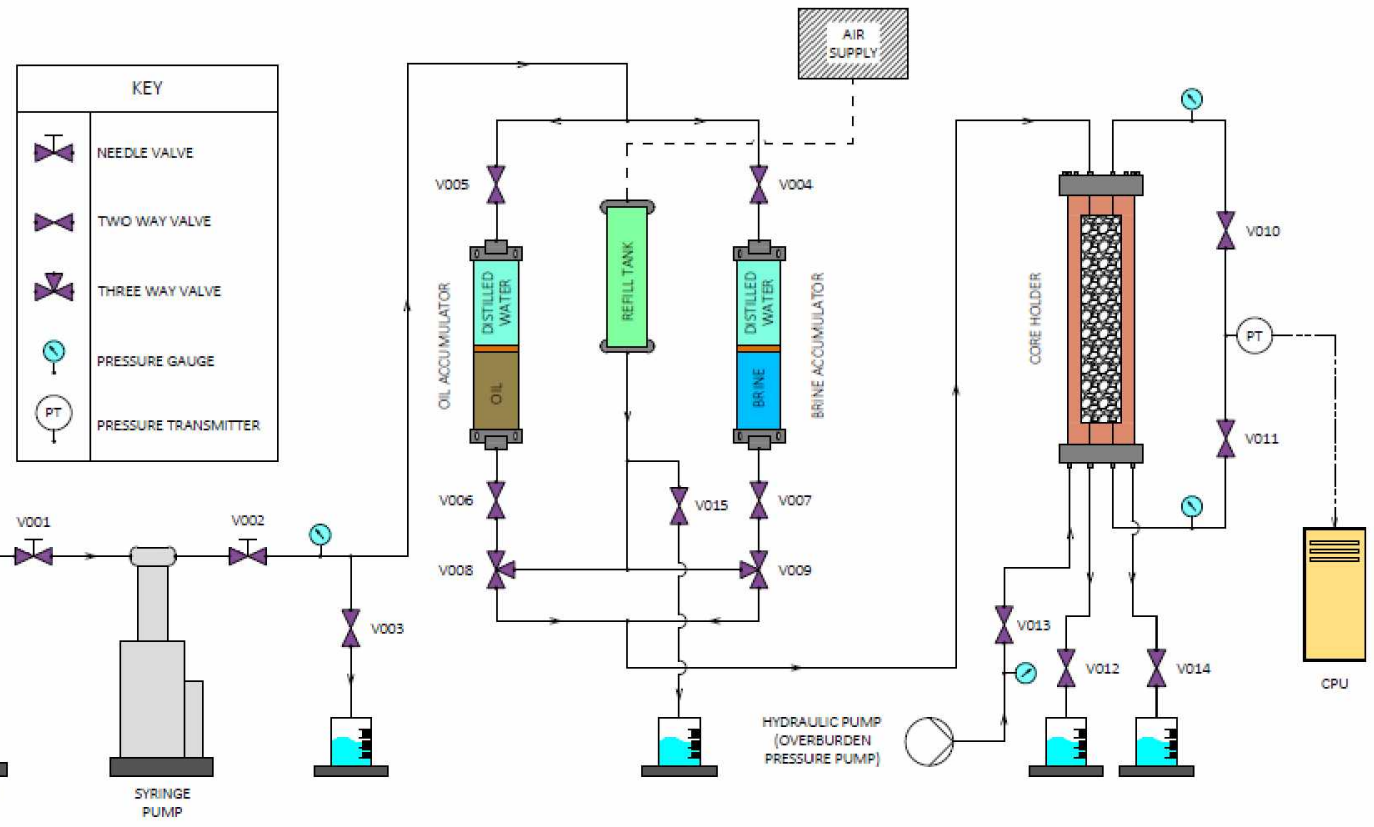

Figure 27 - Schematic of Experimental Setup 
Table 9 - Valve Numbering

\begin{tabular}{|c|c|}
\hline Valve Number & Description \\
\hline V001 & Syringe Pump Inlet Valve \\
\hline V002 & Syringe Pump Outlet Valve \\
\hline V003 & Floating Piston Accumulator (Brine) Inlet Valve \\
\hline V004 & Floating Piston Accumulator (Oil) Inlet Valve \\
\hline V005 & Floating Piston Accumulator (Oil) Outlet Valve \\
\hline V006 & Floating Piston Accumulator (Water) Outlet Valve \\
\hline V007 & Three way valve Floating Piston Accumulator (Oil) Outlet \\
\hline V008 & Three way valve Floating Piston Accumulator (Water) Outlet \\
\hline V009 & Pressure Transmitter (High) Inlet Valve \\
\hline V010 & Pressure Transmitter (Low) Inlet Valve \\
\hline V011 & Overburden Pressure Oil Inlet Valve \\
\hline V013 & Overburden Pressure Oil Outlet Valve \\
\hline V014 & Core Holder Outlet Flow Valve \\
\hline V012 & Refill Tank Outlet Valve \\
\hline V015 & Camp Outlet) \\
\hline
\end{tabular}

Table 10 - Major Components

\begin{tabular}{|c|c|}
\hline Major Items & Vendor \\
\hline Syringe Pump & Teledyne Instrument Inc \\
\hline Floating Piston Accumulator & Vindum Engineering Inc \\
\hline Pressure Gauge & Alaska Instrument Company Inc \\
\hline Pressure Transmitter & Engineered Equipment Inc \\
\hline Core Holder & Core Laboratories \\
\hline Data Acquisition & National Instruments \\
\hline Frame & Jonsmachine \\
\hline Valves and Fitting & Teledyne Instrument Inc \\
\hline Lab View Tool Kit for Pump & Jatco Inc \\
\hline Molds for Core & Alaska Industrial Hardware \\
\hline Enerpac Pump & Jonsmachine \\
\hline Pin and Swivel Join &
\end{tabular}




\subsection{System Components}

\subsubsection{Injection Pump}

This pump is a syringe precision type, which makes it the ideal equipment for a wide range of chemical feed applications requiring flow rates up to $204 \mathrm{ml} / \mathrm{min}$ at pressures up to 5000 psig, Figure 28. Its cylinder capacity is $500 \mathrm{ml}$. Table 11 gives the technical specifications of the pump. The pump controller rests on top of the pump base, which regulates all pumping functions. Controller input is made through the keypad on the front panel, shown in Figure 29.

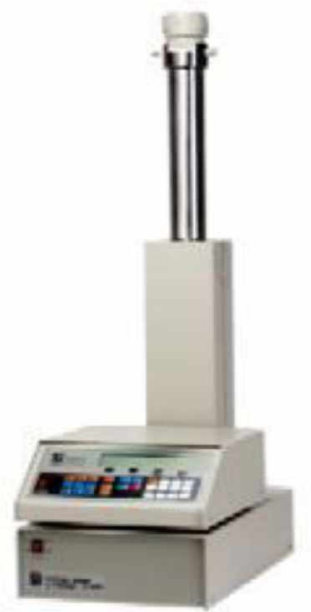

Figure 28 - Teledyne ISCO Pump

Table 11 - Technical Specification of Teledyne ISCO Pump

\begin{tabular}{|c|c|}
\hline Capacity & $507 \mathrm{ml}$ \\
\hline Flow Range (ml/min) & $0.001-204$ \\
\hline Flow Accuracy & $0.5 \%$ of set point \\
\hline Pressure Range (psi) & $10-5,000$ \\
\hline Wetted Materials (standard) & Nitronic 50, PTFE, Hastelloy C-276 \\
\hline Plumbing Ports & $1 / 8^{\prime \prime}$ NPT \\
\hline Operating Temperature & $5-40^{\circ} \mathrm{C} \mathrm{Ambient}$ \\
\hline Power required & $100 \mathrm{Vac}, 117 \mathrm{Vac}, 234 \mathrm{Vac}, 50 / 60 \mathrm{~Hz}(\mathrm{specify})$ \\
\hline Dimensions (HxWxD, cm) & $103 \times 27 \times 45$ \\
\hline Weight & Pump module - 33 kg; controller $-3 \mathrm{~kg}$ \\
\hline
\end{tabular}




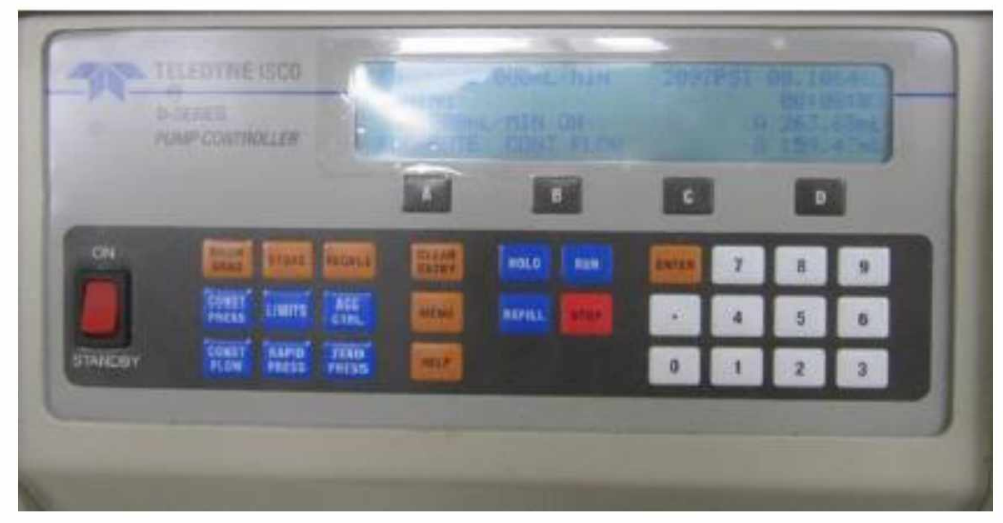

Figure 29 - Pump Controller Front Panel

\subsubsection{Pump Refill Procedure}

1) Turn on the red switch on controller.

2) Close the outlet valve of pump - V002.

3) Open the inlet valve of pump - V001, connected to distilled water.

4) Press "REFILL" on controller to flow liquid into the pump.

5) When the cylinder is full, the controller will flash "FULL CYLINDER." Press "STOP."

6) Close V001.

\subsubsection{Pump Injection Procedure}

1) Turn on the red switch on controller.

2) Make sure the cylinder is full. If not, refill the cylinder as described in the section above.

3) Make sure V001 is closed and open V002.

4) Press MENU to display Menu 1.

5) Press 1 for UNITS.

6) In the Units menu, press 3 to select psi for the pressure units.

7) In the Units menu, press 5 to select ML/MIN for the flow units.

8) Press PREVIOUS (D) to return to Menu 1.

9) Press RETURN (D) to exit Menu 1. 
10) Press CONST FLOW to set the pump mode to constant flow.

11) The words ENTER FLOW should flash on the display. Use the numeric key to enter the flow and press ENTER. (Note: In case of any error, press CLEAR ENTRY to delete).

12) Press RUN. Observe the flow rate displayed on the first line.

\subsubsection{Refill Tank}

A transparent PVC pipe was used as a feed to the two accumulators connected to an air supply with a rubber hose, Figure 30. The refill tank could be filled with water or oil depending on the accumulator to be refilled. Air pressure provided from the laboratory should not exceed 100 psi.

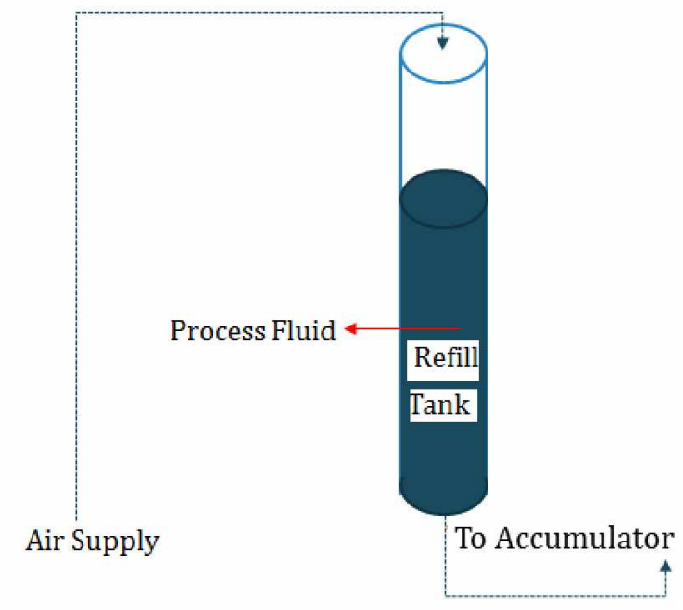

Figure 30 - Refill Tank Flow Schematic

\subsubsection{Core Holder}

The core holder used is an FCH-style, biaxial-type core holder, which means that a common radial and axial overburden pressure, and therefore stress, is applied to the core sample. The core holder uses D-glass composite as the material of construction for the body of the core holder. These materials are compatible with nuclear magnetic resonance imaging and microwave, $\mathrm{x}$-ray, and gamma ray scanning. Figure $\mathbf{3 1}$ is the schematic diagram of the core holder and Table $\mathbf{1 2}$ gives the part lists. 


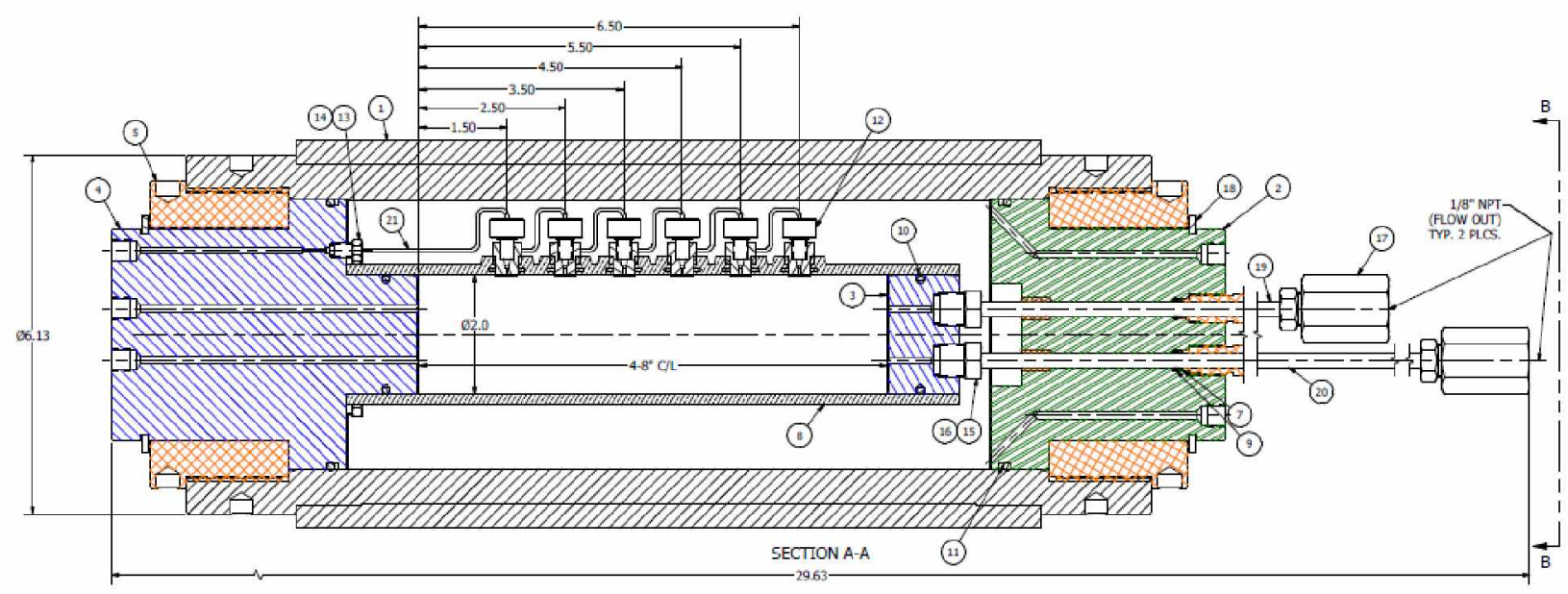

Figure 31 - Schematic of Core Holder

Table 12 - Core Holder Part List (Refer Figure 31)

\begin{tabular}{|c|c|}
\hline Part Number & Description \\
\hline 1 & BODY, FCHD-2.0 \\
\hline 2 & BUSHING, DCHH-2.0 \\
\hline 3 & FLOATING DISTRIBUTION PLUG, Ø2.0" \\
\hline 4 & DIST. PLUG, FIXED, 2.0" \\
\hline 5 & AMPEND CAP \\
\hline 6 & AMP GUIDE, MALE CONNECTOR \\
\hline 7 & BACK UP RING \\
\hline 8 & SLEEVE, $2.0,6$ TAPS \\
\hline 9 & O-RING, \#2-010 \\
\hline 10 & O-RING, \#2-224 \\
\hline 11 & O-RING, \#2-245 \\
\hline 12 & TWO-PIECE UPCHURCH \\
\hline 13 & GLAND, MALE AF1 (HIP) \\
\hline 14 & SLEEVE, MALE AF1 (HIP) \\
\hline 15 & GLAND, HF4 (HII) \\
\hline 16 & COLLAR, HF4 (HII) \\
\hline 17 & COUPLING, HF4 to $1 / 8^{\prime \prime} \mathrm{NPT}, \mathrm{HIP}$ \\
\hline 18 & SNAP RING，EXTERNAL， Ø3.62" \\
\hline 19 & NIPPLE, C\&T, 1/4" OD x .083" ID x 10.5", HIP HM4 \\
\hline 20 & NIPPLE, C\&T, 1/4" OD x .083" ID x 14.5", HIP HM4 \\
\hline 21 & 21 0" PK00063-020T PK TUBING, $1 / 16$ in OD X .020 in WALL, PEFK \\
\hline
\end{tabular}




\subsubsection{Core Holder Assembly}

The core holder consists of an outer shell, rubber sleeve, floating distribution plug, and top and bottom bushing. The outer shell is a hollow cylinder with clamps to hold the core holder, Figure 32. A core sample is inserted into the rubber sleeve. Incremental flowing pressures can be measured along the core length by pressure tapings provided on a rubber sleeve, Figure 33.

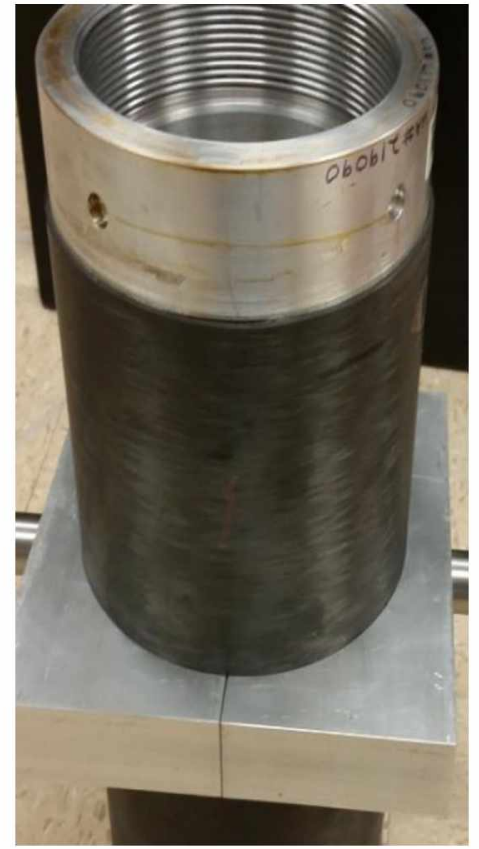

Figure 32 - Outer Shell of Core Holder

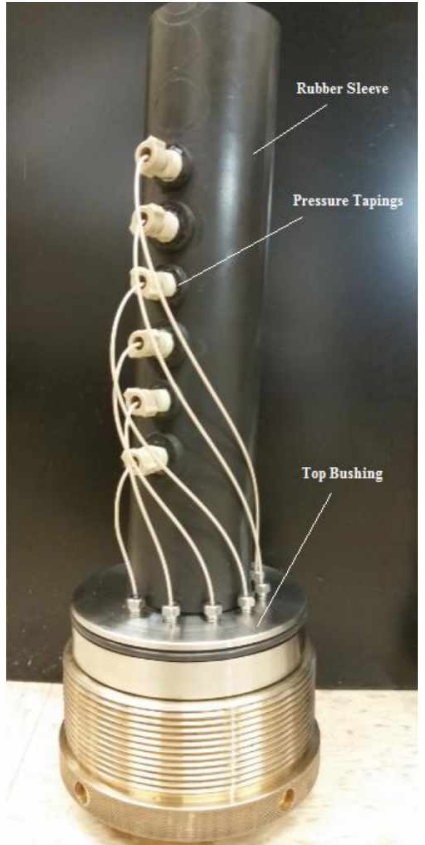

Figure 33 - Pressure Tapping from Top Bushing of Core Holder to Rubber Sleeve

The floating distribution plug is able to slide inside the rubber sleeve, Figure 34, and allows cores of length up to 8 ". This feature ensures solid contact between the distribution plug and core sample if irregular-length cores are used.

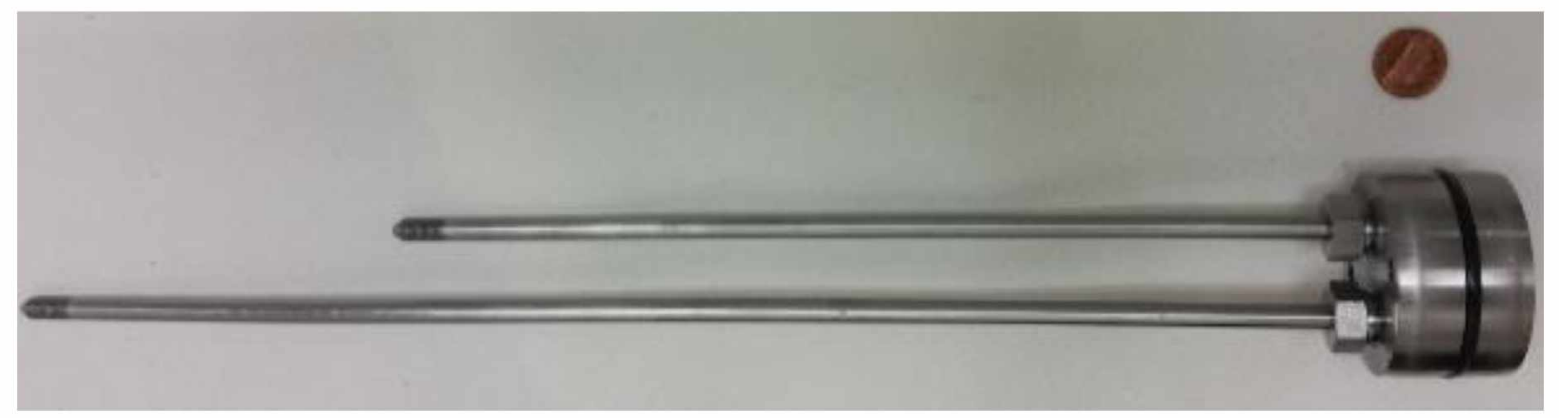

Figure 34 - Floating Distribution Plug 
Figure 35 is a schematic of the top plug. It has the $1 / 8$ " NPT outlet for six overburden pressure tapings. The $1 / 8$ " NPT dual injection ports allow two fluids to be injected simultaneously into the core sample, or one of these inlet lines can also be used to measure the injection pressure at the core injection face. The fluids do not mix in the injection line, but at the core face.

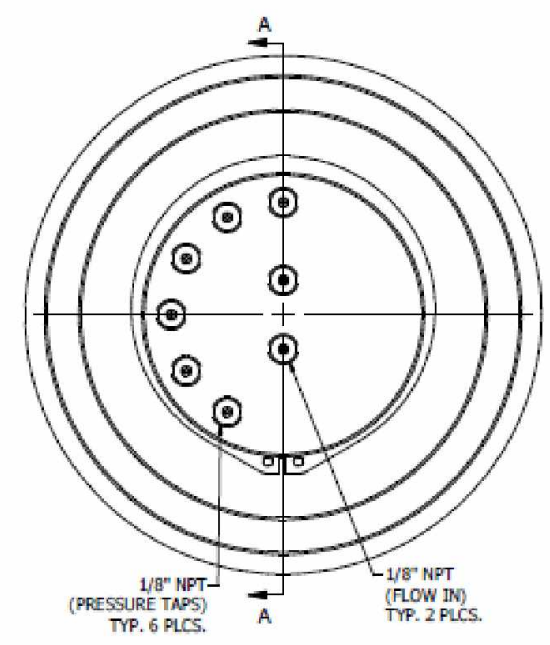

Figure 35 - Core Holder Top Bushing

Figure 36 and Figure 37 show the bottom plug bushing of the core holder. It has $1 / 8$ " NPT hydraulic oil inlets and outlets, and 1/8" NPT dual outlet ports where the distribution plug outlet slides to come out.

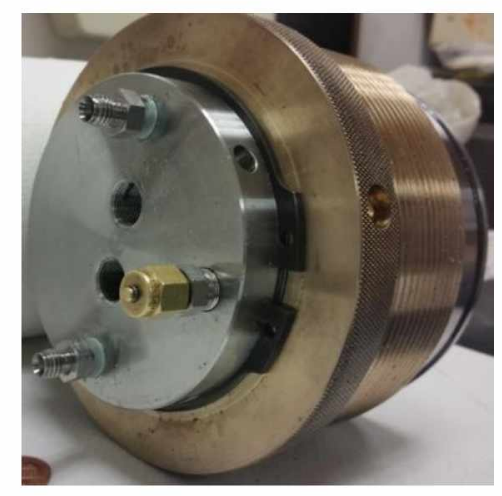

Figure 36 - Core Holder Bottom Bushing

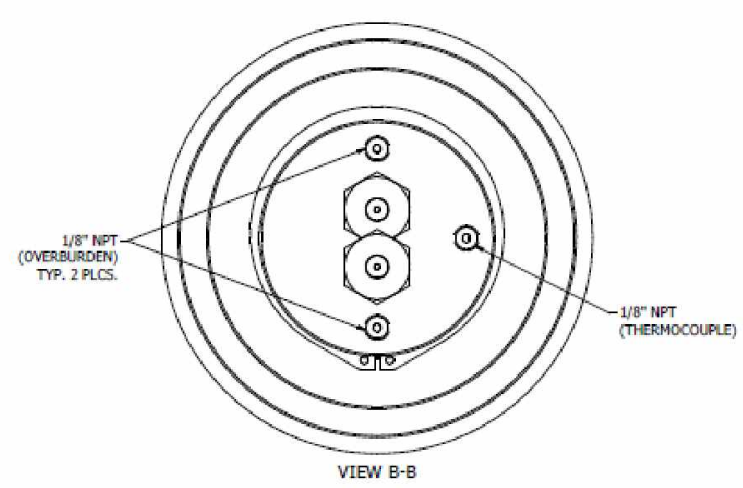

Figure 37 - Schematic of Core Holder Bottom Bushing 


\subsubsection{Core Holder Connection}

Inset the core in the rubber sleeve and push the distribution plug till the top of the sample such that the surface of plug and sample touch each other. Assemble the tubes through the bottom bushing. Parts are shown in sequence in Figure 38. Slide the O-rings onto the tubes followed by the backup rings. Slide brass gland onto the tubes and thread into the ports on bottom bushing. This will push the O-rings and backup rings into the sealing surface (inside the bushing). Note that the O-rings are rubber and have a circular cross section, while the backup rings are graphitefilled Teflon (they feel rigid) and have a rectangular cross section. Connect the high pressure coupling to convert $1 / 4$ " NPT to $1 / 8$ " NPT.

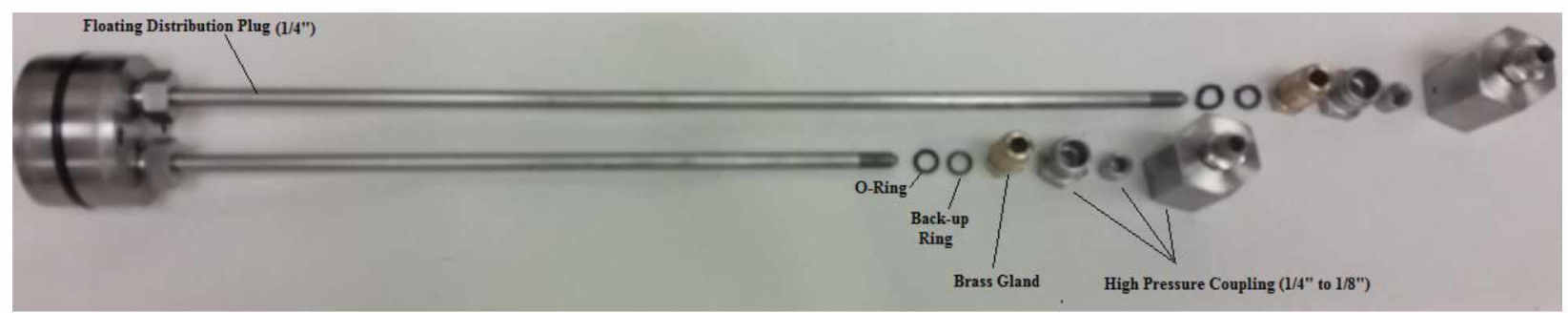

Figure 38 - Floating Distribution Plug and Outlet Assembly

\subsubsection{Floating Piston Accumulators}

The Floating Piston Accumulator (FPA) is used to inject fluids at ambient or reservoir conditions. It is held under pressure by an external source. The accumulator is a floating piston type free surface where the oil is in direct contact ahead of the piston. It consists of a cylinder with two end closures and a floating piston moving freely inside. The piston separates the cylinder into two chambers: one for the driving fluid and one for the process fluid, Figure 39. 


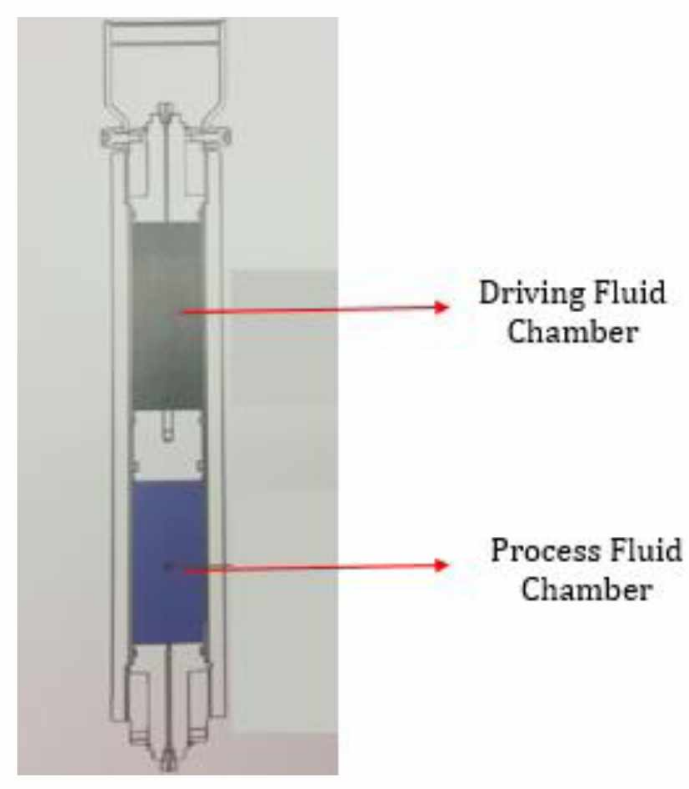

Figure 39 - Schematic of Floating Piston Accumulator

The piston is moving following the pressure gradient between the two chambers. The FPAs have a large capacity of $1000 \mathrm{ml}$ with a pressure of 10,000 psi. The accumulator is sealed with $\mathrm{O}$-rings, which are expansion-resistant with a good life expectancy. The sealing system is adapted for high pressure and temperature conditions.

\subsubsection{Overburden Pressure Pump}

This pump provides the necessary pressure to confine the core sample inside the core holder to simulate the overburden pressure. Pressure ranging from $500-10,000$ psi acts on the rubber sleeve inside the core holder, which in turn contacts the core sample.

To refill the overburden pump with hydraulic oil, open the black cap and pour hydraulic oil. After refilling, place the cap back into vent mode. Overburden pressure can be monitored by the pressure gauge at the outlet of the pump. The net confining pressure or the differential confining pressure applied to the core is the difference between the overburden pressure and injection pressure. The injection pressure should never exceed the confining pressure. Also, an excess of overburden pressure may damage the rubber sleeve.

The ENERPAC pump, Figure 40, has a $3 / 8$ " NPT connection to a $1 / 8$ " reducing union for tubing, which connects to the bottom $1 / 8$ " NPT connection of the core holder. While filling the outer shell 
of the core holder, hydraulic oil should be pumped from the bottom of the core holder to the top to avoid air being trapped inside the rubber sleeve.

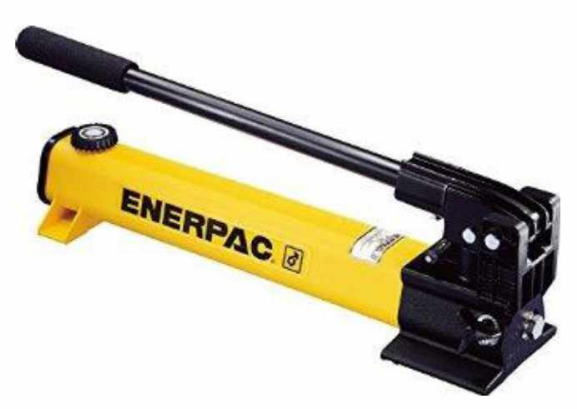

Figure 40 - Overburden Pressure Pump

\subsubsection{Tubings, Valves, and Fittings}

The flow line connects the various parts of the setup and facilitates the flow of oil and brine during the experiment. It is $1 / 8$ " in diameter with a wall thickness of 0.03 ". The tubing is of stainless steel. All the flow lines, valves, and fittings are suitable for a maximum pressure of $5000 \mathrm{psi}$.

\subsubsection{Frame}

The frame is designed such that it has three sections, Figure 41. The frame is on top of four wheels and can be moved from one location to another and locked to make it stationary. The frame is made from extrusions and an aluminum sheet. The 6" extrusions have T-slots along the length to provide attachment points for other components, which makes the frame easy to assemble and reconfigure. The base and the panel are made of $1 / 8$ " aluminum plate. The frame is $5.83 \mathrm{ft}$ high, $5.41 \mathrm{ft}$ long, and $3.08 \mathrm{ft}$ wide.

The frame has a pin and swivel system for the core holder. This mechanism allows rotation of the core holder 90 degrees from the horizontal to the vertical position. It can also be fixed using a pin. Core holders and accumulators mount on to the frame using stainless steel clamps and pins. The final laboratory set up is shown in Figure $\mathbf{4 2}$. 

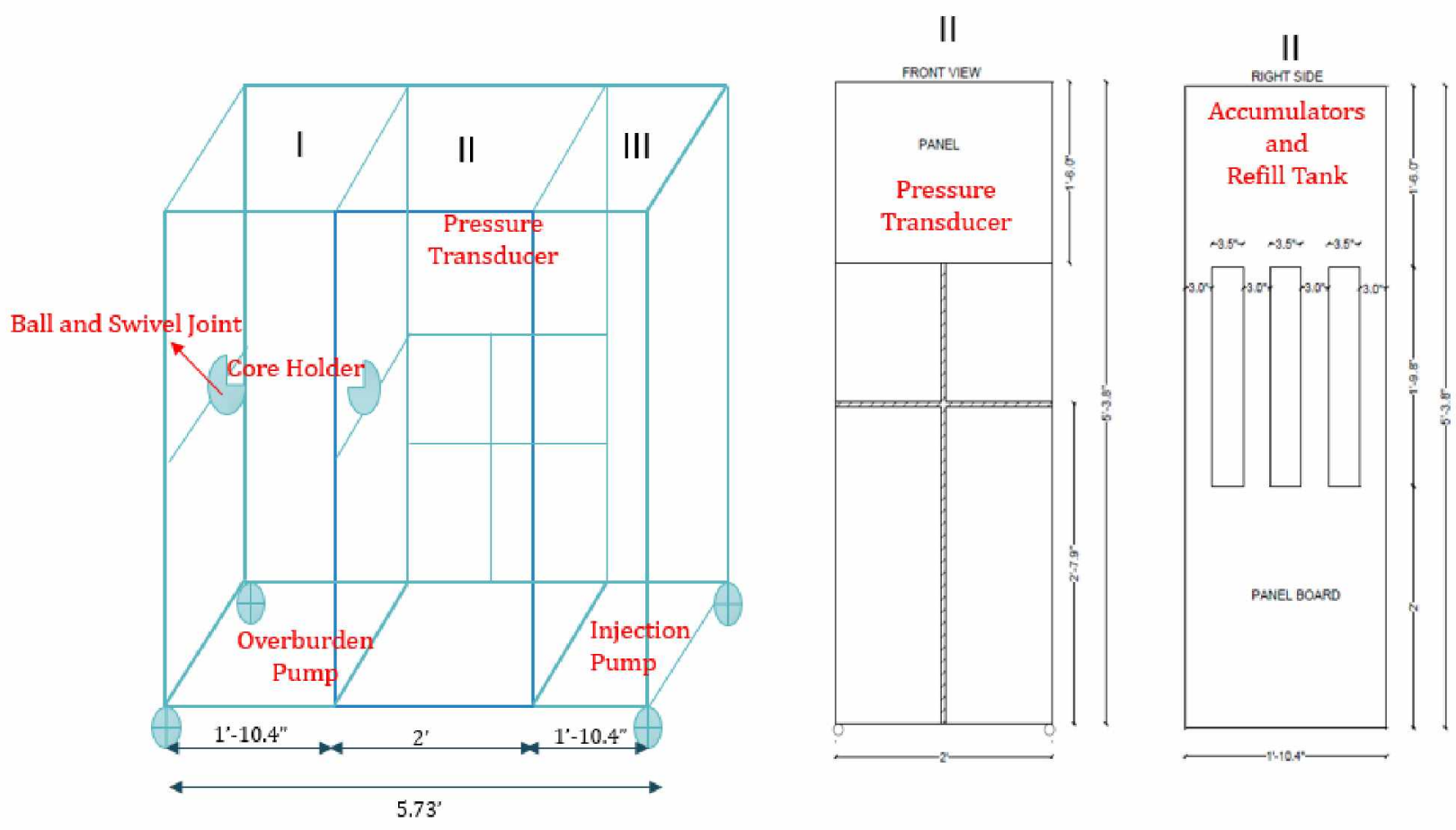

Figure 41 - Frame Designed for Laboratory Setup 


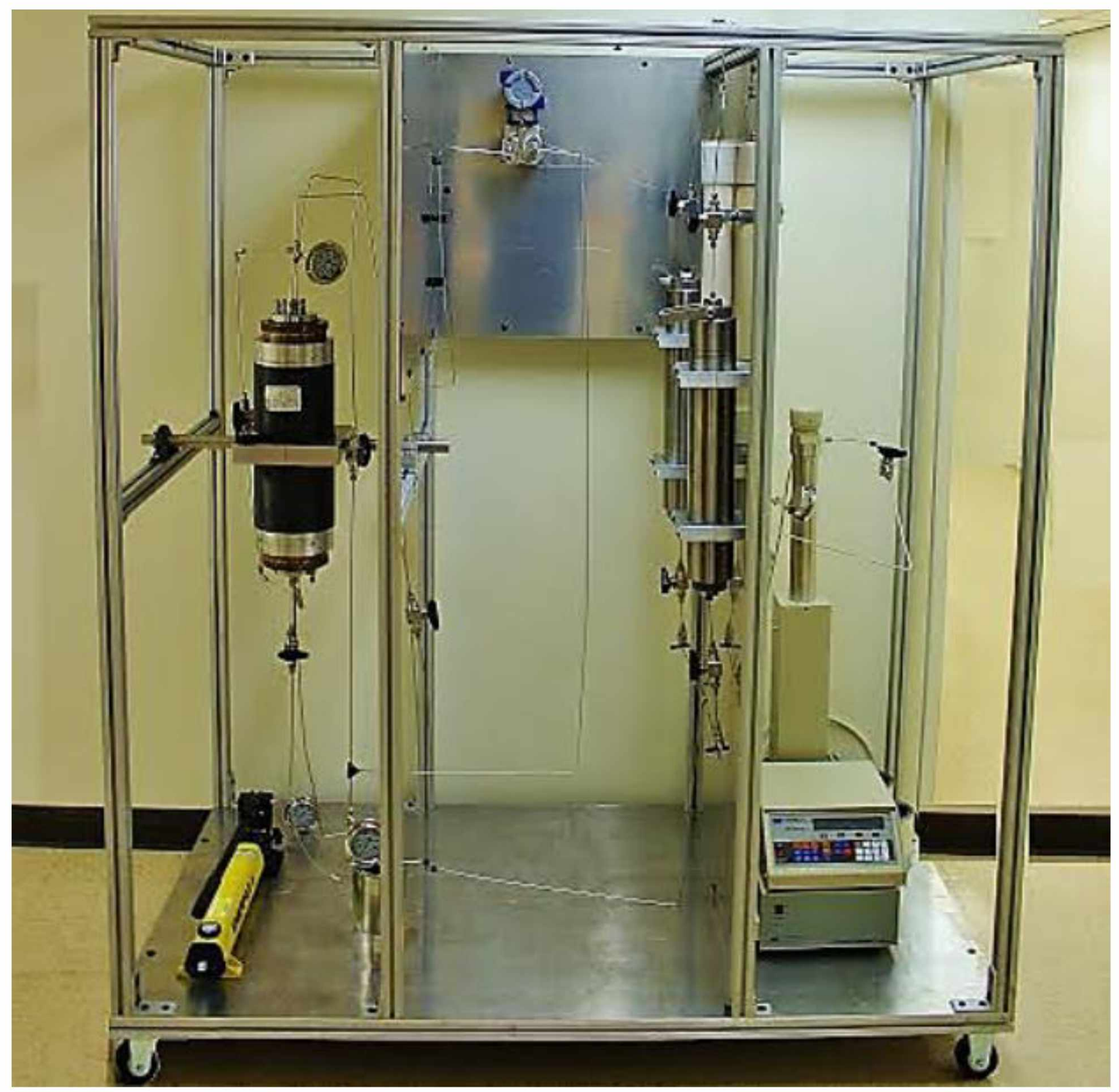

Figure 42 - Laboratory Setup for CHOPS 


\section{Chapter 5. Data Acquisition}

It was necessary to record all the parameters that define the process, such as the flow rate and pressure drop across the core, in the experiment to propose any hypothesis or come to a conclusion.

\subsection{Pressure Transmitter}

The pressure drop was sensed with a set of differential pressure transmitter, which measures the differential pressure between the inlet and outlet of the core. It was a Foxboro IGP10 pressure transmitter (0-3000 psi), Figure 43. The transmitter measures analog signals from 4 to $20 \mathrm{~mA} .4$ $\mathrm{mA}$ corresponds to 0 psi and $20 \mathrm{~mA}$ corresponds to 3000 psi.

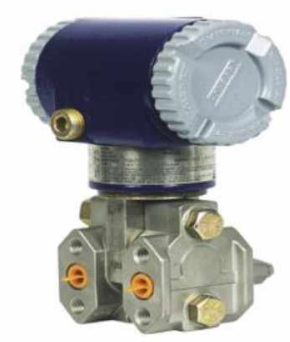

Figure 43 - Foxboro IGP 10 Pressure Transmitter

\subsection{Analog Current Input Module - NI 9203}

The analog signals need to be converted to digital ones. Therefore, the pressure transmitter was connected to an analog input module that senses analog current and converts it to digital. For this, a National Instruments 9203 (NI 9203) 8 channel, +/- $20 \mathrm{~mA}$ and 16 bit Analog Input Module was used, Figure 44. The NI 9203 had a 10-terminal, detachable, screw-terminal connector that provided connections for 8 analog input channels, Figure 45 .
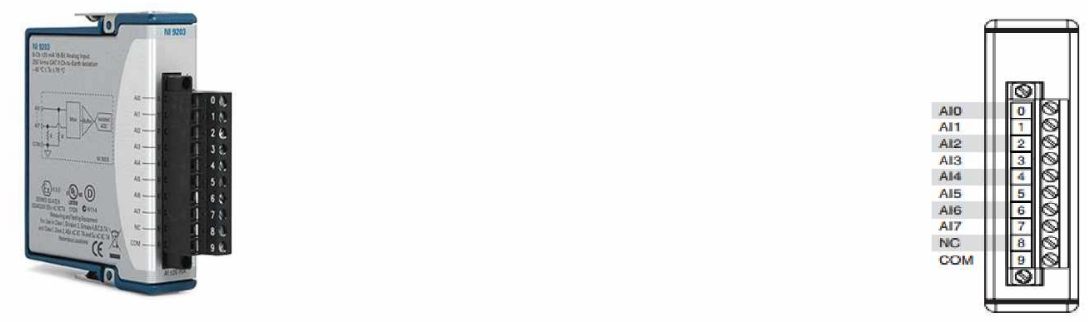

Figure 44 - NI 9203 Current Analog Input Module

Figure 45 - NI 9203 Terminal Assignments 
Each channel had an AI terminal to which a current signal was connected. The NI 9203 also had a common terminal, COM, internally connected to the ground of the module. The analog input signal was conditioned and converted to digital output.

\subsection{Wiring Transmitter and Analog Input Module}

To make the connection to a single terminal on the NI 9203, 2-wire ferrules were needed. The power source required is of $11.5-42 \mathrm{VDC}$. The positive terminal of the pressure transmitter was connected to the positive terminal of the adapter. The negative terminal of the pressure transmitter was connected to the positive terminal of NI 9203. Using another wire, connect the negative terminal of NI 9203 and negative terminal of power supply, Figure 46. NI 9203 was plugged into NI DAQ, which is a device between the data acquisition application and the National Instruments devices, Figure 47 and Figure 48.

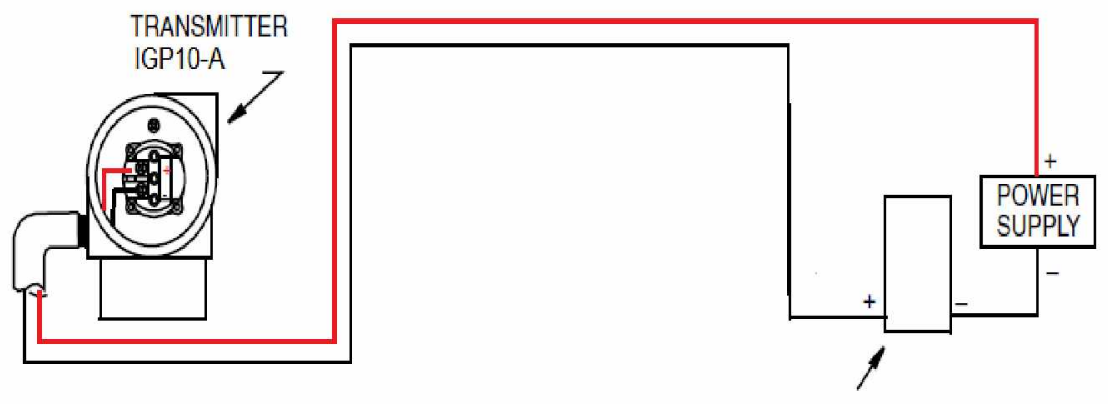

NI 9203

Figure 46 - Wiring Sketch of Data Acquisition System

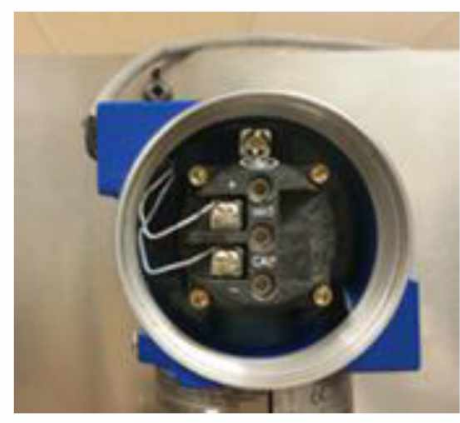

Figure 47 - Pressure Transmitter Connections

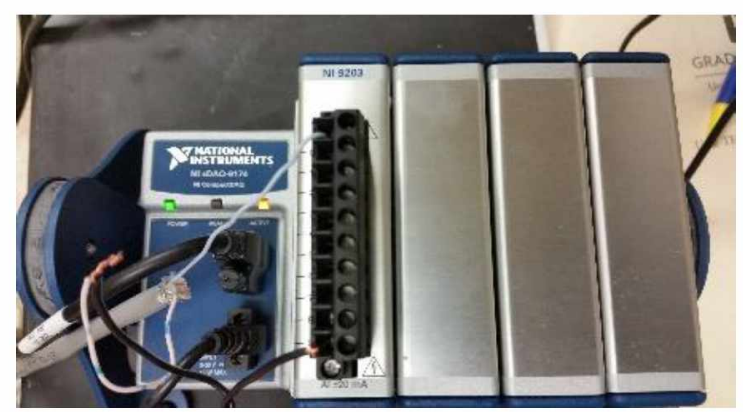

Figure 48 - NI 9203 Connections 


\subsection{LabVIEW Software}

The NI DAQ was connected using a laptop. LabVIEW software was used for data acquisition. LabVIEW 2015 was installed on the laptop. It has two components : a block diagram and a front panel. The block diagram is a back panel that contains the graphical source code. All the terminals in the block diagram are placed on the front panel.

As NI 9203 is a current analog input module, default current input/output module in LabVIEW is selected. Figure 49 is the block diagram for default current input/output module. Changes were made in the Data Acquire section. As $4 \mathrm{~mA}$ corresponds to 0 psi and $20 \mathrm{~mA}$ corresponds to 3000 psi, the digital current output values from NI 9203 were converted to pressure values using a linear relationship given in Equation (6). The front panel showed the pressure profile with time. The file was saved as ".vi”.

Pressure (in psi) $=187500 \times$ Current (in Amperes) -750

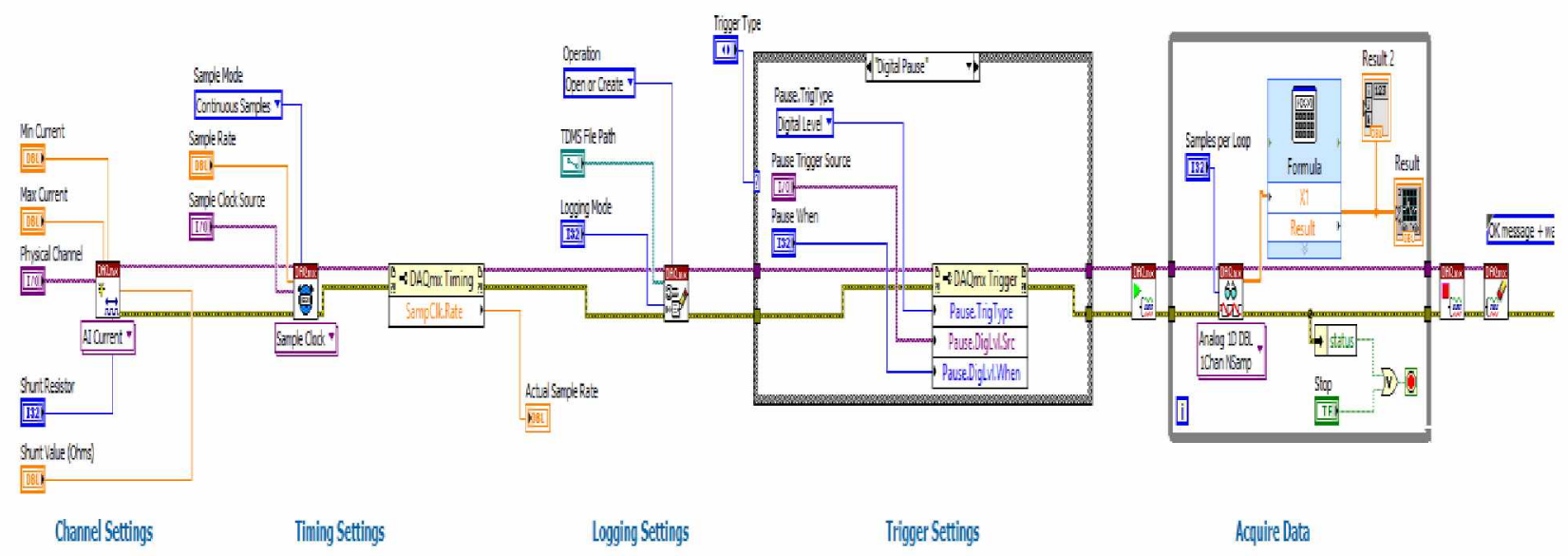

Figure 49 - Block Diagram in LabVIEW

Figure 50 was the front panel of LabVIEW. The front panel is user friendly. The data were recorded in following steps -

1) Select the Physical Channel where the terminal from pressure transmitter is connected to NI 9203.

2) Input the sampling rate. 
3) Change the Logging Mode to "log and read."

4) Select the location where the file needs to be stored.

5) Click on START for recording data.

6) Click on STOP when the data recording needs to be stopped.

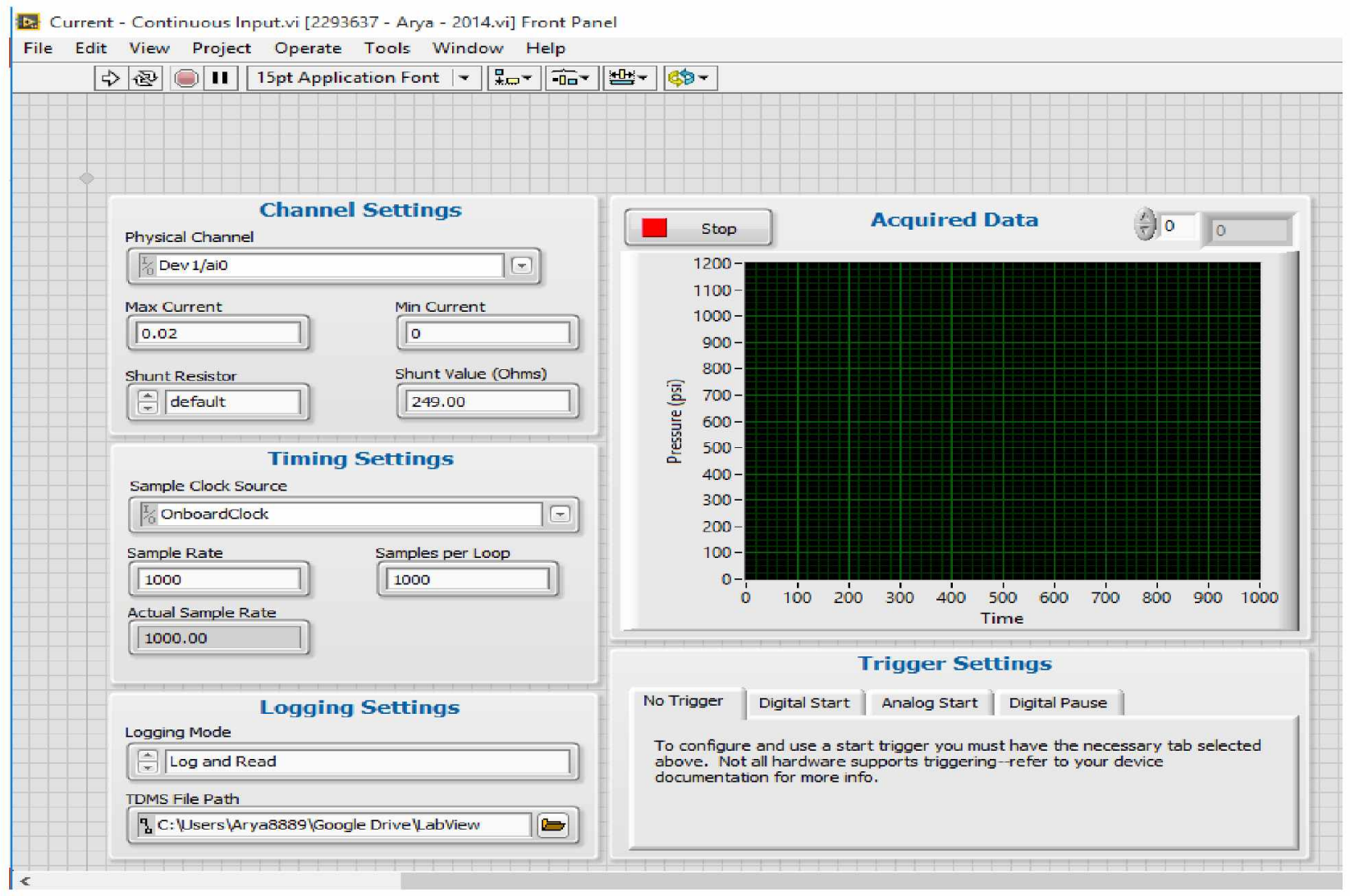

Figure 50 - Front Panel in LabVIEW

\subsection{Permeability Calculation}

The data points recorded were in terms of pressure (psia). The values were transported to Microsoft Excel. Using Darcy's Equation, Equation (7), the permeability of the core was calculated.

$Q=\frac{k A P}{\mu L}$. 


\section{Chapter 6. Experimental Procedure and Troubleshooting}

The experimental procedure were divided into the following sections:

1) Placing of Core Sample

2) Emptying Accumulator

3) Charging Accumulator

4) Saturating Core Sample

5) Heavy Oil Injection

6) Depressurizing System.

\subsection{Placing of Core Sample}

Figure 26 summarizes the methodology of preparing a core sample. It takes 21 days for the sample to be ready for use. After 21 days, the sample is taken out of the mold. Top and bottom surfaces were made smooth using a file. The samples were neatly wrapped using Teflon tape. The sample was put into the core holder rubber sleeve. The procedure discussed in Section 3.3.3 was used to complete the connection of the core holder assembly.

\subsection{Emptying Accumulator}

The procedure to empty the accumulator before charging it with oil is given below. Figure $\mathbf{5 1}$ is the flow schematic for emptying the accumulator.

1) Make sure the pump cylinder is full.

2) Close V001, V003, V004, V007, and V009.

3) Set V008 so that the feed is from the accumulator and the flow is towards the refill tank.

4) Open V002, V005, V006, V008, and V015.

5) Press RUN to initiate syringe pump operation

6) STOP the pump when the pressure inside it starts to build when the top of the accumulator is full of water. This confirms that the piston inside the accumulator is at bottom. 


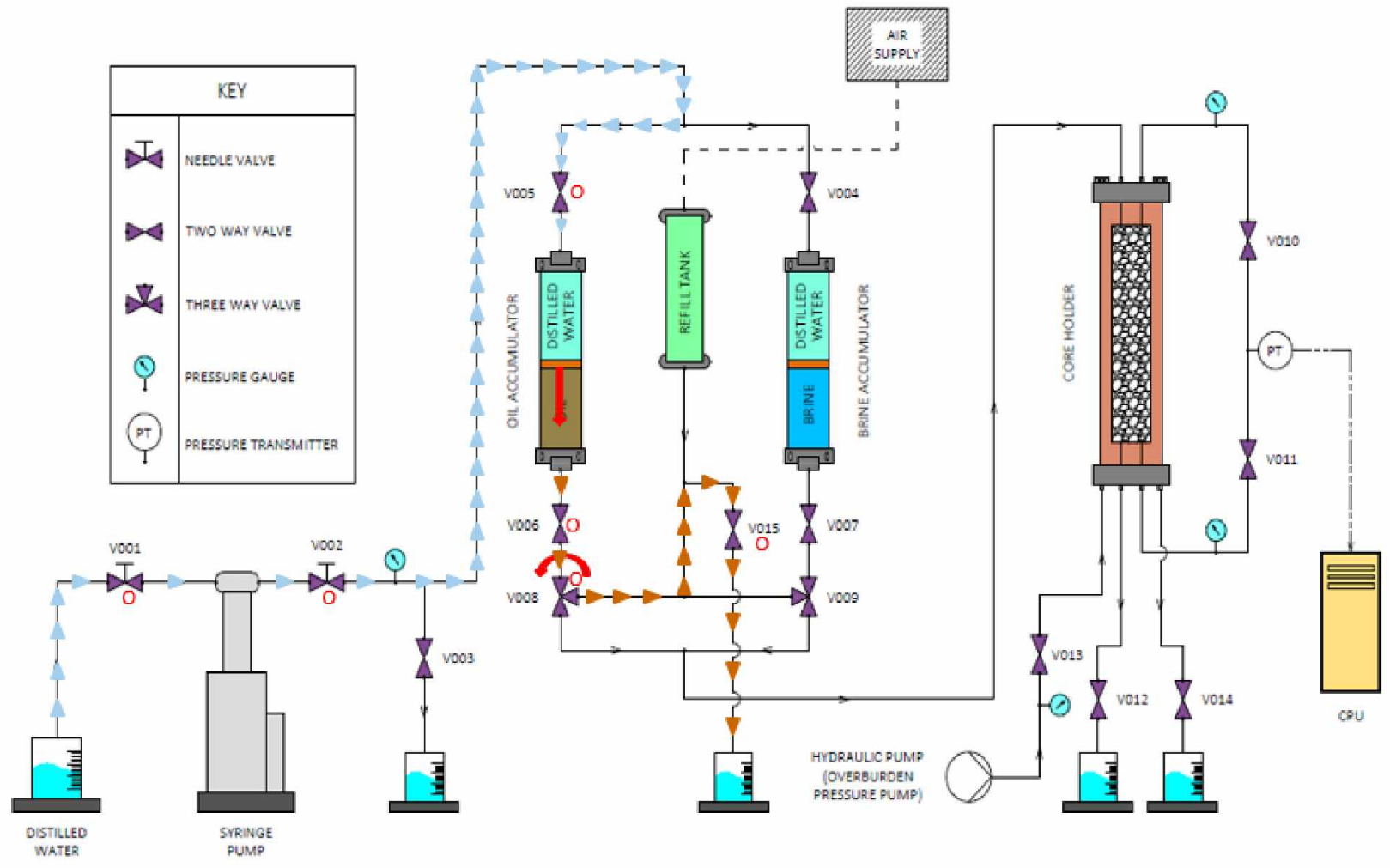

Figure 51 - Flow Diagram for Emptying Accumulator Before Charging

\subsection{Charging Accumulator}

The procedure to charge the accumulator with oil is given below. Figure $\mathbf{5 2}$ is the flow schematic for emptying the accumulator.

1) Close V001, V002, V004, V007, V009, and V015.

2) Set V008 so that the feed is from the refill tank and the flow is towards the accumulator.

3) Open V003, V005, V006, and V008.

4) Using a funnel, pour $500 \mathrm{ml}$ of oil into the refill tank.

5) Close the nozzle and connect the rubber tube to the inlet of the refill tank.

6) Connect the other end of the rubber tube to the air supply.

7) Slowly open the air supply nozzle.

8) Observe the level of liquid in the refill tank and collect the water at the collecting tank. 
9) Close the air supply and make sure the refill tank is empty.

10) Close V003.

Caution: In the case of any observed leakage, close the air supply immediately.

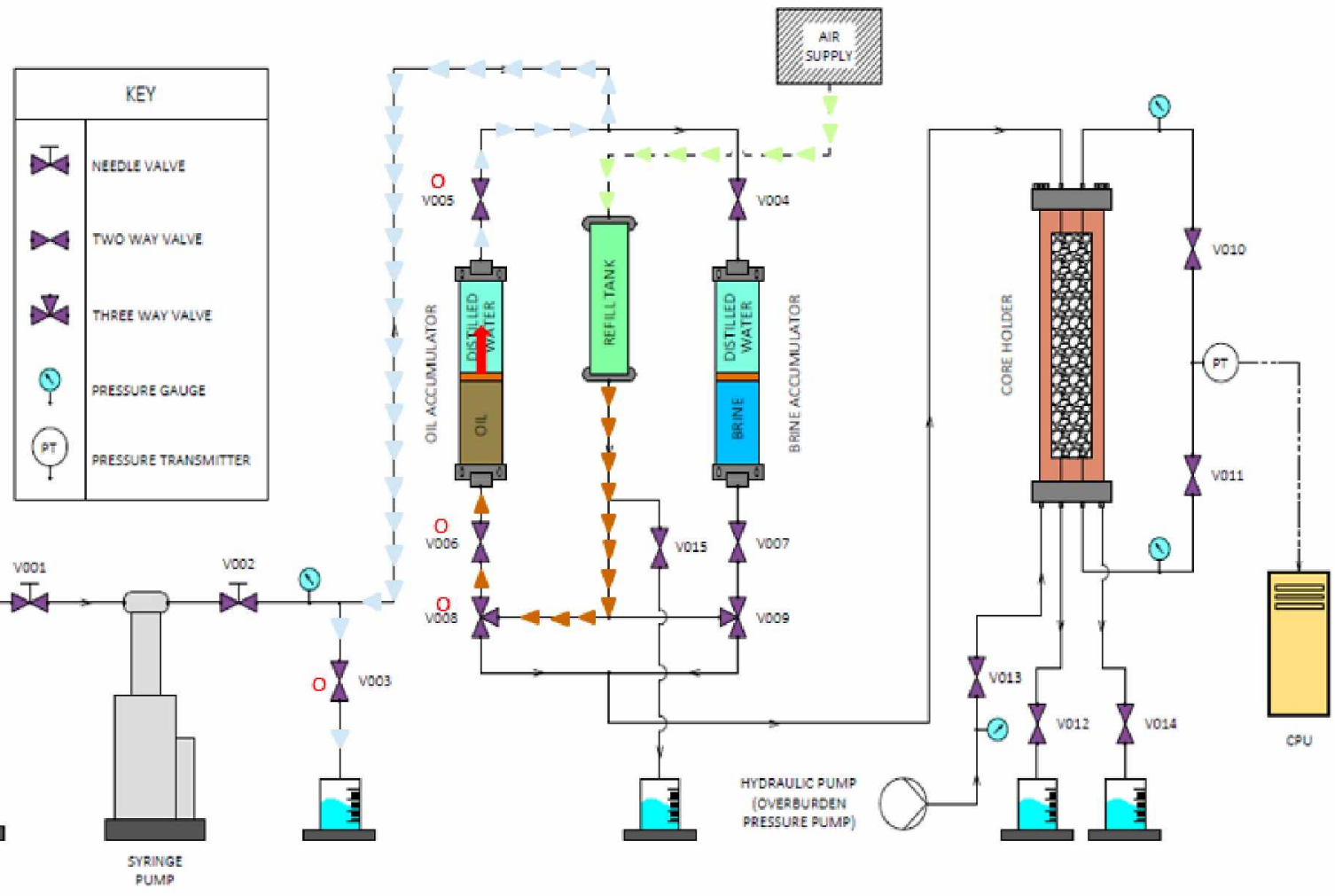

Figure 52 - Flow Diagram for Charging of Accumulator

\subsection{Saturating Core Sample}

As described in Sections 5.2 and 5.3, charge the brine accumulator with water. Figure $\mathbf{5 3}$ shows the flow schematic for saturating the core with water. The procedure is as follows:

1) Remove vent/fill cap from reservoir of the hydraulic pump.

2) Fill the reservoir with hydraulic oil to the mark shown in the pump.

Note: Check the oil level regularly; the oil needs to be changed every 12 months.

3) Open V013 and V014.

4) Close release valve on hydraulic pump by turning clockwise. 
5) Operate pump handle to deliver hydraulic power to system.

6) Close V014 once hydraulic oil starts coming out of the system.

7) Observe the pressure on the gauge.

8) Pressure will be maintained until release valve is opened.

9) Open V002, V004, and V007.

10) Close V003, V005, V006, V008, V0012, and V014.

11) Open three way valve V009 to the core holder.

12) Open V010 and V011 to take pressure transducer online.

13) Set the pump at constant rate of $5 \mathrm{~m} / \mathrm{min}$.

14) Press RUN to initiate syringe pump operation.

15) Stop the pump after injecting 1.5 PV of core with water.

Note the pressure on the outlet of the syringe pump gauge and core holder inlet gauge and STOP the pump in case of any emergency. Also, if overburden pressure drops below injection pressure, liquid leaks out of the core holder. Therefore, the injection pressure and overburden pressure should be observed throughout the experiment. 


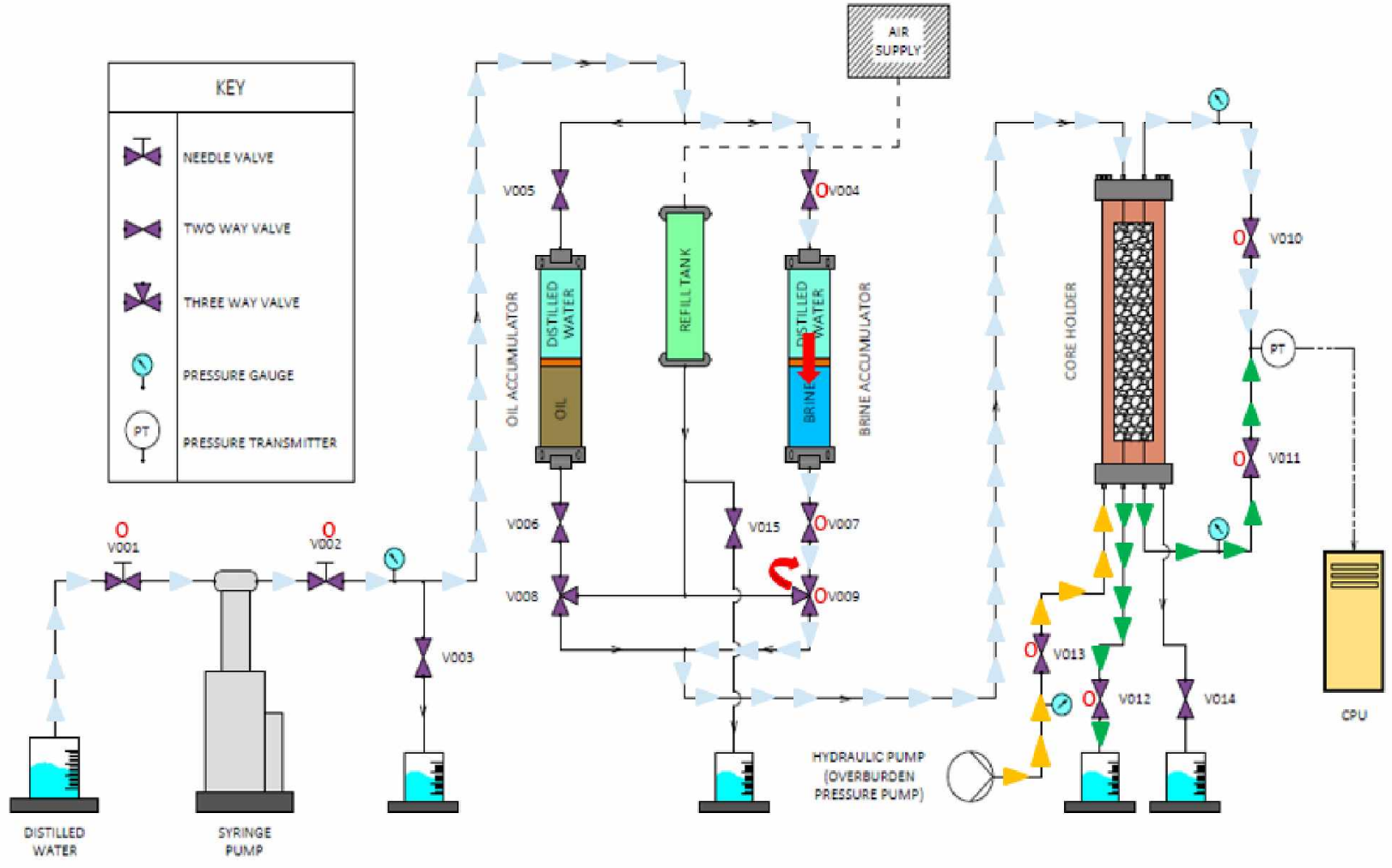

Figure 53 - Flow Diagram for Saturating Core with Water

6.5 Heavy Oil Injection

After saturating the core completely with water, heavy oil in injected. Figure $\mathbf{5 4}$ gives the flow diagram of injecting heavy oil into the core. The procedure is as follows:

1) Close V001, V003, V004, V007, V009, V012, V015, and V014.

2) Open V002, V005, and V006.

3) Open three way valve V008 to the core holder.

4) Open V010 and V011 to take pressure transducer online.

5) Set the pump at constant rate of $0.5 \mathrm{ml} / \mathrm{min}$.

6) On LabVIEW, change the Logging Settings to "Log and Read." Select the path where the file needs to be stored. Click on Start.

7) Press RUN to initiate syringe pump operation. 
8) Observe the increase in pressure of injection pump. Increase the overburden pressure as the injection pressure is increasing.

9) Change the rate of injection after injecting $2.5 \mathrm{PV}$ with heavy oil.

10) Collect the samples for each rate separately and label them.

Note the pressure on the outlet of syringe pump gauge and core holder inlet gauge and STOP the pump in case of any emergency.

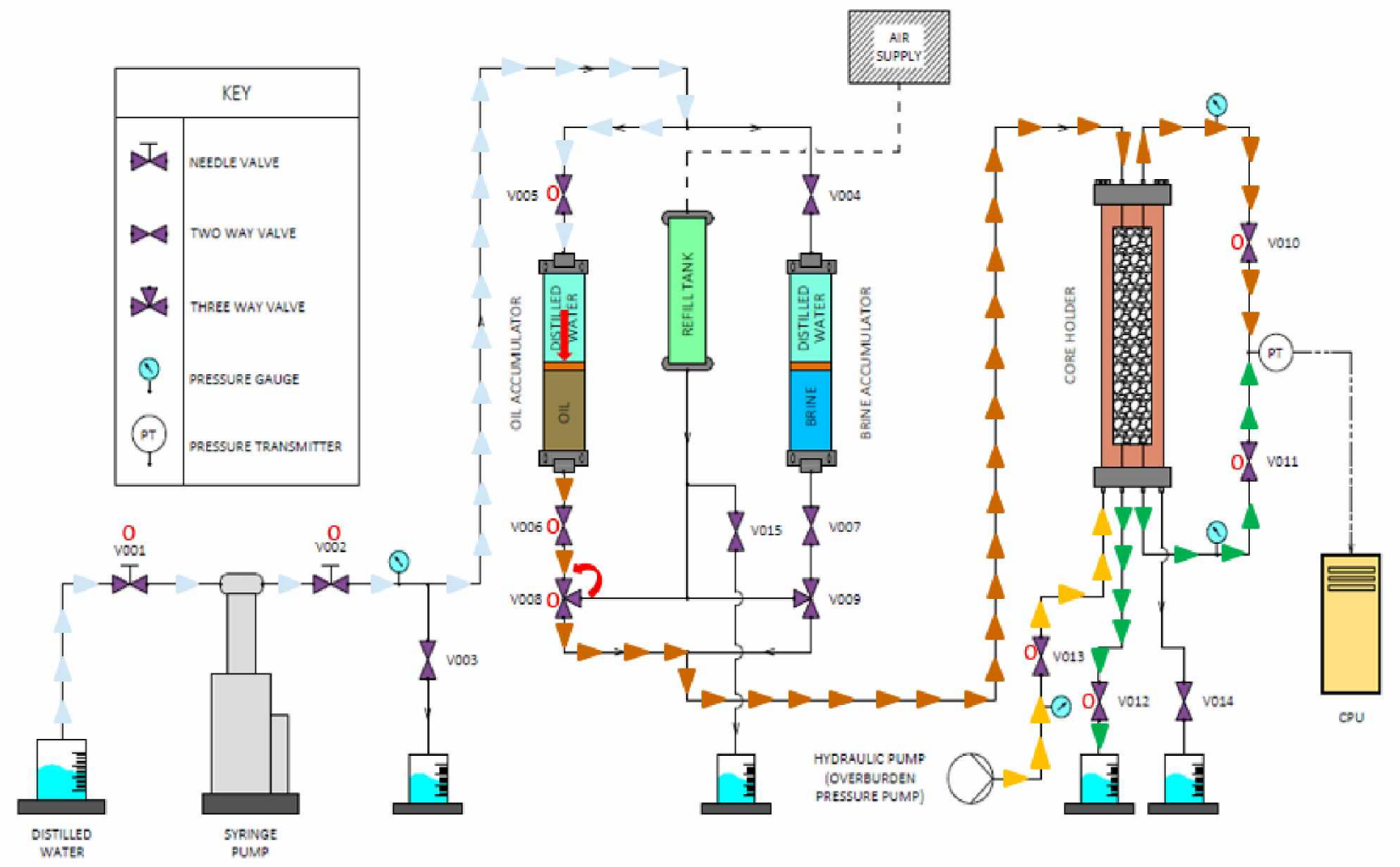

Figure 54 - Flow Diagram for Heavy Oil Injection into the Core Holder

\subsection{Depressurizing System}

1) Once the experiment is over or the differential confining pressure exceeds 4500 psi, press STOP on the controller of syringe pump.

2) Slowly open the outlet of core holder V014 to train hydraulic oil.

3) To depressurize the hydraulic pump, open the release valve (turn anti-clockwise), allowing oil to flow back to the reservoir. Wait till all the gauges shows zero psi. 


\section{Chapter 7. Exploratory Experiments}

Exploratory experiments are the initial experiments conducted to test setup limitations' establish a foundation that will lead to future studies and to see if the observations can be explained by the existing theories. Hence, basic experiments are conducted to test the limitations of the built setup to perform CHOPS experiments.

\subsection{Objective}

The measured compressive strength of the synthetic core was 511 psia. The net Differential Confining Pressure (DCP) on the core is the difference between the overburden pressure on the core and the injection pressure into the core. For DCP greater than the core compressive strength, the core will be crushed while DCP less than the compressive strength of the core will not crush the core during experiment. Experiments were conducted to explore how varying the oil injection rate for two cases - differential confining pressure a) less and b) greater than the compressive strength of core affected the varying average core permeability due to wormhole generation.

\subsection{Experimental Parameters}

A gear lubricant of $680 \mathrm{cp}$ was used as heavy oil for the experiments. Table $\mathbf{1 3}$ gives the physical properties of the heavy oil used for the experiment and Table 14 provides the physical properties of one of the cores used for exploratory experiments.

Table 15 summarizes the experimental parameters for both cases.

Table 13 - Physical Properties of Synthetic Heavy Oil used for Exploratory Experiment

\begin{tabular}{|c|c|}
\hline Appearance & Brown, liquid at room temperature \\
\hline Odor & Slight hydrocarbon \\
\hline Initial Boiling Point and Boiling Range & $>280{ }^{\circ} \mathrm{C} / 536^{\circ} \mathrm{F}$ estimated value(s) \\
\hline Pour point & Typical $-9^{\circ} \mathrm{C} / 16^{\circ} \mathrm{F}$ \\
\hline Vapor pressure & $<0.5 \mathrm{~Pa}$ at $20^{\circ} \mathrm{C} / 68^{\circ} \mathrm{F}$ (estimated value(s)) \\
\hline Specific gravity & Typical 0.912 at $15^{\circ} \mathrm{C} / 59^{\circ} \mathrm{F}$ \\
\hline Density & Typical $912 \mathrm{~kg} / \mathrm{m}^{3}$ at $15^{\circ} \mathrm{C} / 59^{\circ} \mathrm{F}$ \\
\hline Kinematic viscosity & Typical $680 \mathrm{~mm}^{2} / \mathrm{s}$ at $40^{\circ} \mathrm{C} / 104^{\circ} \mathrm{F}$ \\
\hline
\end{tabular}

Table 14 - Physical Properties of Core

\begin{tabular}{|c|c|c|c|c|}
\hline Length & Diameter & Porosity & Bulk Volume & Pore Volume \\
\hline 4 inches & 2 inches & 0.33 & $205.93 \mathrm{~cm}^{3}$ & $61.78 \mathrm{~cm}^{3}$ \\
\hline
\end{tabular}


Table 15 - Cases for Exploratory Experiments

\begin{tabular}{|c|c|c|}
\hline Experiment & $\begin{array}{c}\text { Differential Confining Pressure (DCP) } \\
\text { (psi) }\end{array}$ & Remarks \\
\hline I & 500 & DCP less than compressive strength of core \\
\hline II & 1000 & DCP more than compressive strength of core \\
\hline
\end{tabular}

The experiments were conducted at ambient temperature. The rate of injection into the core was increased after every 2.5 pore volumes. Table 16 gives rate of injection into the core and time took to inject 2.5 pore volumes.

Table 16 - Rate of Injection and Time Taken to Inject 2.5 Pore Volumes

\begin{tabular}{|c|c|c|}
\hline Rate & \multicolumn{2}{|c|}{ Time } \\
\hline$(\mathrm{ml} / \mathrm{min})$ & $\min$ & $\mathrm{hrs}$ \\
\hline 0.5 & 308.89 & 5.15 \\
\hline 1 & 154.44 & 2.57 \\
\hline 3 & 51.48 & 0.86 \\
\hline 5 & 30.89 & 0.51 \\
\hline 7 & 22.06 & 0.37 \\
\hline 10 & 15.44 & 0.26 \\
\hline
\end{tabular}

\subsection{Experimental Procedure}

The experimental procedure is discussed in detail in Chapter 5. For Experiment I, the Differential Confining Pressure was maintained at 500 psia and for Experiment II, the Differential Confining Pressure was maintained at 1000 psia. Data were recorded for both cases and the samples were collected for each rate.

\subsection{Results and Discussion}

Figure 55 shows a semi-log plot of permeability versus pore volume injected for a differential confining pressure of 500 psia. In this case, the differential confining pressure was less than the compressive strength of the core; therefore, it was believed that the core was not crushed during the experiment. It was observed from the plot that pressure increased with increasing injection rate. Initially, when oil was injected, the core was completely saturated with water. As the core was primarily saturated with water, the heavy oil injected at $0.5 \mathrm{ml} / \mathrm{min}$ tried to replace the water. The average permeability of the core was calculated throughout the injection process. Water with 
$100 \%$ initial saturation was displaced with higher viscosity oil in vertically downward direction. The reduction in the calculated average permeability with time is due to increase in saturation of heavy oil. The fluctuation in pressure data is hard to explain but potentially could be due to local variations in pore size and permeability. At higher rates the curve became smooth potentially due to development of continuous flow paths for the flowing fluid, oil in this case. At a higher rate, 10 $\mathrm{ml} / \mathrm{min}$, the experiment was stopped after injecting almost one pore volume, because the differential confining pressure went up to 4200 psia.

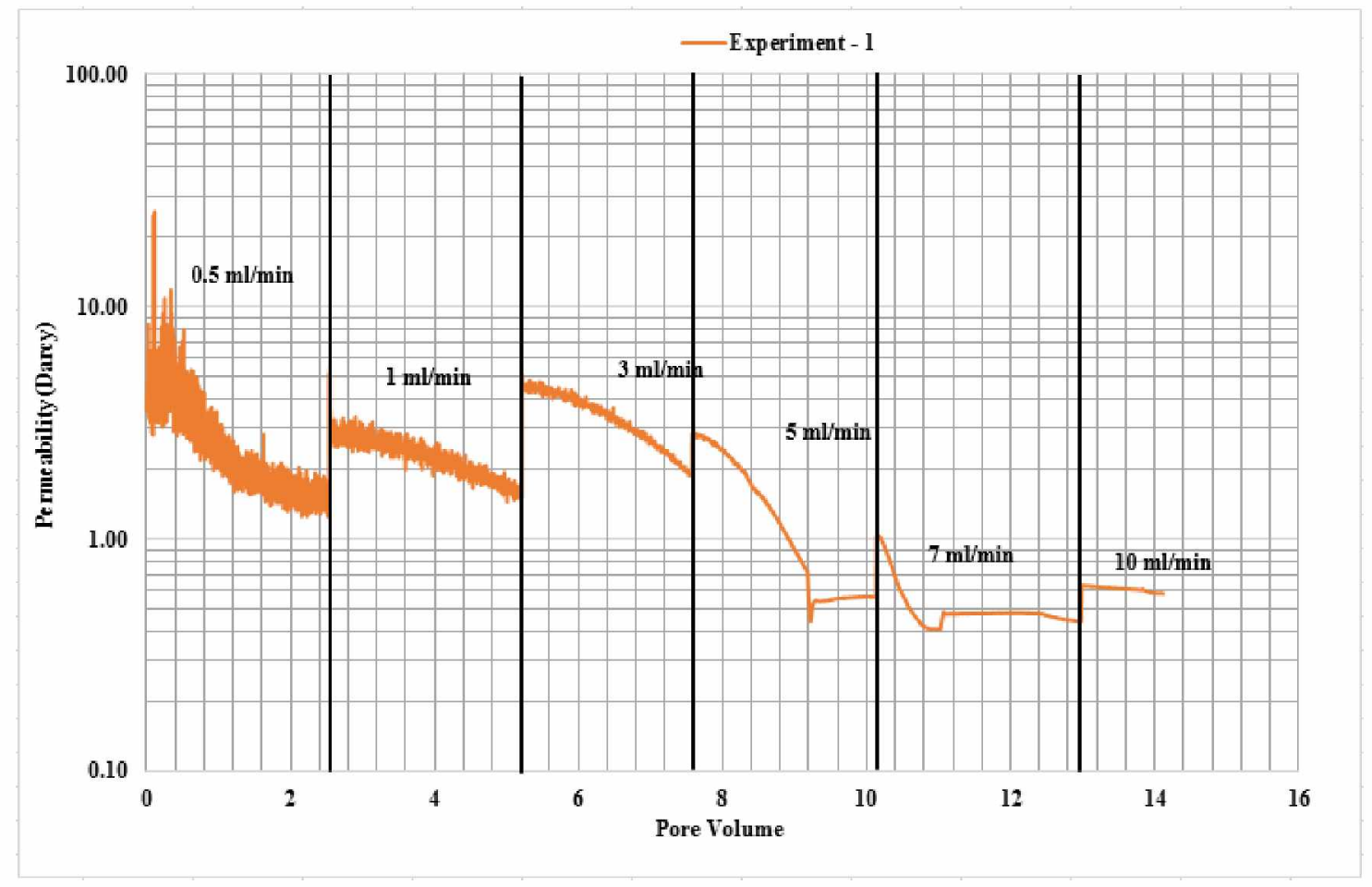

Figure 55 - Core Permeability versus Pore Volume Injected for Varying Rate of Injection and Constant Differential Confining Pressure of 500 psia

Figure 55 shows semi-log plot of permeability versus pore volume for a differential confining pressure of 1000 psia. In this case, the differential confining pressure was more than the compressive strength of the core; therefore, it is believed that the core was completely crushed during the experiment. As the core was completely crushed, more resistance was offered against heavy oil injection. It is believed that crushing the core could lead to release of small fines that plugged the flow paths and reduced the overall conductivity of the core. Because of this, it was observed that the differential pressure across the core increased as more heavy oil was injected. 
Therefore, after injecting 7.7 pore volumes, the experiment was terminated. At higher pore volumes, the permeability of the core dropped steeply due to a sudden increase in differential confining pressure.

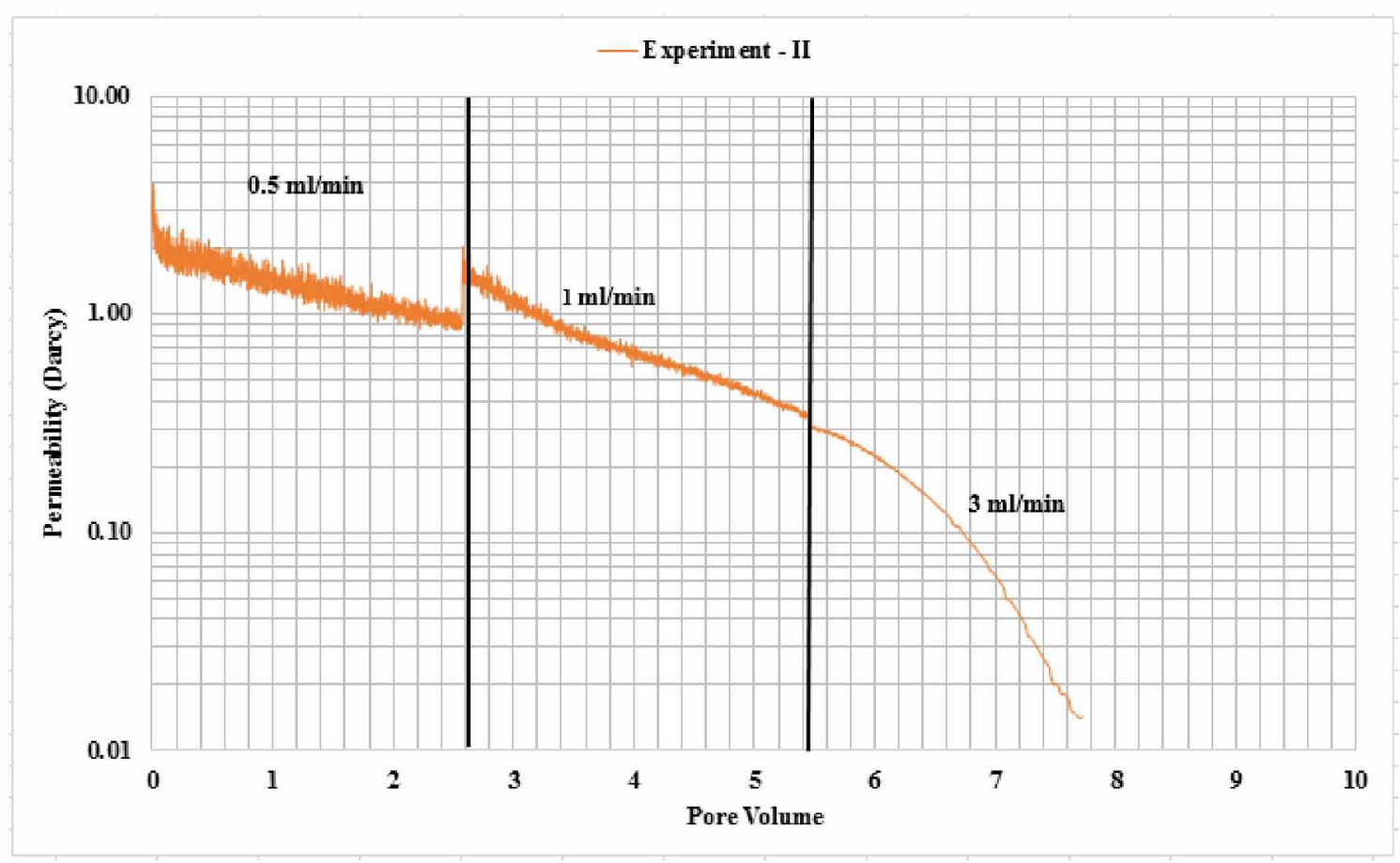

Figure 56 - Core Permeability versus Pore Volume Injected for Varying Rate of Injection and Constant Differential Confining Pressure of 1000 psia

It can be concluded from the exploratory experiments that when the core is completely crushed, the pressure drop across the length of the core is very high so the experiment could not be run for longer duration. The initial permeability of the core in the case of DCP 500 psia is greater than that of DCP 1000 psia. Therefore, it is suggested that the experiments should be conducted at differential confining pressures less than the compressive strength of the core. Also, it is suspected that when the core is completely crushed, the $1 / 8$ " outlet is getting clogged, causing the differential pressure across the core to increase rapidly.

Before starting the injection process, the core was subjected to overburden pressure (500 psi and 1000 psi for Exploratory Experiments I and II respectively). The bottom of the core was opened to atmosphere. So, when oil was injected from the top of the core, the net differential pressure at the top of the core was lower different that the net differential pressure at the bottom of the core. So, the core at bottom at the beginning is suspected to get completely crushed; therefore, the flow 
is restricted at the bottom resulting in an increase of differential pressure across the core thereby decreasing the permeability of core. This can be avoided by using a back pressure regulator.

The differential pressure across the length of the core increased slowly for lower rates of injection into the core. Therefore, the rate of injection should be between $0.5 \mathrm{ml} / \mathrm{min}$ and $3 \mathrm{ml} / \mathrm{min}$. 


\section{Chapter 8. Statistical Design of Experiments}

Design of experiments (DOE) is a statistical method to systematically determine the relationship among factors affecting a response variable. A good experimental design avoids systematic error, as the experiments are randomly performed to eliminate the effects of unknown or uncontrolled parameters.

In this study DOE was used to determine the effect of oil viscosity and injection rate on the evolution of core permeability. A factor in DOE is a controlled independent variable whose levels are set by the experimenter. A Response Variable is a variable whose value is dependent on the factors. Therefore, in this DOE, the factors were oil viscosity and injection rate, and the response variable was core permeability. Table 17 gives input values for high and low levels for the two factors and permeability of the core $(\mathrm{Y})$ is the response variable for DOE. Lubricating oils of viscosity $370 \mathrm{cp}$ and $525 \mathrm{cp}$ were used for the experiments.

Table 17 - Factors, Levels and Response Variable

\begin{tabular}{|c|c|c|c|c|}
\hline Factors & Labe 1 s & $\begin{array}{c}\text { High Level } \\
(+\mathbf{1})\end{array}$ & $\begin{array}{c}\text { Low Level } \\
\mathbf{( - 1 )}\end{array}$ & $\begin{array}{c}\text { Center Point } \\
\mathbf{( 0 )}\end{array}$ \\
\hline Oil Viscosity (cp) & $\mathrm{X}_{1}$ & 680 & 370 & 525 \\
\hline Injection Rate (ml/min) & $\mathrm{X}_{2}$ & 0.5 & 3 & 1.75 \\
\hline
\end{tabular}

\subsection{Two Level and Two Factor Design}

A full factorial experiment is an experiment whose design consists of two or more factors having different levels and whose experimental units take on all possible combinations of these levels across all such factors. Full factorial two level experiments are also referred to as $2^{k}$ designs, where $k$ denotes the number of factors being investigated in the experiment. A full factorial two level design with $k$ factors requires $2^{k}$ runs for a single replicate.

This DOE is a $2^{2}$ design with two factors, Oil Viscosity $\left(\mathrm{X}_{1}\right)$ and Injection Rate $\left(\mathrm{X}_{2}\right)$, investigated at two levels. A single replicate of this design will require four runs $\left(2^{2}=2 \times 2=4\right)$. The effects investigated by this design are the two main effects, $\mathrm{X}_{1}$ and $\mathrm{X}_{2}$, and the interaction effect, $\mathrm{X}_{1} \mathrm{X}_{2}$. These high and low levels can be generically coded as +1 and -1 . As the high and low levels are two extremes, a center point is considered, which makes it 5 runs (single replicate). 
Table 18 is the design matrix for the factors investigated. The design matrix shows all possible combinations of high and low levels for each input factor.

Table 18 - Full Factorial Design for Two Factors and Two Levels

\begin{tabular}{|c|c|c|c|}
\hline Experiments & $\mathbf{X}_{1}$ & $\mathbf{X}_{\mathbf{2}}$ & $\mathbf{X}_{\mathbf{1}} \mathbf{X}_{\mathbf{2}}$ \\
\hline Experiment -1 & - & - & + \\
\hline Experiment -2 & - & + & - \\
\hline Experiment -3 & + & - & - \\
\hline Experiment -4 & + & + & + \\
\hline Experiment -5 & 0 & 0 & 0 \\
\hline
\end{tabular}

\subsection{Replication and Randomization}

Replication is repetition of the basic experiments. All experiments have some variation because of human and experimental errors, a term which represents the differences that can occur if the same treatments were applied several times to the same experimental units. This type of variation can be minimized by repeating the experiments.

Therefore, the five basic designed experiments were repeated twice. This ensured an accurate estimate of the experimental error, thereby increasing the precision.

Randomization in experimental design is assigning experimental runs randomly. The purpose of randomization is to remove biases that cannot be controlled. Another advantage of randomization with replication is that it forms the basis of any valid statistical test.

Therefore, all ten experimental runs were randomly assigned and performed. Table 19 gives the sequence of five basic experiments repeated twice and randomly assigned. 
Table 19 - Sequence of Randomly Assigned Experimental Runs

\begin{tabular}{|c|c|c|c|}
\hline Experiments & $\mathbf{X}_{1}$ & $\mathbf{X}_{2}$ & $\mathbf{X}_{\mathbf{1}} \mathbf{X}_{\mathbf{2}}$ \\
\hline Experiment -1 & - & - & + \\
\hline Experiment -5 & 0 & - & 0 \\
\hline Experiment -3 & + & + & - \\
\hline Experiment -2 & - & 0 & + \\
\hline Experiment -5 & 0 & + & - \\
\hline Experiment -4 & + & - & - \\
\hline Experiment -3 & + & + & + \\
\hline Experiment -2 & - & - & + \\
\hline Experiment -1 & - & + & + \\
\hline Experiment -4 & + & & + \\
\hline
\end{tabular}

\subsection{Experimental Procedure}

The experiment procedure is discussed in detail in Chapter 5. The differential confining pressure for all 10 runs is kept to be 500 psia. For each experiment, the rate and viscosity is kept constant. Each experiment was conducted on separate core with same characteristics.

\subsection{Results and Discussion}

Figure 57 shows semi-log plot of permeability versus pore volume injected for all five designed experiments at a differential confining pressure of 500 psia. It was observed that when heavy oil was injected, the pressure drop across the length of the core increased, hence, the overall permeability trend for all five experiments was declining initially. The initial permeability recorded at lower pore volumes of injection for high viscosity oil, $680 \mathrm{cp}$, was noisy and there was more fluctuation. It was also observed that the initial permeability recorded for low viscosity oil, $370 \mathrm{cp}$, at a lower rate of $0.5 \mathrm{ml} / \mathrm{min}$, was not noisy. For high viscosity oil, more pore volume was injected for calculated permeability to become stable, whereas for low viscosity oil, the calculated permeability became stable at lower pore volumes (less than 1). There was a drastic change in calculated permeability at lower pore volumes, whereas the change was not significant at higher pore volumes because the sand was stabilized. In most of the plots, there was a sudden increase in calculated permeability that decreased rapidly. At lower pore volumes, calculated permeability 
was maximum for high viscous oil at higher rates and at lower pore volumes, calculated permeability was lowest for low viscous oil at lower rates.

It is hypothesized that injecting oil of different viscosities at different rates affects the internal structure of the core in different ways (there is fluid-rock interaction) and thus, at lower pore volumes of injection, the permeability of the core for high viscosity oil is almost $11.2 \%$ greater than for low viscosity oil.

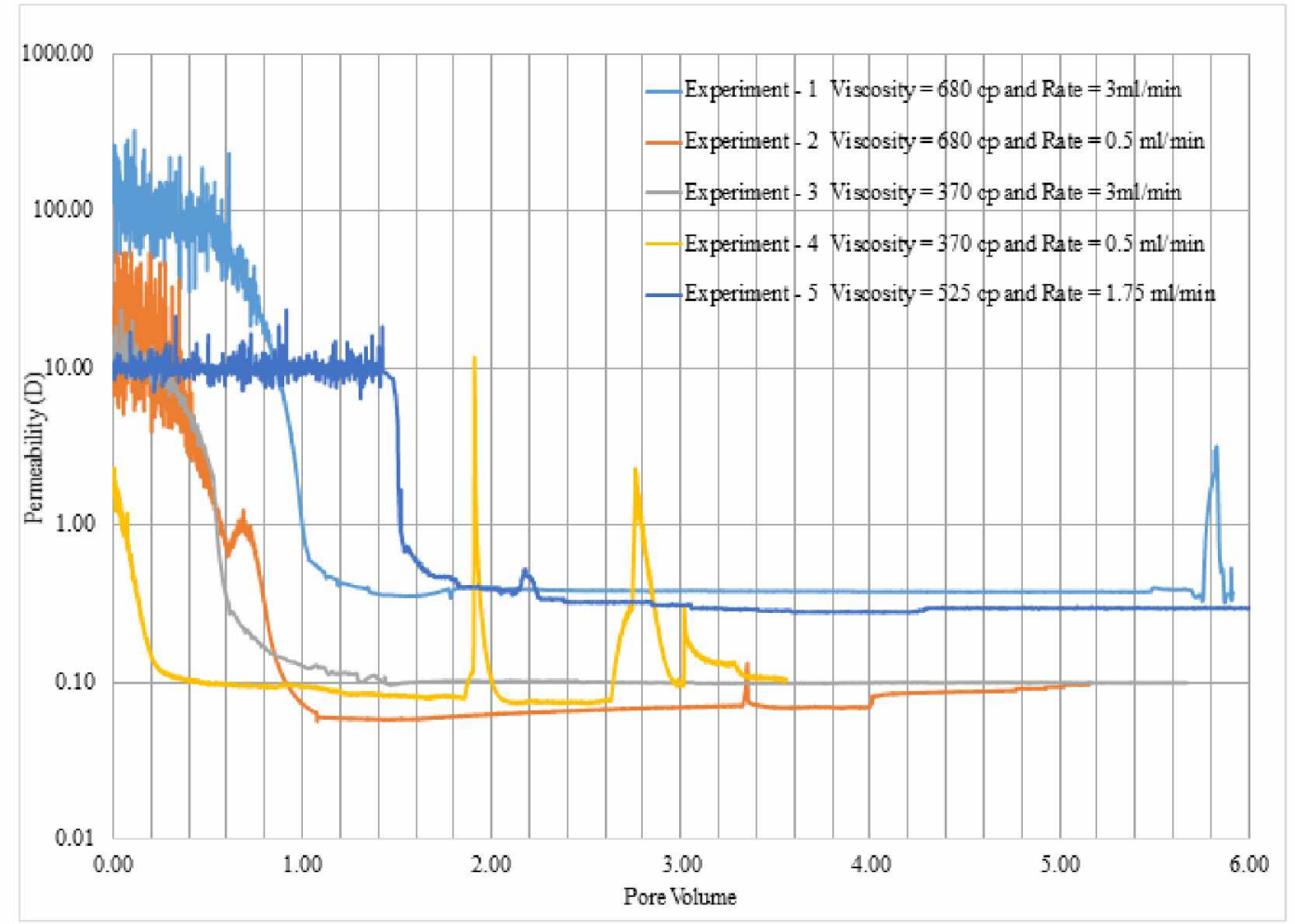

Figure 57 - Permeability versus Pore Volume for Five Basic Experimental Runs using Design of Experiments at DCP 500 psi.

Figure $\mathbf{5 8}$ is the core sample removed from the core holder after Experiment - 1 was over. It was observed that the core was predominantly saturated with heavy oil and was very friable. Each experiment was conducted on different cores with similar characteristics. Also, Figure $\mathbf{5 9}$ shows the effluent sample collected during the experiment. It was observed that the sample collected consisted of water, sand, foamy oil, and heavy oil. 

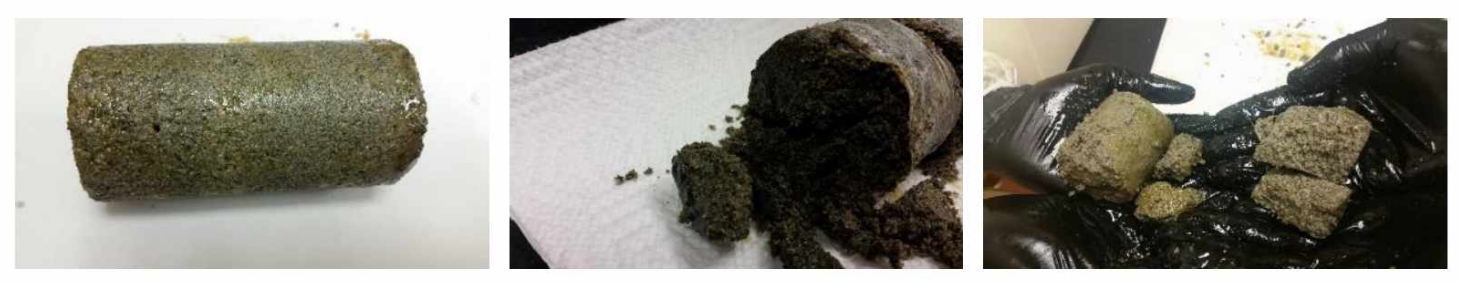

Figure 58 - Core Samples Post Experiment
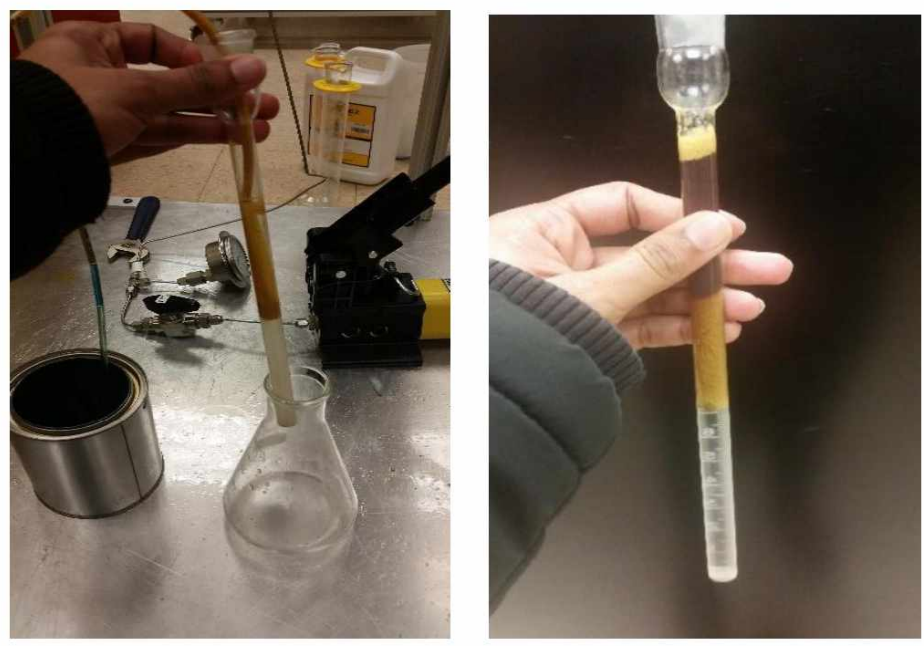

Figure 59 - Sample Collected at the Outlet of Core Holder

\subsection{Qualitative Comparison of Results with Existing Literature}

As discussed in Section 1.3.3, Tremblay et al., 1996, performed laboratory experiment to understand the sand production during heavy oil recovery and scanned the sand pack used during the experiment with computerized tomography techniques in order to observe the wormhole propagation in real time. Injection and production pressures were plotted against time, Figure 9. The pressure profiles from Tremblay's experiment were digitized to compute the differential pressure across the sand pack. The differential pressure across the sand pack was plotted against time along with the differential pressure across the synthetic core for the designed experiments conducted for this research again as shown Figure 60.

The sand pack used in Trembley's experiment was saturated with heavy oil $(21500 \mathrm{cp})$ and packed to a pressure of $27.2 \mathrm{MPa}$, and the injection flow rate was changed from $0.3 \mathrm{ml} / \mathrm{min}$ to $0.6 \mathrm{ml} / \mathrm{min}$ whereas in the experiments conducted for this research, the synthetic core was completely 
saturated with water before flooding it with heavy oil, representing an ideal water wet reservoir. Therefore, it was observed that in Tremblay's experiment the differential pressure across the sand pack increased gradually whereas in the experiments conducted in this research, the differential pressure across the synthetic core increased rapidly as the oil displaced water.

The pressure gradient reached a peak and then started decreasing in both the cases. The decrease in pressure gradient was due to increase in production pressure due to collapsing of sand and subsequent decrease in injection pressure, which can be explained by increase in permeability. This decrease in pressure gradient was significant in case of Tremblay's experiment because the orifice used at the outlet was of $1 / 4$ " whereas the outlet of the core holder used in this research was of $1 / 8$ ". As the outlet of the experimental setup was larger in Tremblay's case, more sand was produced at the outlet and the wormhole started developing. It is hypothesized that the wormhole development for the designed experiment in this research was restricted because less sand was produced because of the smaller size at the outlet. Also, Tremblay and his co-workers used sand packs as opposed to the synthetic cores we used here in this study. They also did not impose any confining pressure on their core holder. We also think that one reason why we do not see the same profile is that we did not have a back-pressure regulator at the outlet of our setup. This meant that the pressure distribution across the length of the core was not uniform, with injection pressure at the inlet and atmospheric pressure at the outlet. This meant that the core was continually consolidated at the outlet of the setup.

Tremblay concluded from the $\mathrm{CT}$ scans of sand pack and the porosity profile that the wormhole development was due to bulk production of sand but not because of fine migration. As the sand produced in the designed experiments was small, we can hypothesize that the wormholes were initiated but not developed because of restriction at the outlet for sand to produce in bulk. 


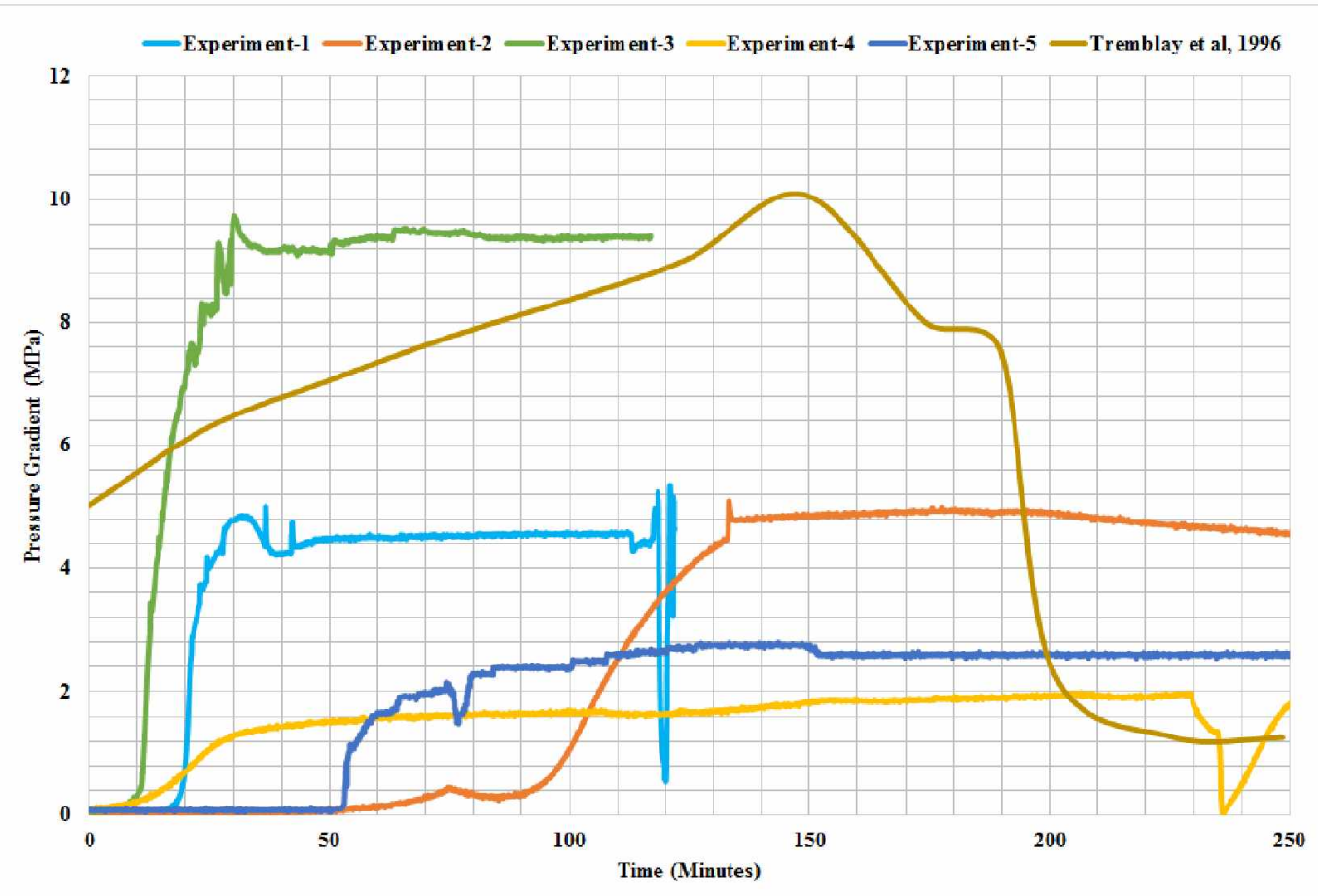

Figure 60 - Comparison of Pressure Profile of Experiments Conducted with Tremblay et al., 1996

Meza-Diaz et al., 2010 determined experimentally the pressure gradient required for initiation of sand production at different rates. Figure $\mathbf{6 1}$ is the digitized plot for the pressure gradient as a function of time measured experimentally by Meza-Diaz et al., 2010. The plot shows that with increase in oil injection rate, the pressure gradient increased with time and was stable for lower rates. At higher rates, the pressure gradients were not stable and were decreasing. This was because, the pressure gradient at the surface of the sand arch exceeds the gradient of the radial stress resulting in failure of arch surrounding a cavity (Bratli and Risnes, 1981). Hence, by increasing the rate in small increments, the sand produced could be transported to the outlet. 


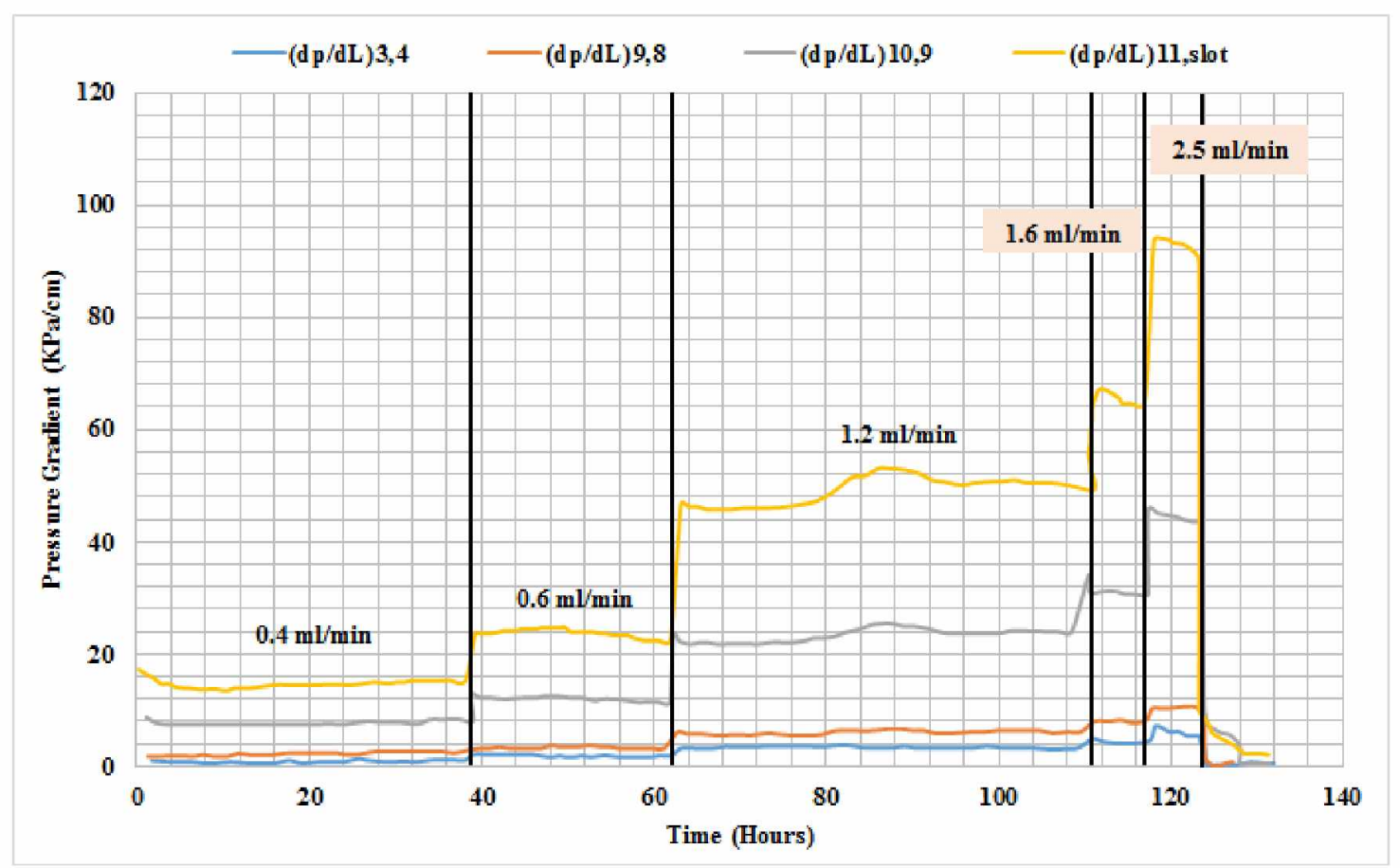

Figure 61 - Digitized Plot for Pressure Gradient as a Function of Time, Meza-Diaz et al, 2010.

Similarly, in the exploratory experiment conducted at a differential pressure difference of 500 psia, it has been observed that the pressure gradient was stable at lower rates, Figure 62. At higher rates, the pressure gradient rapidly increased. This can be explained due to higher pressure drop per unit length because the core was getting crushed and the pressure gradient was less that the critical pressure gradient to transport the sand produced to the outlet. 


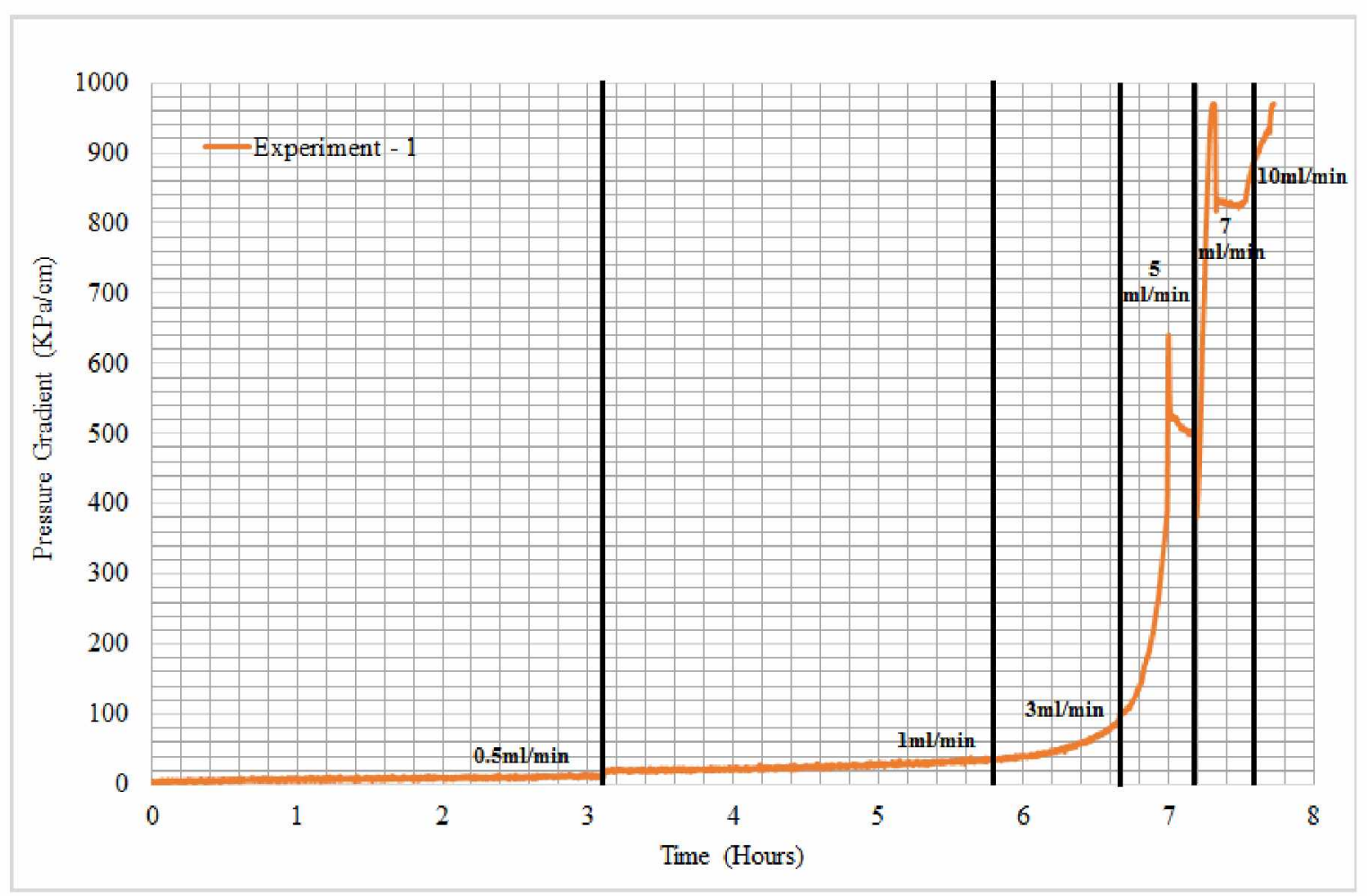

Figure 62 - Pressure Profile as a Function of Time for Exploratory Experiment -1 


\section{Chapter 9. Multiple Linear Regression}

\subsection{Introduction}

Multiple Linear regression is the most commonly used predictive analysis. The dependent variable, Permeability of Core (Y), was assumed to be a linear function of two factors: Oil Viscosity $\left(\mathrm{X}_{1}\right)$ and Injection Rate $\left(\mathrm{X}_{2}\right)$. Their interaction $\left(\mathrm{X}_{1} \mathrm{X}_{2}\right)$ and an error (e) were introduced to account for all other uncontrolled variables:

$Y=\beta_{0}+\beta_{1} X_{1}+\beta_{2} X_{2}+\beta_{3} X_{1} X_{2}+e$

Here, $\beta_{o}$ is the intercept, $\beta_{1}$ is the coefficient of $X_{1}, \beta_{2}$ is the coefficient of $X_{2}$, and $\beta_{3}$ is the coefficient of $X_{1} X_{2}$.

From the results of design of experiments, the value for permeability of core for all five experiments were recorded as $0.5,1,1.5,2,2.5,3$, and $3.5 \mathrm{PV}$. The value for permeability of core at a constant pore volume was the average of permeability of core obtained from repeating the experiment. Table 20 shows an example where $0.5 \mathrm{PV}$ is selected and the value obtained for Permeability of core for all five experiments were recorded. $Y_{1}$ is the value for permeability of core obtained from one experiment and $\mathrm{Y}_{2}$ is the value for permeability of core from repeating the same experiment. $\mathrm{Y}$ denotes the average permeability of core for that particular experiment. Similarly, the data were recorded for $1,1.5,2,2.5,3$, and 3.5 PV for regression analysis.

Regression analysis is done using $\mathrm{R}$, a statistical tool for data analysis.

Table 20 - Permeability of Core for all DOEs at PV $=0.5$

\begin{tabular}{|c|c|c|c|c|}
\hline \multicolumn{5}{|c|}{$\mathbf{P V}=\mathbf{0 . 5}$} \\
\hline $\mathbf{X}_{1}$ & $\mathbf{X}_{\mathbf{2}}$ & $\mathbf{Y}_{\mathbf{1}}$ & $\mathbf{Y}_{\mathbf{2}}$ & $\mathbf{Y}=\left(\mathbf{Y}_{\mathbf{1}}+\mathbf{Y}_{2}\right) / \mathbf{2}$ \\
\hline 1 & -1 & 1.49 & 1.24 & 1.36 \\
\hline-1 & 1 & 2.60 & 0.21 & 1.41 \\
\hline 1 & 1 & 89.61 & 30.82 & 60.22 \\
\hline-1 & -1 & 0.10 & 0.25 & 0.18 \\
\hline 0 & 0 & 14.52 & 20.51 & 17.51 \\
\hline
\end{tabular}




\subsection{Results and Discussion}

The significance level for the regression analysis was considered to be 0.05 . Table 21 summarizes the regression analysis. It gives the coefficient of estimates and P-value for each parameter and different pore volumes.

Table 21 - Summary for Regression Analysis

\begin{tabular}{|c|c|c|c|c|c|c|c|c|}
\hline \multirow{2}{*}{ PV } & \multicolumn{2}{|c|}{ 及o } & \multicolumn{2}{c|}{$\beta 1$} & \multicolumn{3}{c|}{$\beta 2$} & \multicolumn{2}{c|}{$\beta 3$} \\
\cline { 2 - 9 } & Estimates & P-Value & Estimates & P-Value & Estimates & P-Value & Estimates & P-Value \\
\hline 0.25 & 21.86 & 0.09 & 18.37 & 0.12 & 20.66 & 0.11 & 15.79 & 0.14 \\
\hline 0.50 & 16.14 & 0.03 & 15.00 & 0.03 & 15.02 & 0.03 & 14.41 & 0.03 \\
\hline 1.00 & 5.84 & 0.39 & 3.65 & 0.57 & 3.66 & 0.57 & 3.67 & 0.57 \\
\hline 1.17 & 2.93 & 0.68 & 0.09 & 0.99 & 0.11 & 0.99 & 0.12 & 0.99 \\
\hline 1.33 & 1.62 & 0.60 & 0.23 & 0.94 & 0.43 & 0.89 & 0.22 & 0.94 \\
\hline 1.50 & 0.87 & 0.63 & 0.07 & 0.97 & 0.09 & 0.96 & 0.11 & 0.96 \\
\hline 2.00 & 0.23 & 0.21 & 0.07 & 0.56 & 0.09 & 0.47 & 0.10 & 0.09 \\
\hline 2.50 & 0.21 & 0.19 & 0.08 & 0.49 & 0.09 & 0.42 & 0.09 & 0.43 \\
\hline 3.00 & 0.21 & 0.18 & 0.07 & 0.48 & 0.09 & 0.41 & 0.09 & 0.40 \\
\hline 3.50 & 0.20 & 0.15 & 0.07 & 0.45 & 0.08 & 0.37 & 0.09 & 0.36 \\
\hline
\end{tabular}

Figure 63 is a plot coefficient of each factor versus pore volume injected. It was observed that the effect of oil viscosity, injection rate, and their interaction at lower pore volume injected (less than 1) on permeability of core was more than the effect of the same at higher pore volumes injected. The effect of injection rate at lower pore volumes was higher than the effect of other factors. The coefficient of the model decreased steeply with increase in pore volume injected. With further increase in pore volume injected, the effect of model coefficients on core permeability was constant, as the core was predominantly saturated with heavy oil.

Figure 64 is a plot of $\mathrm{P}$-value versus pore volume injected. The P-value for the lower pore volume model was less than the significance level, which implies that the effects of oil viscosity and injection rate on permeability were statistically significant, whereas at higher pore volumes injected, the change in permeability was negligible. This was because at lower pore volumes injected the pressure drop was due to two-phase flow of water and oil, therefore the effect of oil 
viscosity and injection rate were significant, whereas at higher pore volumes there was single oil flow, therefore the effect of viscosity of oil and rate of injection on permeability were not statistically significant.

Regression models developed for permeability based on values recorded at specific pore volumes injected for different injection rates and different oil viscosities demonstrated that at a constant confining pressure for all rates, at lower pore volumes injected $99.8 \%$ of the variance in permeability was explained by oil viscosity, injection rate, and their interaction. At higher pore volumes injected, the variance in permeability is only $40.6 \%$.

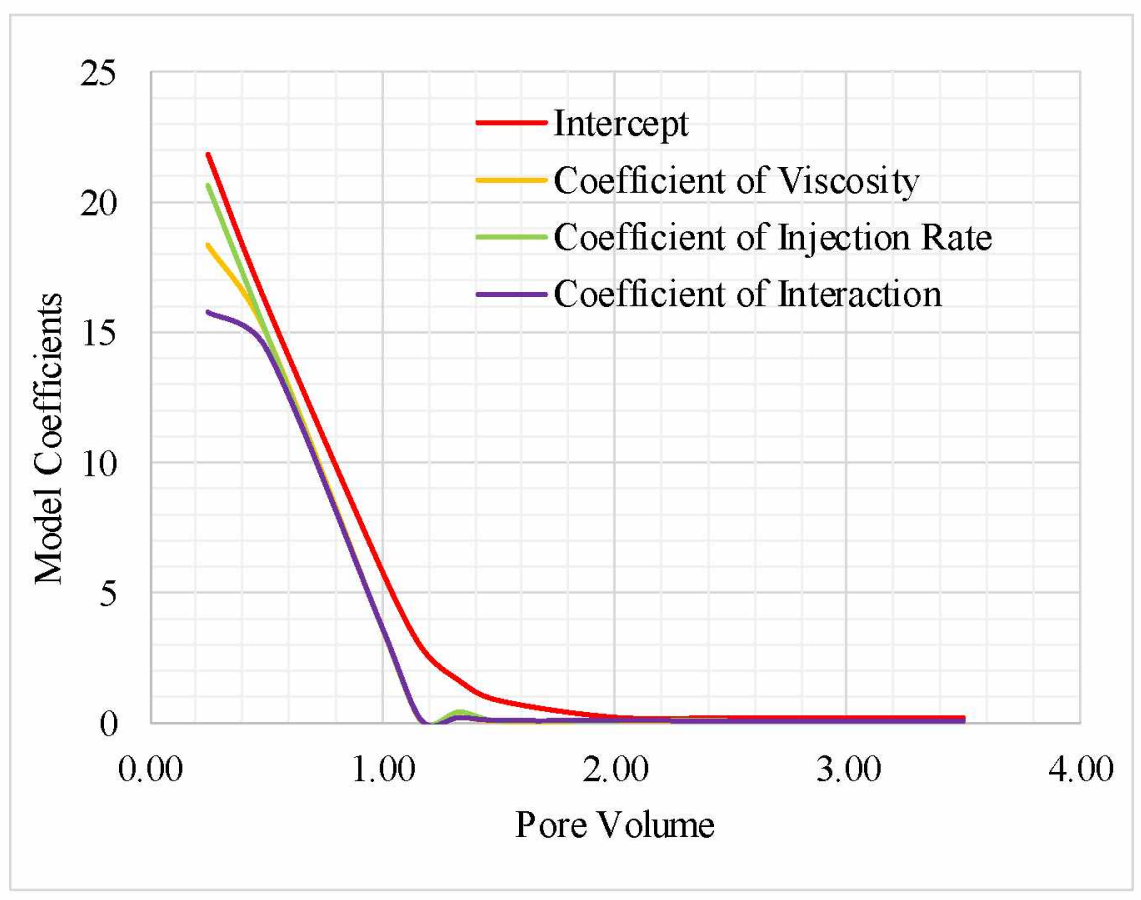

Figure 63 - Effect of Model Coefficients vs. Pore Volumes Injected 


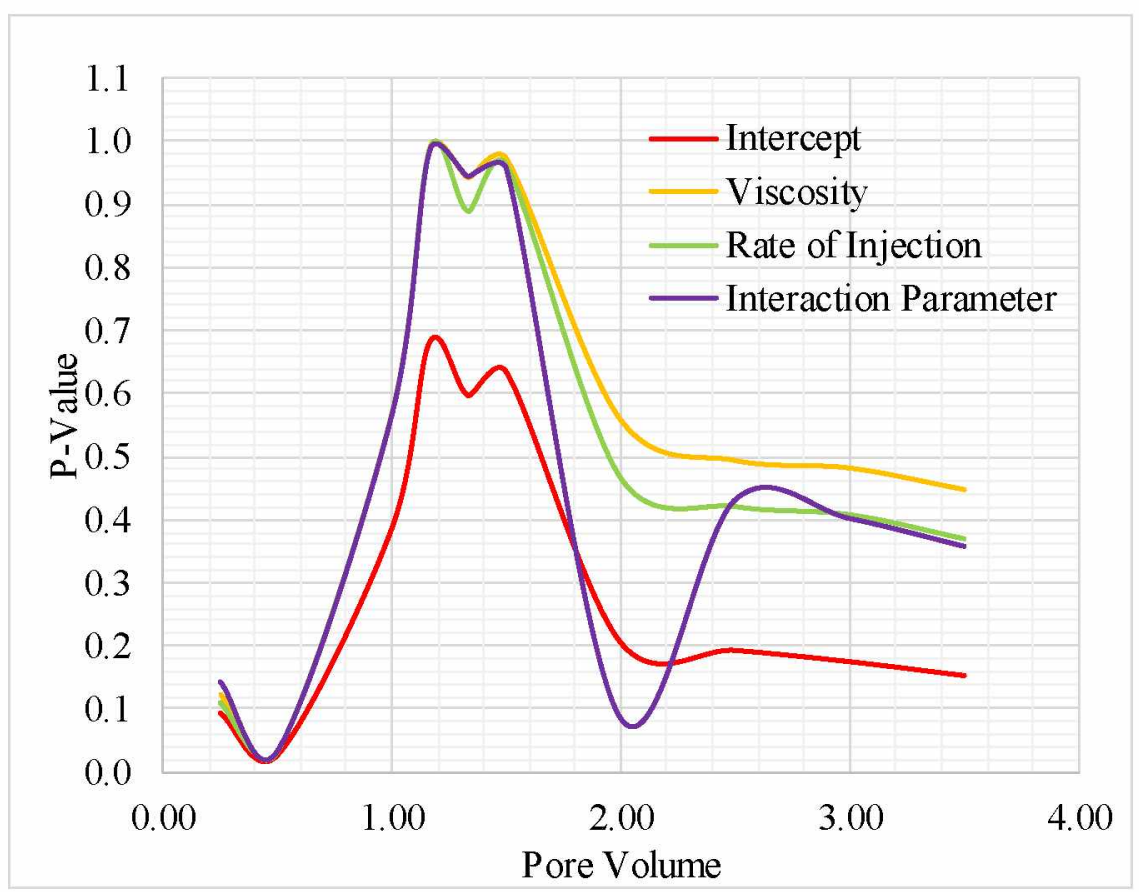

Figure 64 - P-Values at Variable Pore Volumes 


\section{Chapter 10. Conclusions and Recommendation}

\subsection{Conclusions}

1) In previous experiments reported in the literature sand packs were used to investigate the wormhole propagation process during CHOPS. The synthetic cores made using this new methodology are more representative of the unconsolidated formation.

2) Adding more water to hydrate the cementing material weakens the bond between aggregates and results in increase in porosity and absolute permeability. Thus, increasing water to cement/clay ratio, increases the porosity and permeability and decreases the compressive strength of the core. Also, when non-swelling clay was used as a cementing material compared with actual cement, the compressive strength of the samples fall dramatically by $64 \%$ as for same amount of water because clay hydrates more than cement. Thus, hydration of cementing material plays an important role in synthesis of core.

3) Results from Exploratory experiments suggested using lower differential confining pressures (slightly less than the compressive strength of the core) and lower rates to investigate the effect of wormhole propagation. Also, the differential pressure across the length of the core increased slowly for lower injection rates. Therefore, the optimum rate of injection is suggested to be between $0.5-3 \mathrm{ml} / \mathrm{min}$ for the existing setup to conduct experiment for longer duration.

4) Presence of sand in the effluent, suggests that permeability increase at higher pore volumes was due to the sand produced at the outlet. Also, comparing the pressure profile of DOE results with the existing literature, it is hypothesized that in our experiments the wormholes were initiated but not developed due to smaller size of the outlet resulting in restriction of bulk production of sand.

5) The experimental results demonstrated that injecting oil of different viscosities at different rates, effects the internal structure of the core and at lower pore volumes of injection, the permeability of the core for high viscosity oil is almost $11.2 \%$ greater than for low viscosity oil. 
6) Regression models developed for permeability based on values recorded at specific pore volumes injected for different injection rates and two different oil viscosities demonstrated that at a constant confining pressure for all rates, at lower pore volumes injected $99.8 \%$ of the variance in permeability was explained by oil viscosity, injection rate, and their interaction. At higher pore volumes injected, the variance in permeability is only $40.6 \%$. Thus, it is concluded that the effect of oil viscosity, injection rate and their interaction is statistically significant at lower pore volumes injected.

\subsection{Recommendations}

1) From exploratory experiment results, it is suspected that when the core was completely crushed, the $1 / 8$ " outlet was getting clogged, causing the differential pressure across the core to increase rapidly. Therefore, changing the outlet of the core holder from $1 / 8$ " tubing to $1 / 2$ " tubing can reduce the pressure drop in flow lines.

2) The outlet of the core holder was open to the atmosphere. There was no back pressure at the outlet of the core holder. Back pressure can be installed in this set up to ensure liquid entering the core holder matches the reservoir conditions.

3) The cores could not be scanned due to unavailability of a bigger MRI or CT scanner on campus. If the core holder can be scanned both before and after flooding, this can help characterize the nature and growth of the wormhole.

4) Samples received from the core holder outlet can be centrifuged and the sand content of oil can be measured. 


\section{References}

Aitcin, P.C. and A. Neville, 2003. How the water-cement ratio affects concrete strength. Presented at Concrete International, 25 August.

ASTM C109, 2008, "Standard Test Method for Compressive Strength of Hydraulic Cement Mortars (Using 2-in. or [50-mm] Cube Specimens)", ASTM International, West Conshohocken, PA, 2008, DOI: 10.1520/C0109_C0109M-08, www.astm.org.

ASTM C136, 2004, "Standard Test Method for Sieve Analysis of Fine and Coarse Aggregates", ASTM International, West Conshohocken, PA, 2004, DOI: 10.1520/C0136-04, www.astm.org.

ASTM C29, 2009, "Standard Test Method for Bulk Density (Unit Weight) and Voids in Aggregate", ASTM International, West Conshohocken, PA, 2009, DOI: 10.1520/C0029_C0029M-09, www.astm.org.

ASTM C33, 2013, "Standard Specification for Concrete Aggregates", ASTM International, West Conshohocken, PA, 2013, DOI: 10.1520/C0033_C0033M-13, www.astm.org.

ASTM D2434, 2008, "Standard Test Method for Permeability of Granular Soils (Constant Head)", ASTM International, West Conshohocken, PA, 2008, DOI: 10.1520/D2434-68R00, www.astm.org.

Bratli, R. K., \& Risnes, R. (1981, April 1). Stability and Failure of Sand Arches, Society of Petroleum Engineers Journal. SPE-8427-PA. http//dx.doi.org/10.2118/8427-PA

Chilingarian, G. V., and Ean, T. F. 1978. Bitumen, asphalts and tar sand. Elsevier 15-22.

Dusseault, M. 1993. Cold Production And. Enhanced Oil Recovery. Petroleum Society of Canada. SPE J. PETSOC-93-09-01. (Posted on September 1993) http//dx.doi.org/10.2118/93-09-01

Dusseault, M. B. 2001. Comparing Venezuelan and Canadian Heavy Oil and Tar Sands. Presented at Canadian International Petroleum Conference, 12-14 June, Calgary, Alberta. PETSOC-2001061. http://dx.doi.org/10.2118/2001-061

Dusseault, M. 2002. Cold Heavy Oil Production with Sand in the Canadian Oil Industry. http://www.energy. alberta.ca/OilSands/1189.asp (Assessed in May 2015) 
Dusseault, M. B., \& El-Sayed, S. 2000. Heavy-Oil Production Enhancement by Encouraging Sand Production. Society of Petroleum Engineers. Presented at SPE/DOE Improved Oil Recovery Symposium, Tulsa, Oklahoma, USA 3-5 April. SPE-59276-MS. http//dx.doi.org/10.2118/59276$\underline{\mathrm{MS}}$

Han, G., Bruno, M., \& Dusseault, M. B. 2007. How Much Oil You Can Get From CHOPS. Petroleum Society of Canada. Canadian International Petroleum Conference, 8-10 June, Calgary, Alberta. PETSOC-2004-008 http://dx.doi.org/10.2118/2004-008

Head, I.M., Jones, D.M., and Larter, S.R., 2003. Biological activity in the deep subsurface and the origin of heavy oil: Nature, v. 426 , no. 20 , p. $344-352$

International Energy Agency (IEA) - World Energy Outlook 2011, November 2011. https:/www.iea.org/publications/freepublications/publication/WEO2011_WEB.pdf

Jian-Yang, Y., Tremblay, B., \& Babchin, A. 1999. A Wormhole Network Model of Cold Production in Heavy Oil. Society of Petroleum Engineers. International Thermal Operations/Heavy Oil Symposium, 17-19 March, Bakersfield, California, USA. SPE-54097-MS. http://dx.doi.org/10.2118/54097-MS

Larter, S, Whilhelms, A., Head, I., Koopmans, M., Aplin, A., Di Primio, R., Zwach, C., Erdmann, M., and Telnaes, N., 2003, The controls on the composition of biodegraded oils in the deep subsurface - part 1: biodegradation rates in petroleum reservoirs: Organic Geochemistry. v. 34, no. 3. p. 601-613.

Larter, S., Huang, H., Adams, J., Bennett, B., Jokanola, O., Oldenburg, T., Jones, M., Head, I., Riediger, C. and Fowler, M., 2006, The controls in the composition of biodegraded oils in the deep subsurface: Part II. Geological controls on subsurface biodegradation fluxes and constraints on reservoir-fluid property prediction: American Association of Petroleum Geologists Bulletin, v. 90, no. 6, p. 921-938.

Meza-Diaz, B., Sawatzky, R. P., \& Kuru, E. 2010. Sand on Demand: An Approach to Improving Productivity in Horizontal Wells under Heavy Oil Primary Production - Part II. Society of Petroleum Engineers. SPE Western Regional Meeting, 27-29 May, Anaheim, California, USA. SPE-133500-MS. http://dx.doi.org/10.2118/133500-MS 
Tremblay, B., Sedgwick, G., \& Forshner, K. 1996. Imaging of Sand Production in a Horizontal Sand Pack by X-Ray Computed Tomography. SPE J 11(2). SPE-30248-PA. http://dx.doi.org/10.2118/30248-PA

Tremblay, B., Sedgwick, G., \& Forshner, K. (1996, January 1). Modelling of Sand Production from Wells on Primary Recovery. Petroleum Society of Canada Annual Technical Meeting, June 10 - 12, Calgary, Alberta. PETSOC-96-26 http//dx.doi.org/10.2118/96-26

Tremblay, B., Sedgwick, G., \& Vu, D. 1998. CT Imaging of Sand Production In a Horizontal Sand Pack Using Live Oil. Presented at Annual Technical Meeting, June 8 - 10, Calgary, Alberta. PETSOC-98-78. http//dx.doi.org/10.2118/98-78

U.S. Energy Information Administration (EIA) - The Annual Energy Outlook 2011, September 2011. http://www.eia.gov/oiaf/aeo/gas.html

Young, J. P., Mathews, W. L., \& Hulm, E. 2010. Alaskan Heavy Oil: First CHOPS at a vast, untapped arctic resource. Society of Petroleum Engineers. Presented at SPE Western Regional Meeting, Anaheim, California, USA 27-29 May. SPE-133592-MS. http://dx.doi.org/10.2118/133592-MS 
Appendix - Abbreviations and Nomenclature

List of Abbreviations

\begin{tabular}{|c|c|}
\hline Abbreviation & Full Meaning \\
\hline CHOPS & Cold Heavy Oil Production with Sand \\
\hline DCP & Differential Confining Pressure \\
\hline API & American Petroleum Institute \\
\hline IEA & International Energy Agency \\
\hline EIA & U.S. Energy Information Administration \\
\hline ASTM & American Society for Testing and Materials \\
\hline BHP & Bottom Hole Pressure \\
\hline A/C & Aggregate to Cement \\
\hline W/C & Water to Cement \\
\hline FPA & Floating Piston Accumulator \\
\hline NPT & National Pipe Thread Taper \\
\hline LabVIEW & Laboratory Virtual Instrument Engineering Workbench \\
\hline DOE & Design of Experiment \\
\hline USGS & United States Geological Survey \\
\hline PV & Pore Volume \\
\hline & \\
\hline
\end{tabular}


List of Symbols

\begin{tabular}{|c|c|}
\hline Symbols & Meaning \\
\hline$\gamma_{o}$ & Specific Gravity of Oil \\
\hline DRUW & Unit Weight of Blend, $\mathrm{kg} / \mathrm{m} 3$ \\
\hline$\rho_{\text {Blend }}$ & Density of Blend, $\mathrm{kg} / \mathrm{m}^{3}$ \\
\hline$W_{\text {bucket }}$ & Weight of the bucket, $\mathrm{kg}$ \\
\hline$V_{\text {bucket }}$ & Volume of bucket, $\mathrm{kg} / \mathrm{m}^{3}$ \\
\hline$W_{\text {bucket+blend }}$ & Weight of bucket and blend, $\mathrm{kg}$ \\
\hline$G_{m m}$ & Maximum Theoretical Specific Gravity \\
\hline A & Mass of dry blend, g \\
\hline $\mathrm{B}$ & Mass of pycnometer + water, $g$ \\
\hline $\mathrm{C}$ & Mass of pycnometer + water + dry blend, $g$ \\
\hline K & Coefficient of permeability, $\mathrm{cm} / \mathrm{s}$ \\
\hline$l$ & Length of specimen, $\mathrm{cm}$ \\
\hline $\mathrm{t}$ & Time for discharge, $\mathrm{s}$ \\
\hline $\mathrm{q}$ & Volume of discharge, $\mathrm{cm}^{3}$ \\
\hline$A^{\prime}$ & Cross-sectional area of permeameter, $\mathrm{cm}^{2}$ \\
\hline $\mathrm{h}$ & hydraulic head difference across length, $\mathrm{cm}$ \\
\hline $\mathrm{Cs}$ & Compression Strength, psi \\
\hline $\mathrm{P}^{\prime}$ & Total Maximum Load, lbf \\
\hline$A^{\prime \prime}$ & Area of Loaded Surface, in ${ }^{2}$ \\
\hline $\mathrm{q}$ & Flow Rate, $\mathrm{cm}^{3} / \mathrm{s}$ \\
\hline A & Area of cross section of core sample, $\mathrm{cm}^{2}$ \\
\hline $\mathrm{L}$ & Length of the core, $\mathrm{cm}$ \\
\hline $\mathrm{P}$ & Differential pressure across the length of core, atm \\
\hline$\mu$ & Oil Viscosity, cp \\
\hline $\mathrm{k}$ & Permeability of Core, Darcy \\
\hline $\mathrm{X}_{1}$ & Oil Viscosity, $\mathrm{cp}$ \\
\hline
\end{tabular}




\begin{tabular}{|c|c|}
\hline $\mathrm{X}_{2}$ & Rate of Injection, $\mathrm{ml} / \mathrm{min}$ \\
\hline $\mathrm{Y}$ & Permeability of Core, Darcy \\
\hline $\mathrm{X}_{1} \mathrm{X}_{2}$ & Interaction Parameter \\
\hline$\beta_{0}$ & Intercept \\
\hline$\beta_{1}$ & Coefficient for Permeability \\
\hline$\beta_{2}$ & Coefficient for Rate of Injection \\
\hline$\beta_{3}$ & Coefficient for Interaction Parameter \\
\hline
\end{tabular}

